\title{
1. 1 1 in
}

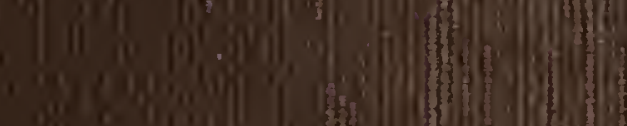




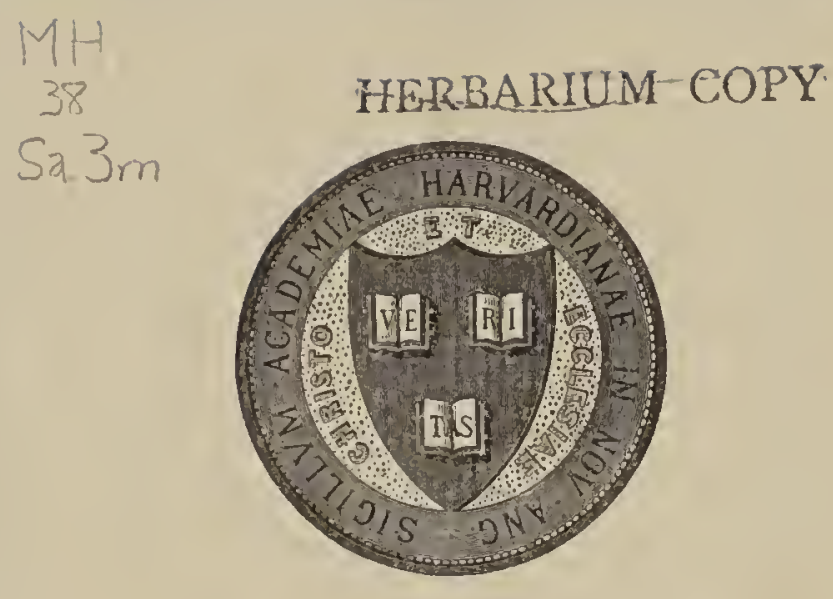

HARVARD UNIVERSITY

L I B R A R Y

OF THE

GRAY HERBARIUM

$$
\begin{aligned}
& \text { Beceiverl } \\
& \text { Rebound April 12, 1955 }
\end{aligned}
$$





\section{CONSPECTUS}

\section{FASCICULI TERTII.}

\begin{tabular}{|c|c|c|c|c|c|c|}
\hline \multicolumn{2}{|l|}{ Alocke } & \multicolumn{5}{|c|}{ Mesembryanthema } \\
\hline & \&. & Fig. & & & s. & Fig. \\
\hline 1. aspera & 2 & 2 & 1. aloides & & 4 & $\mathbf{3}$ \\
\hline 2. cordifolia & 3 & 1 & 2. aguinum . & & 5 & 8 \\
\hline 3. asperiuscula & 3 & 2 & 3. caninum . & & 5 & 0 \\
\hline 4. miargaritifera & .. 6 & 5 & 4. dolahriforme. & & 6 & 3 \\
\hline 5. Radula & 6 & 8 & 5. bellidiforum . & & 12 & 1 \\
\hline 6. subatteunata & 6 & 11 & $\because$ virise. & & 12 & $1 \beta$ \\
\hline 7. glabrata . & 6 & 13 & "subulatu & & 12 & $1 \gamma$. \\
\hline 8. subfasciata & 6 & 14 & 8. brevicaule. . & & 16 & $\mathbf{2}$ \\
\hline 9. reticulata & . 10 & 1 & 9. Schollii & & 17 & 1 \\
\hline 10. atrovirens & . 10 & 2 & 10. rigidicaule & . & 17 & 2 \\
\hline 11. cymbaefolia & . 11 & 1 & 11. sarmentosum. & . & 17 & $\mathbf{3}$ \\
\hline 12. arach noides & . 12 & 2 & 12. australe . . & . & 18 & $\mathbf{2}$ \\
\hline 13. virens . . & . 15 & 8 & 13. Rossi . . & . & 19 & 2 \\
\hline 14. serrulata & . 20 & 1 & 14. filamentosum . & . & 20 & 1 \\
\hline 15. variegata & . 20 & 2 & 15. serrulatum . & . & 20 & 2 \\
\hline 16. micracantha & . 21 & 1 & 16. rubricaule. & . & 20 & 3 \\
\hline 17. tenuior & . 25 & 3 & 1\%. lieteropetalum & . & 21 & 2 \\
\hline 18. maculata . & - 29 & 1 & 18. inclaudens . & . & 21 & 4 \\
\hline 19. puichira & - 29 & 2 & 19. vireus . . . & . & 24 & 1 \\
\hline 20 nigricans & - $\quad 29$ & $\tau$ & 20. glaucum . . & . & 25 & 1 \\
\hline 21. brachyphylla & - 29 & 8 & 21. formosum . & . & 27 & 4 \\
\hline$\alpha$ & & & 22. falcatum & & 29 & $\mathbf{2}$ \\
\hline & & & 23. caulescens & .. & 30 & 1 \\
\hline & & & 24. deltoides & . . & 30 & 2 \\
\hline & & & 25. muricatım & & 30 & 3 \\
\hline & & & 26. luteum . & . . & 38 & 2 \\
\hline & & & 27. croceum & . . & 39 & 3 \\
\hline & & & 28. verruculatum. & . . & 39 & 1 \\
\hline & & & 29. defoliatum . & . . & 43 & 1 \\
\hline & & & 30. sulcatum & & 44 & 1 \\
\hline & & & 31. umbellifiorum & . & 44 & i \\
\hline & & & 32. flexuosum . . & . . & 44 & 7 \\
\hline & & & 33. coccineum & & 46 & 1 \\
\hline & & & 34. variabile & . . & 46 & 2 \\
\hline & & & 35. parrifolinm & & 50 & 3 \\
\hline & & & 36. floribundum . & & 51 & 8 \\
\hline
\end{tabular}





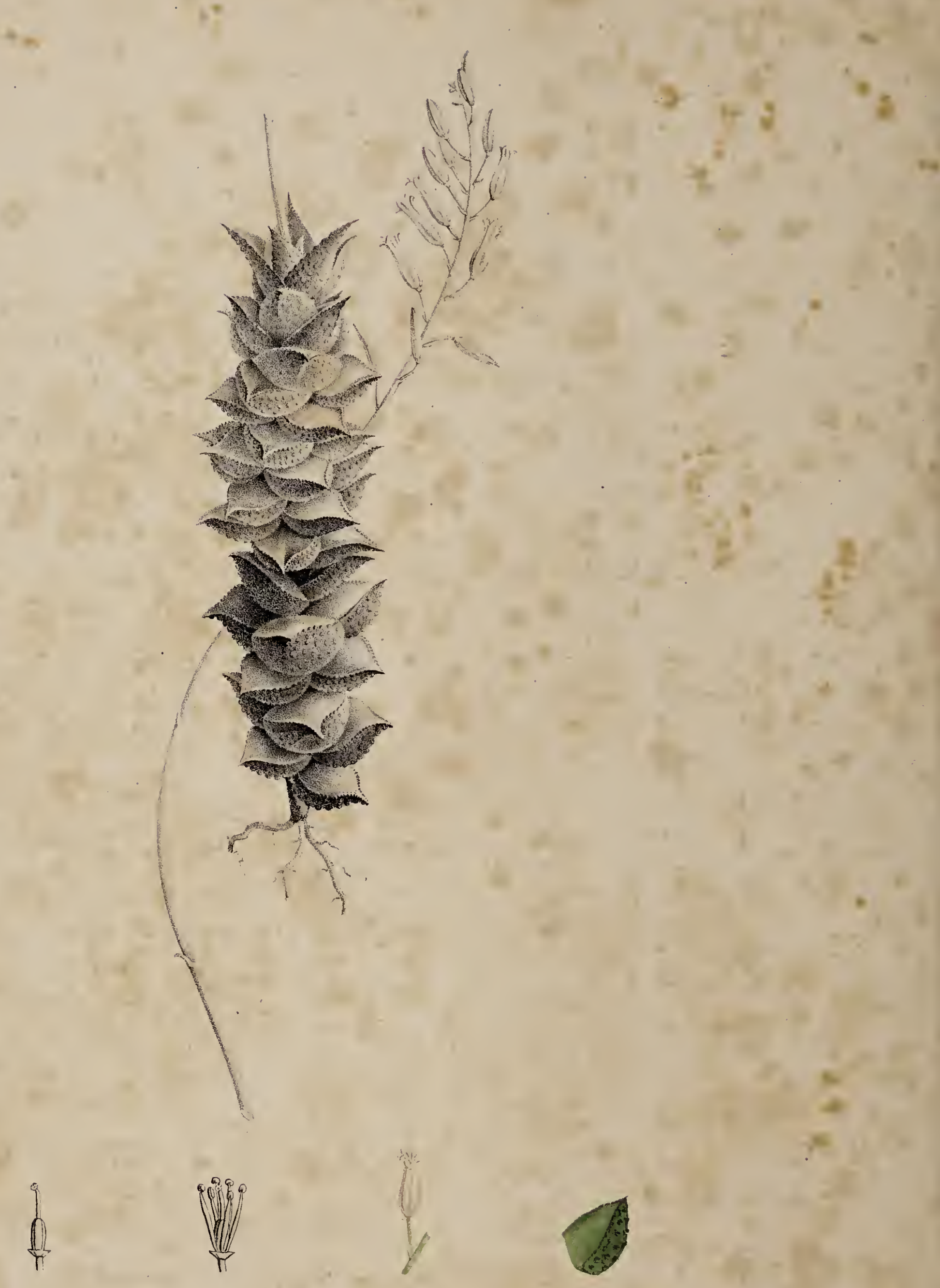

些。

(\$.2. - Fig. 2.) 
(\$. 2. Fig. 2.)

\section{A L O E A S E R A Haw.}

\section{(APICRA Willd.)}

ALOE aspera; caulescens, foliis spiraliter quinquefariis confertis patentissimis orbiculatoovatis acutis rigidis, supra planis laevibus, subtus hemisphaericis apice carinatis, tuberculisque concoloribus asperis, ad margines tuberculato-crenatis.

A. aspera; caule stricto, foliis trifariis patulis ovato-orbiculatis acutis concavis subtus dense papillosis. spreng. Syst. 2.p. 69 .

Apicra a spera; caulescens stricta, foliis trifariis patulis, orbiculato-ovatis, carinatis, acutis, supra concavis, subtus dense papillosis. Willd. Mag. p. 224.

Apicra aspera; foliis adultis trifarie spiraliter subirregularibus, orbiculato-ovatis subacuminatis, pallide viridibus; supra concavis laevibus; subtus tuberculis viridibus validis numerosis spatsis; perigonio cylindrico laevi. IIow. Suppl. p. 63.

II aworthia aspera; foliis trifariis orbiculato-ovatis acuminatis viridibus; supra subconcavis; subtus valde tuberculatis, caule stricto. Haw. Synop. p. 90. Limn. Soc. Trans. \%. p. 6. Ait, Kew. ed. 2. vol. 2. p. 299. - Nob. Cat. rais. p. 7. Schult. Syst. 7. p. 65̃1. (Sub Alve.)

B. major; fere duplo major. Haw, suppt. p. 63.

RADIX cylindracea, carnosa, fibrosa.

CAULIS pollices 4-6 altus, strictus, foliis tectus, basi rarissime prolifer.

FOLIA conferta, quinquefariam in linea spirali disposita, lin. 6-7 longa, et tolidem medio lata, basi angustiora, apice abrupte acuta, jumiora erecto-patentia, seniora patentissima, stricta, rigida, crassissima, laeteviridia; supra plana aut convexiuscula laevia, subtus hemisphaerica, imo apice carinulata, papillis concoloribus asperis dense obducta, ad margines tuberculato-crenata.

PEDUNCULUS Roralis simplex, bracteis quibusdam sterilibus instructus, sordide roseus.

FLORES subspicati, erecti, pedicellati. Bracteae minutissimae pallide rosene, pedicello triplo breviora.

PERIATHIUM obclavato-tubulosum, tereti-hexagonum, pallide et spurco-roseum, limbo regulari palulo; laciniae obtusae, albo-roseae linea saturatiore notatae.

STAMINA perianthii tubo breviora, subaequalia. Filamenta subulata albida. Antherne favie. 
PISTHLLUM. Ovarium cylindraceo-trigomm. Stylus filamentis brevior. Sligma obtusum.

CAPSULAM maturam non vidi.

Habitat in Prom. bon. Spei. - Floret aestate.

Observ. Haec pulchra species a Cl. Masson anno 1895 in Angliam advecta rarius hodie in hortis occurrit. Var. major a Cl. Haworth ei adscripta milhi ignota est. 


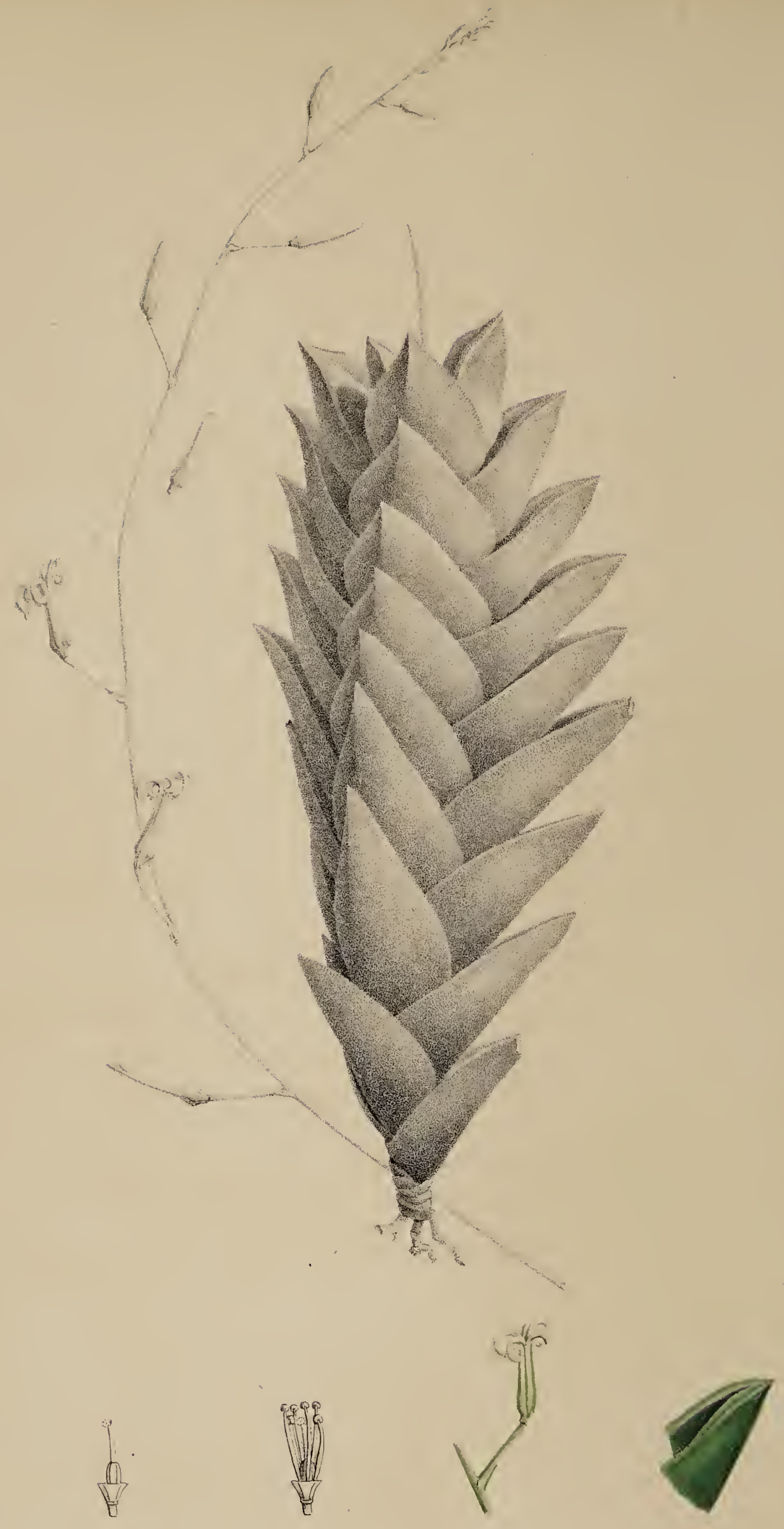

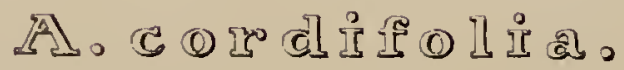

$$
\text { (\$.3. - Fig.1.) }
$$


(\$. 3. Fig. 1.)

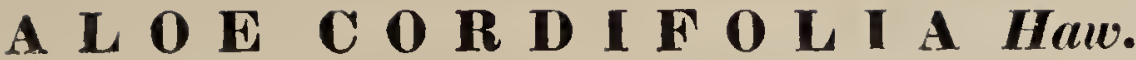

\section{(HAWORTHIA Duval.)}

ALOE cordifolia; caulescens prismatica, foliis trifariam imbricatis suberectis lato-ovatis crassissimis atro - viridibus, supra planiusculis subtus convexis imo apice carinatocompressis, utrinque rugosis ad margines cartilagineis.

II aworthia cordifolia; foliis rigidissimis cordato-amplexicaulibus crassissimis atroviridibus, superne carinatis asperiusculis, distincte marginatis; marginibus asperis. IIaw. Suppl. p. 60. - Scluult. Syst. 7. p. 653.

RADIX cylindracea, carnosa, fibrosa.

CAULIS poll. 6-7 allus, strictus, simplex, foliis vestitus.

FOLIA conferta, trifariam imbricata, prisma lateribus bipollicaribus planinsculis formantia, suberecta, pollicem cum lin. 6-9 longa, et lin. 9-11 medio lata, basi paulum angustiora et apice aculiuscula, crassa, rigidissima, alroviridia, utrinque rugosa, juniora supra concava, seniora planiuscula apicem versus subcanaliculata, subtus convexa superne carinatocompressa, ad margines cartilaginea, rugosa.

PEDUNCULUS floralis simplex, filiformis, nudus, viridis.

FLORES laxe racemosi, subpatentes, longissime pedicellati. Bracteae minimae.

PERIANTHIUM ad \%/3 tubulosum, obclavatum, pallide viridulum, viride striatum, limbo bilabialo, labiis revolutis; laciniae albido-roseae, obtusae, linea media basi viridi superne rosea notatcu, canaliculatae.

STAMINA periconthii tubo breviora, alternatim inaequalia. Filamenta subulata albida. Antherae flavae.

PISTILLUM. Ovarium cylindraceo-trigonum. Stylus filamenta breviora adaequans. Stigma obtusum.

CAPSULAM maturam non vidi.

Habitat in Prom. bon. Spei. - Floret mense Augusto.

Observ. Haec pulchra species crassissina est hujusce Sectionis, et jam anno 1818 in Horto Kewensi culta. Rarissime adhuc in hortis occurit quia vix soboles profert. 




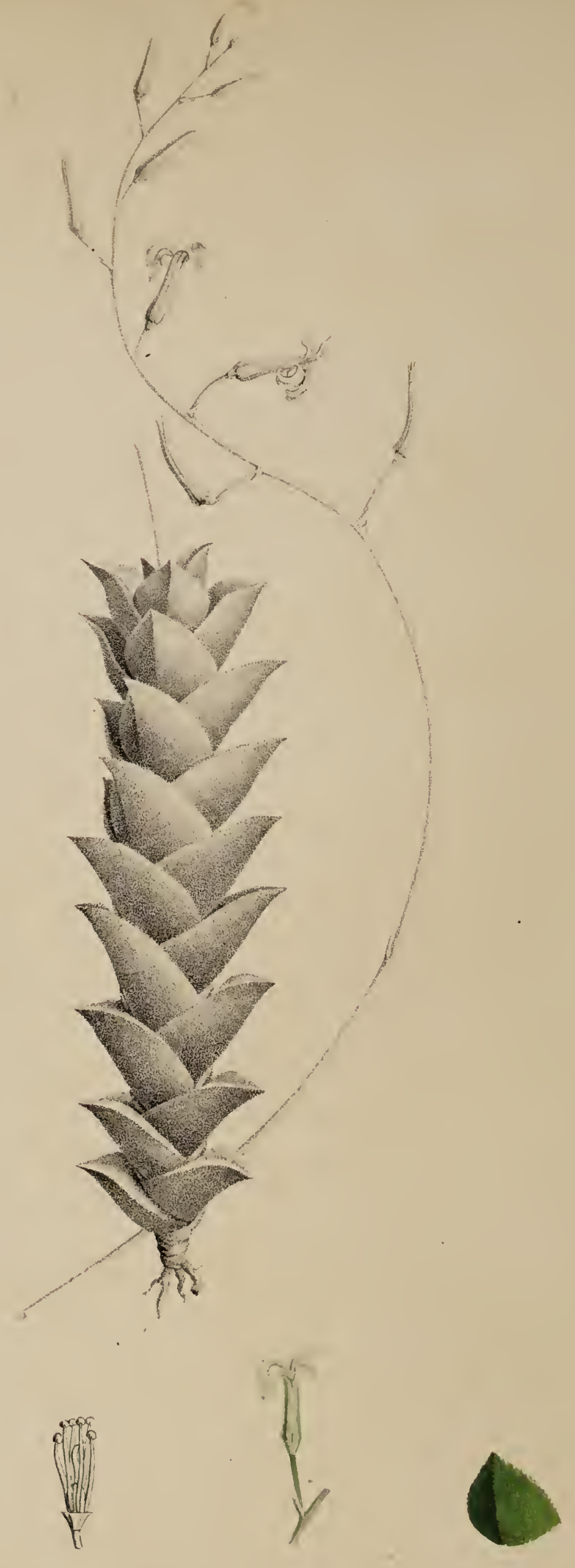

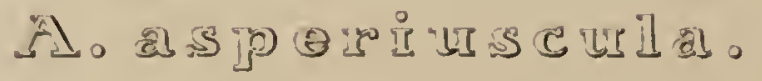

$$
\text { (.\$. 3. - Fig. 2.) }
$$


(\$. 3. Fig. 2.)

\section{ALOE ASPERIUSCULA How. (HAWORTHIA Duval.)}

ALOE asperiuscula; caulescens prismatica, foliis trifariam imbricatis suberectis ovatis crassis luride viridibus basi rubescentibus, supra planiusculis cum linea media excavata, subtus convexis superne carinatim compressis, utrinque et praesertim ad margines rugosis.

H aworthia lsperiuscula; foliis rigidissimis orbiculato-cordatis subacntis, angulatim a centro arcte inflexis, atro-viridibus, marginulatis, superne asperiusculis; margine aspero. Haw. Suppl. p. 60. - Scluell Syst. \%. p. 653.

RADIX carnosa, cylindracea, filrosa.

CAULIS poll. 4-5 altus, strichus, simplex, foliis vestitus.

FOLIA subconferta, trifariam remote imbricala, prisma lateribus planiusculis formantia, suberecta, vix recurvula, lin. 9-10 longa, et lin. 7-8 medio luta, basi paulum angustiora, apice acuta, luride viridia inferne spurco-rufescentia, crassa, rigidissima, utrinque rugosa; juniora supra concava, seniora planiuscula linea media canaliculatim excavata, subtus basi convexa, sed a medio ad apicem carinato-compressa, ad margines cartilaginea, aspera.

PEDUNCULUS floralis simplex, filiformis, mudus, viridulus.

FLORES laxe-racemosi, subpatentes, longissime pedicellati. Bracteae minimae.

PERIANTHIUM ad \%/3 tubulosum, ubclavatum, pallide viridulum, viride strialum, limbo bilabiato, labiïs revolutis; laciniae albido-roseae, obtusae, linea media viridi notalae, canaliculatae.

STAMINA perianthii tubo breviora, alternatim inaequalia. Filamenta subulata, favescentia. Antherae flavae.

PISTILLUM. Ovarium cylindraceo-trigomum. Stylus filamenta breviora adaequans. Stigma obtusum.

CAPSULAM maturam non vidi.

Habitat in Prom. bon. Spei. - Floret mense Augusto.

Observ. Cum praecedente in Horto Kewensi e seminibus Capensibus orta, anno 1818 jam culta, haec species tamen in hortis raro occurrit. Differt a praecedente staturia multo minore, et a sequente foliis crassioribus minus dense imbricantibus. 




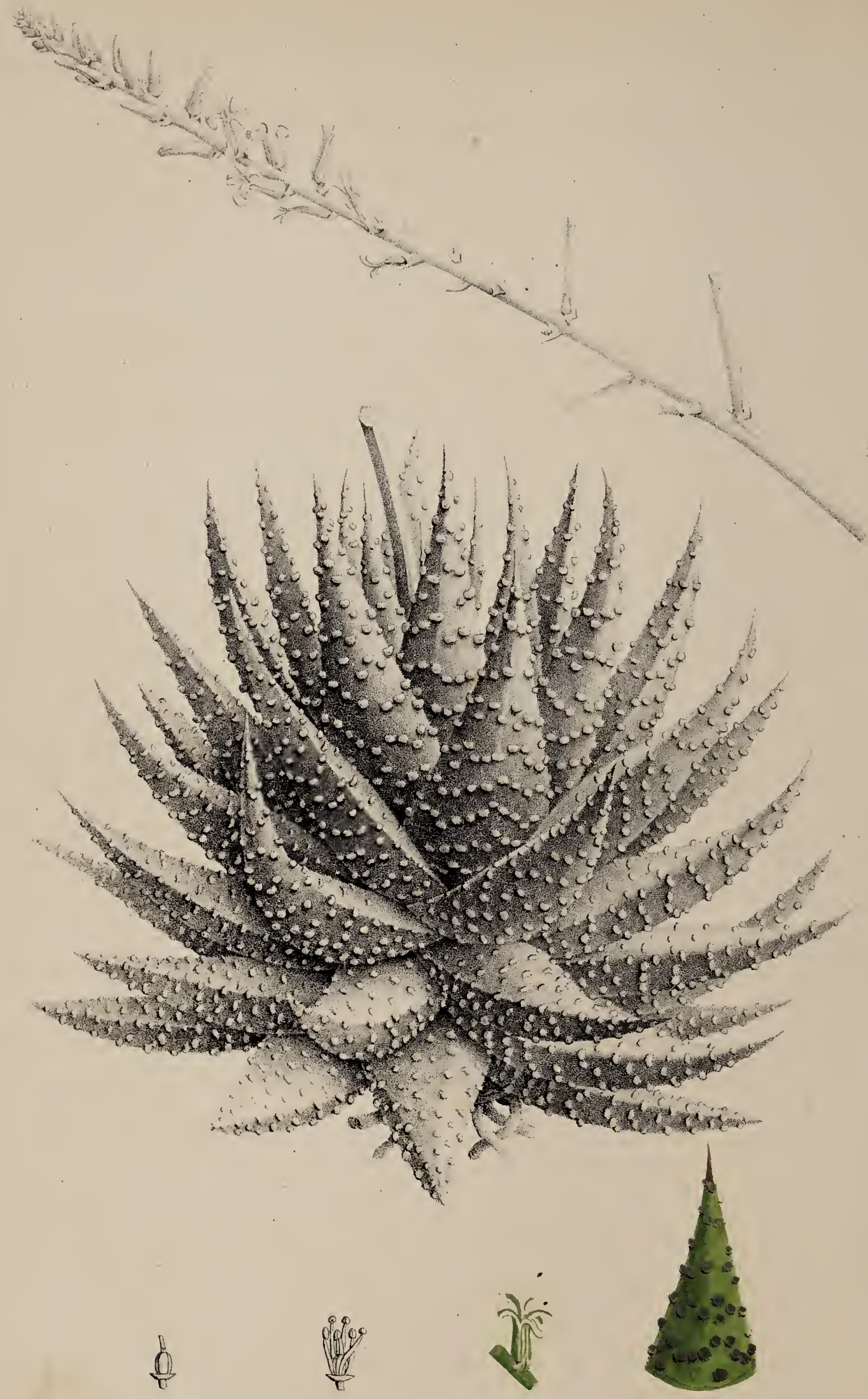

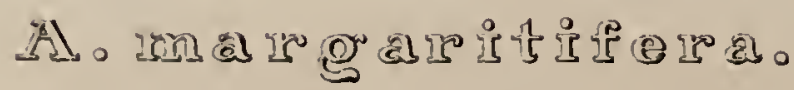

(\$.6. - Fig.5.) 
(5. 6. Fig. 5.)

\title{
A L O E M A R GA I T I F R A Haw.
}

\author{
(HAWORTHIA Dural.)
}

ALOE margaritifera; subacaulis, foliis erecto-incurvulis ovato-acmuinatis suprat planiusculis subtus convexis superme olduse triquetris, utrinque tuberculis renotis magnis apicem versus rarioribus, bracteis pedicello longioribus.

A. margarilifera; subacaulis dichotomo - prolifera, foliis erecto-patulis longe ovato-acuminatis perviridibus apice obtuse triquetris rigidis, supra planiusculis utrinque tuberculis magnis confertis; bracteis pedicello longioribus. Nob. in Hor. nyck. $p .320$.

Apicra margaritifera ß. major; foliis quadripollicaribus papillis magnis. Willd. May p. 269. (excl. Syn. Dillenii.)

Haworthia margaritifera; acaulis, dichotoma, foliis quadripollicaribus longe ovatoacuminatis erecto-patulis, tuberculis margaritaceis magnis, subtus parum majoribus; florum pedicellis antiquis bracteas fere aequantibus, capsulis transverse rugosis trifarie quadratis. Iaw. Suppr. p. 55.

Haworthia major; Hav. Synop. p. 92. Limn. Trans. 7. p. 11. (excl. Syn. DC. Pl. gruss.)-Schult. Syst. 7. p. 648.

Aloe margaritifera; acaulis, foliis patulis ovatis obtuse trigonis utrinque grosse papillosis, scapo ramoso, corollis subsessilibus infundibuliformibus. Will. Emum. $\% .386$.

A. margaritifera; acaulis, foliis trigonis cuspidatis papillosis, floribus racemosis cernuis cylindricis. Ait. Kew. ed. 1. Vol. 1. p. 468. - Willd. Spec. pl. 2. p. 188. - Ait. Kew. ed. 2. Vol. 2.p. 301.

Alö̈ africana margaritifera minor. Commel. Hort. Amst. p. 21. Fig. 11. (icon mult ubsyme fore.)

RADIX cylindracea, carnosa, fibrosa.

CAULIS mullus, aut e superpositione folion aetate lirevis.

FOLIA mullifaria, satis mumerosa, juniora evecto-incurvala, seniora patentiu, potl. 3 longa, et lin. 15 basi lata, ovato-acuminata et in setulam exeuntia, supra plano-convexiuscula, subtus valde comexa, apicem versus obtuse carinulata, perviridia, urinque tuberculala, huberculis margarilaceis validis, inferne remoliusculis superne valde remotis, irregutmiler in fascias dispositis, distinctis nec ad carinulam confluentibus.

PEDUNCULUS floralis bipedalis, crassus, nudus, teres, rividis, superne ramosus, ramulis basi bracteis sterilibus instructis.

FLORES spicati, suberecti, brevissime pedicellati. Bracteate latiusculce, smarcoviridulae, albido-marginatae, acuminatae, pedicello duplo longiores.

PERIANTHIUM ad 1/2 hbulosum, obclavatum viridudum saturatius striatum, timbo bilabiato revoluto; laciniae obfusae albidae, medio linea viridi notalae, interioribus. (suprema latissima excepta) canaliculation inflexis.

STAMINA perianthii hubo breviora, alternatim incequatia. Fildmenta subulata, viridula. Autherae luteae. 
PISTILLUM. Ovarium cylindraceo-trigonum. Stylus filamentis brevior. Stigma oblusum.

CAPSULA matura orbiculato-trigona, transverse rugosa.

Habitat in Prom. bon. Spei. - Floret aestate.

Observ. Synonyma quae ad hanc antiquam speciem referri debent haud facile discernenda sunt. Species ipsa in lortis nostratibus saepissime e semine renovata plerumque adulterata reperitur; sed variat solum in foliorum colore plus minusve intense viridi, et in tuberculorum numero ac magnitudine. Ad maximas hujusce sectionis pertinet et a praecedentibus speciebus satis est diversa. Errore in Horto Dyckensi dixi lanc speciem esse dichotomo-proliferam; soboles in plantis annosioribus semper sunt intrafoliaceae. 



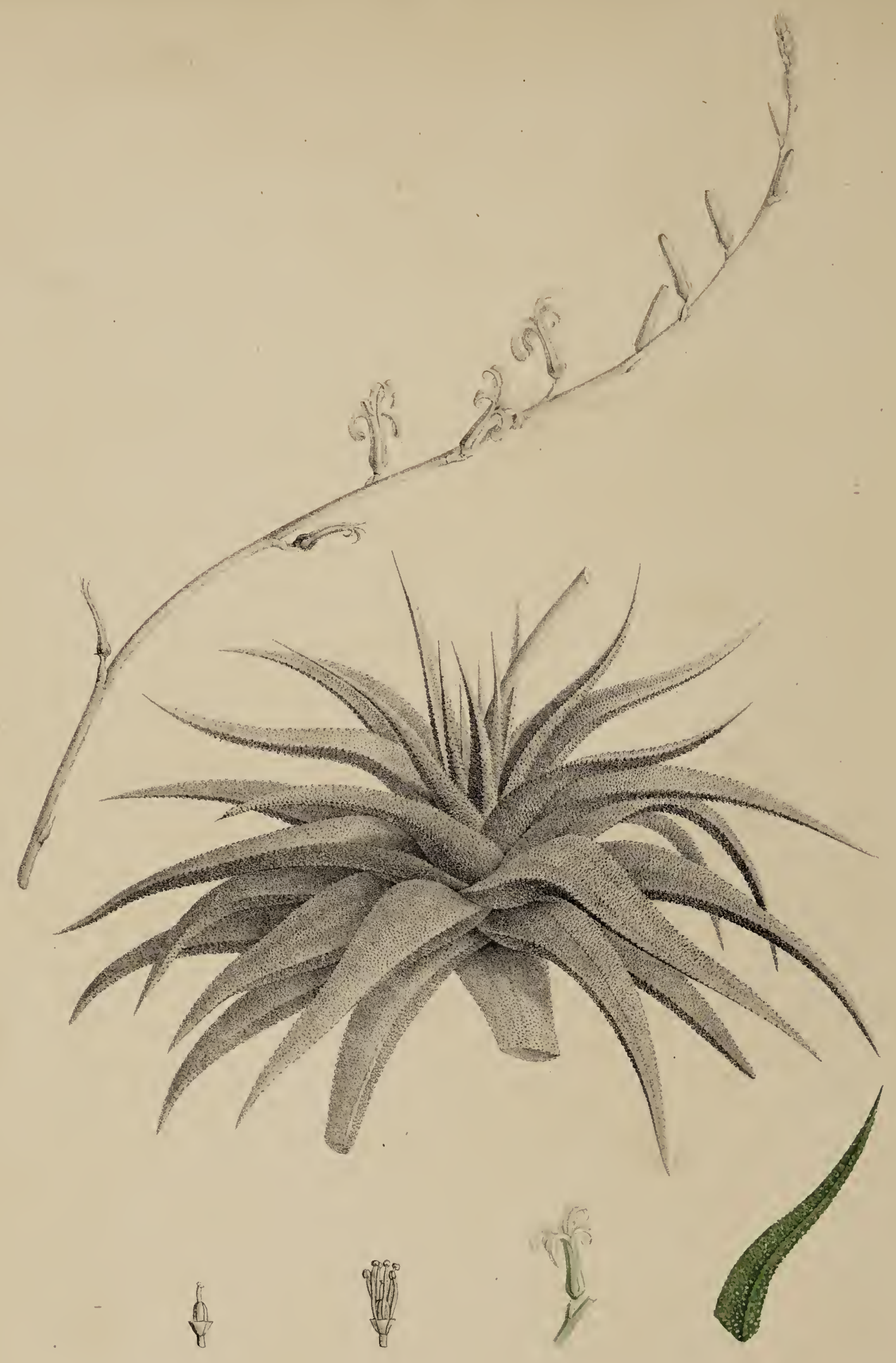

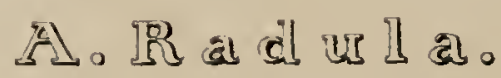

(\$.6. _ Fig. 8 ) 


\section{(\$. 6. Fig. 8.)}

\section{A L O O L I A A D U L A Jacq.}

(IITORTHIA Dueal.)

ALOE Radula; acaulis sobolifera, foliis paucis recurvato-patentibus in cuspidem triquetran louge productis, supra plano-concavis, utrinque tuberculis aequalibus minutissimis creberrimis sparsis. Nob. Hort. Dyck. pag. 3.23.

A. Radula; foliis patulis oblongo-lanceolatis acuminatis apice subtrigonis supra planiusculis utrinque tenuissime calloso-tuberculatis. spreng. Syst. vot. 2. p. 69.

A. Radula B. media; foliis utrinque tuberculis margaritaceis minutissimis scabris. Nob. Cat. rais. p. 4. - Schull. Sysl. 7. p. 645 .

Haworthia Radula ß. pluriperlata; baccis minutissimis numerosissimis. Haw. Revis.p. ox. II avorthia Radula; foliis erecto-recurvis subulato-attenuatis, undique asperis, tuberculis miuutissimis, crebris, sparsis, cretace0-margaritaceis. Haw. Synop. p. 23.

Apicra $\boldsymbol{R}$ adula; acaulis, foliis patulis oblongo-lauceolatis acuminatis, apice subtrigonis supra planiusculis, junioribus subconcavis, utrinque tenuissime papillosis. Willd. Mag.p. 2ro

Alo $\ddot{e} \boldsymbol{R}$ adula; acaulis, foliis oblongo-lanceolatis apice subtrigonis tenuissime papillosis, scapo ramoso, corollis pedicellatis infundibuliformibus. Will. Enum. p. 386 .

Alö̈ Radula; acaulis, foliis ensiformibus denticulatis, tuberculis cartilagineis utrinque scahris, floribus racemosis erectis. Jacq. Hort. Schönb. 4. p. 11. Ł. 422.

\section{BADIX carnosa, cylindracea, fibrosa.}

CAULIS nullus.

FOLIA multifaria, juniora patenti-erecta, seniora recurvato-patentissima, apice saepe incurvula, poll. 3 cum dimidio longa, et lin. 8-9 basi lata, subinde uttenuata, et in cuspidem trifuetram longe producta, viridia, supra plano-concava, linea medio sulppromimala notata, subtus triquetra comvexu, utrinque tuberculis margaritaceis mumerosissimis minulissimis irregulariter sparsis tecta, et radulae instar aspera.

PEDUNCULUS foralis sen scapus pedalis et ultra, mudns, teres, viridis, sulvormosus; rameulis bracteis sterilibus busi instructis.

FLORES subspicati, breve pedicellati. Bractene latiusculae, virides, pedicello paulum longiores.

PERIATHIUM vix ad $\% / 3$ tubulosum, obclavatum, albidum perviride striatum, limblo bilabiato; laciniae obinsae albidae linea medio viridi notatae, exteriores planiusculae magis revolutac, interiores longiores (suprema excepta), canaliculatae.

STAMINA perianthii tubo breviora, alternatim inaequalia. Filamenta subulata Aavida. Antherae aurantiacae. 
PISTILLUM. Ovarium cylindraceo-trigonum. Stylus filamentis brevior. Stigma obtusum.

CAPSULAM maturam non vidi.

Habitat in Prom. bon. Spei. - Floret aestate.

Observ. Haec species versus annum 1800 in Hortum Schoenbrunnensem advecta fuit, et a Cl. Jacquinio descripta. Hodie in hortis vulgatissima occurit, et a caeteris omnibus hujusce Sectionis foliis minus crassis, tuberculisque margarilaceis minutissimis atque creberrimis longe recedit. 



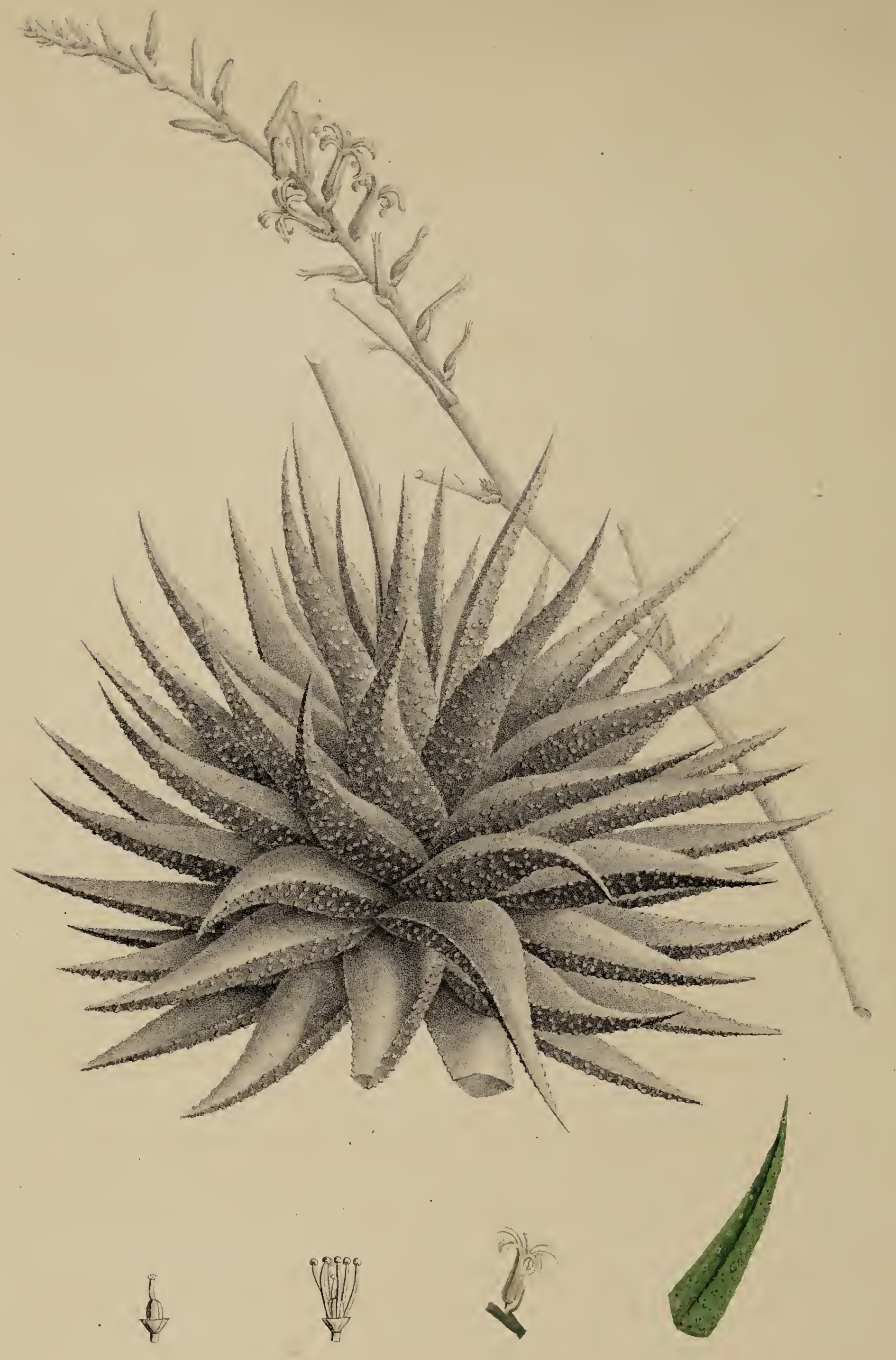

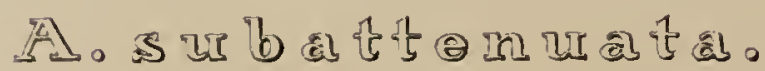

(s.6. - Fig.11.) 
(\$. 6. Fig. 11.)

\section{A L O E S S U B A T T E N U A T A Nob. \\ (HAWORTHIA Duval.)}

ALOE subattenuata; acaulis vel subacaulis sobolifera, foliis erecto-patulis cuspidatoaltenuatis utrinque perviridibus, supra laeviusculis sublus tuberculis margaritaceis distinctis validis subserialiter dispositis.

A. subattenuata; caulescens sobolifera, foliis erecto-patulis cuspidato-attenuatis perviridibus, supra convexis laeviusculis, subtus tuberculis margaritaceis distinctis subserialiter dispositis, floribus rose0-albis. Nob. Cat. Hort. Dyck. p. 324.

A. subattenuata; acaulis, foliis cuspidato-attenuatis erecto-patulis, perviridibus, supra convexis, glabriusculis, subtus tuberculis margaritaceis, validis, distinctis. Schult. Syst. 7. p. 1712.

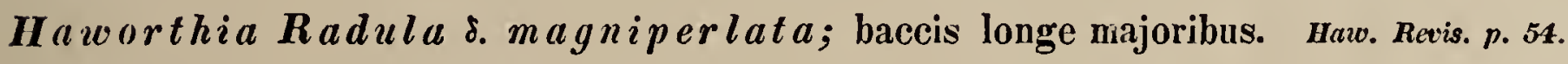

A. semimargaritifer $a$ r. minor; acaulis, foliis subtripollicaribus, tuberculis numerosis parvis. Nob. Cat. rais. p. 6.

$\boldsymbol{R A D I X}$ carnosa, cylindracea, fibrosa.

CAULIS nullus, aut in plantis adultis e superpositione foliorum brevis.

FOLLA multifaria, numerosa, juniora erecta, seniora patentia, poll. 3 cum dimidio longa et lin. 8-9 basi lata, sensim attenuata, et in cuspidem triquetram producta, viridia inferne cum tinctura rosea, supra convexiuscula linea media tuberculis quibusdam viridulis notata, subtus convexa, tuberculis morgaritaceis validis distinctis subserialiter in lineas transversas dispositis.

PEDUNCULUS floralis pedalis et ultra, subramosus, temis, nudus', viridis ; ramulis bracteis sterilibus basi instructis.

FLORES subspicati, erecti, brevissime pedicellati. Bracteae latiusculue, roseae, pedicello duplo longiores.

PERIANTHIUM ad $2 / 3$ tubulosum, obclavatum, pallide roseum viride striatum, limbo bilabiato; laciniae subaequales, revolutae, obtusulae, albidae, medio linea basi viridi superne rosea notatae.

STAMINA perianthii tubo breviora, subaequalia. Filamenta subulata Ravida. Antherae aurantiacae.

PISTILLUM. Ovarium cylindraceo-trigonum. Stylus filamentis brevior. Stigma obtusum. 
CAPSULAM maluram non vidi.

Iabitat in Prom. bon. Spei. - Floret aestate.

Observ. Hanc plantam quoque amo 1814 Vindobonae in Horto privato S. M. Francisci I inveni, et propter folia supra laeviuscula primo A. semimargariliferae ut varietatem minorem adscripsi; serius tamen a caeteris semimargarilaceis longe recedit, et ei locum prope $\boldsymbol{A}$. attenuatam tribuendum mihi visum est. $\mathbf{A b} \boldsymbol{A}$. subulata differt statura minore, foliis minus in cuspidem productis, tuberculisque validioribus, sicut et sobolibus ad basin plantae frequentissimis. 



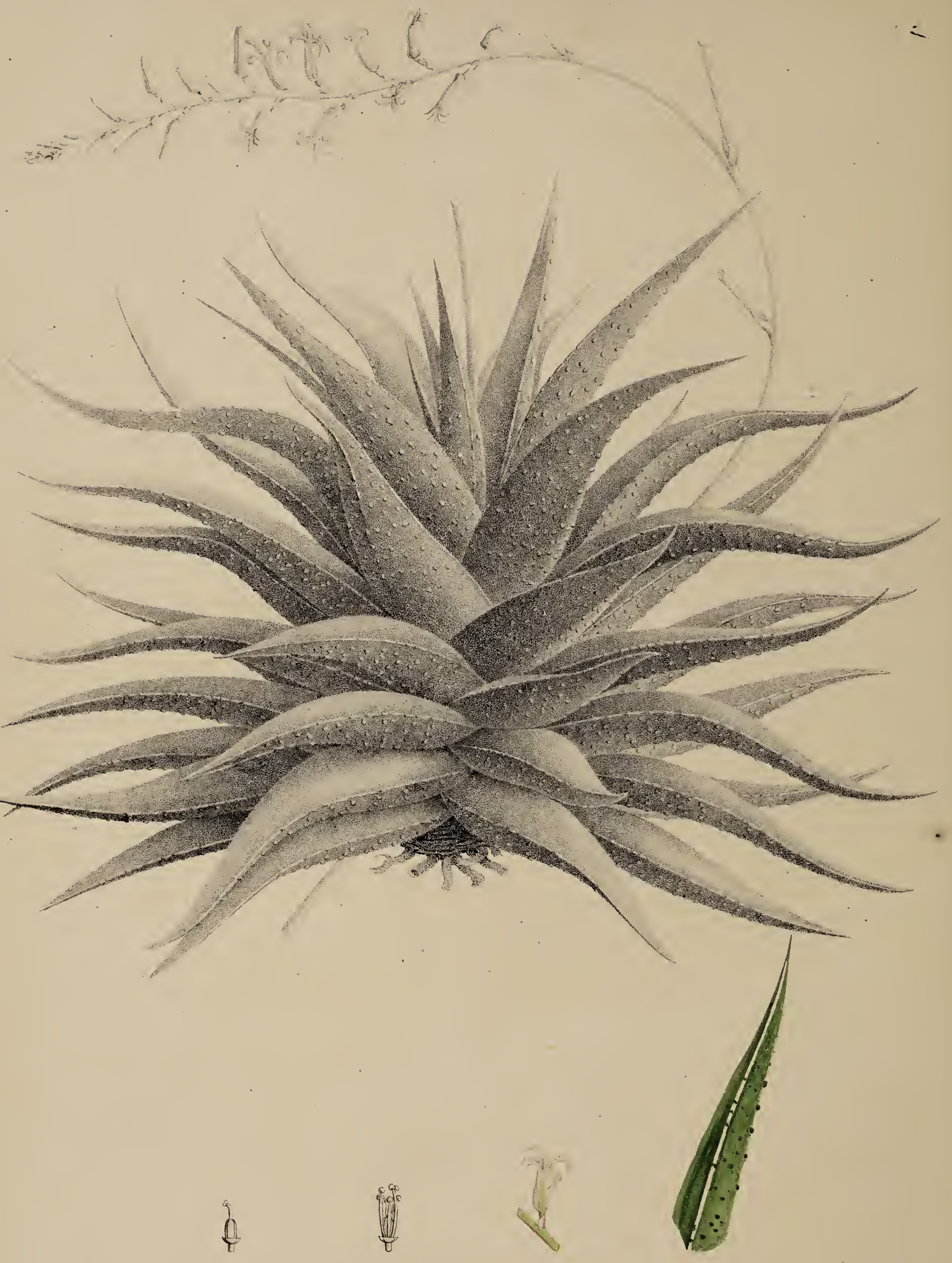

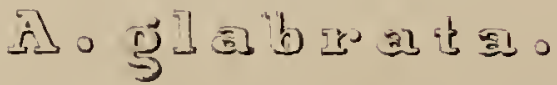

4. (1. - Fivi 13 . 
(\$. 6. Fig. 13.)

\title{
I I O E G L A B R A T A Nob.
}

\author{
(H.AWORTIIIA Duval.)
}

ALOE glabrata; subcaulescens, foliis erecto-recurvis octofariis in cuspidem triquetram longe productis glaucescenti-perviridibus nitidis, supra convexiusculis laevibus, subtus parce margaritaceo - tnberculatis, tuberculis subserialibus distinctis ad margines carinamque in lineam cartilagineam albam confluentibus.

A. glabrata; subacaulis, foliis erecto-patentibus in cuspidem triquetram attenuatis subglancescentibus, supra convexiusculis laevibus subtus parce tuberculis margatritaceis subserialibus distinctis, ad margines carinamque confluentibus. Nob. Hort. Dyck. p. 325.

RADIX carnosa, cylindracea, fibrosa.

CAULIS e superpositione foliorum brevis, in plantis ralultis dichotome divisus.

FOLIA mumerosa, subconferla, spivaliter octofaric disposita, juniora erecto-patula, seniora recurvato-expansa, apice saepe incurvula, poll. 4-6 longa, et pollicem basi luta, sensim attenuata et in cuspidem triquetram longe producta, glancescente perviridia, nitida, supru plano-convexa laevissima, subtus parce tuberculala, tuberculis margarilaceis remotiusculis parvulis, distinctis, subserialiler disposilis, basin et apicem versus saepe evanescentibus, ad margines creberrimis et sensim, sicut et ad corinam, in lineam tenuem cartilagineam albam interrupte confluentibus.

PEDUNCULUS floralis sen scapus tripedalis et ultra, procumbens nisi suffullus, mudus, teres, livide virens, superne ramosus; ramulis bracteis sterilibus basi instructis.

FLORES racemosi, erecto-patentes, momerosi, pedicellati. Bracleae latiusculae, fuscue, pedicellum aequantes.

PERIANTHIUM ad $9 / 3$ tubulosum, obclavatum, viridulum roseo-striatum, limbo bilabiato; laciniae revolutae, acutiusculae, albidae, linea media basi viridi et superne rosen notatıe, canaliculatıe.

STAMINA perianthii tubo breviora, alternatim inaequalia. Filamenta subulata, viridula. Antherae crocene.

PISTILLUM. Ovarium cylindraceo-trigomem. Styhus filumentis brevior. Stigma oltusum.

CAPSULAM maturam non vidi. 
Habitat in Prom. bon. Spei. - Floret mense Augusto.

Observ. Species laec egregia in Itorlo Berolinensi e semine Capensi orta est, et variat casualiter foliis plus minusve erectis et colore plus minusve intense perviridi. Foliis supra omnino laevibus et statura accedit ad A. subfnscialam; sed floribus minoribus, tuberculisque rarioribus aliter dispositis, et ad foliorum margines interrupte confluentibus, longe ab ea differt. Ad lanc speciem porro alteram plantau ut varielatem refero, quae propter tubercula foliis concoloria pro specie propria laberi potuerit et inde icone et descriptione propria illustrare volo. 



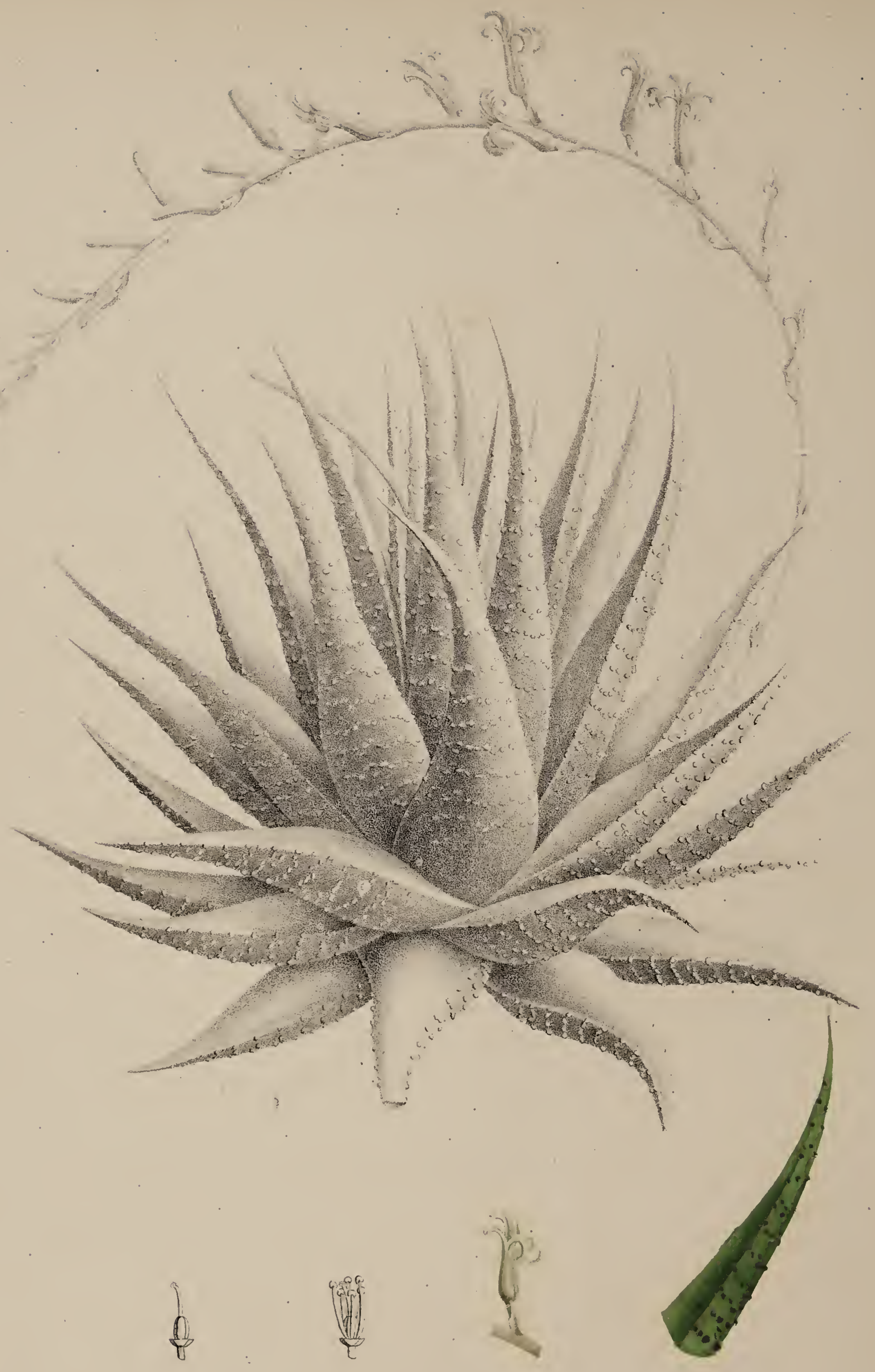

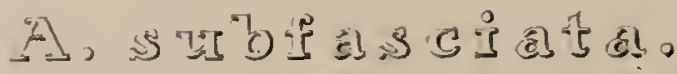

$(\$ .6 .-\operatorname{Tig} 14$. 
(5. 6. Fig. 14.)

\title{
I LOE SUBAASCIATA Nol.
}

\author{
(HAWURTHIA Dwal.)
}

ALOE subrasciata; subcaulescens, foliis erecto-patulis strictis in cuspiden triquetram longe productis laete viridibus, supra convexinsculis laevibus, sublus et ad margines tuberculis minutissimis in fascias transversas subconfuentibus. Not. Hor\%. Dyck pag. 32.5 - Schult. Syst. 7. pag. 1712.

A. subulata; acanlis, foliis laete viridibus erecto-patulis strictis a basi ad apicem attenuatis et in cnspidem triquetram longissime productis, supra convexiusculis lacvibus, subtus tuberculis margaritaceis parvulis transversim fascialis. Nob. obs. bot. 1822. (crrore (ypoyraphico.) - Schull. Syst. 7. p. 646.

A. Fasciata. B. major; foliis multo latioribus et longioribus supra glabris subtus papillosis, papillis minoribus et minus regularitor in fascias transversales confluentibus. Nob, Cat. rais. p. 5. - Itaw. Reris. p, 51. (sub IIaworthia.)

RADIX carnosa, cylindracea, fibrosa.

CAULIS e superposilione foliorum brevis, in phanlis adullis dicholome divisus.

FOLIA numerosa, conferta, spiraliter mullifarie disposila, juniora evecta, seniova erecto-patenlia, stricta, vix incurvula, pollices 5 longa et pollicem basi lata, sensim altemata, el in cuspidem triquelram longe produch, laete viridia, supra comvexinscula laevia, subfus et ad margines ubberculis margarilaceis minutis, in fascias transversales remotas subcom/luenlibus instructa.

PEDUNCULUS floralis seu scapus tripedalis et ultra, procumbens misi stiffullus, mudus, teres, fuscus, superne ramosus; ramulis bracteis sterilibus basi instructis.

FLORES racemosi, suberecti, numerosi, pedicellati. Bracteae latue, fuscae, pedicellum requantes.

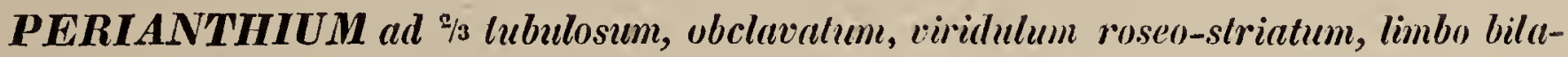
biato; laciniae revohutae, aculiusculae, albidae, linea medla basi vividi superne rosea nolatae, canaliculatae.

STAMINA perianthii tubo breviora, allernation inaenualia. Filamenta subulata, lutescentia. Antherae purpurascentes.

PISTILLUM. Ovarium cylindracen-trigonum. Slylus filementa adreguans. Stigma obtusım. 
CAPSULAM maturam non vidl.

Habilat in Prom. bon. Spei. - Floret mensibus Augusto et Septembri.

Observ. Hanc plantam anno 1814 in Horto Academico Vindobonensi cum A. subulata cultam inveni, et primo pro varietate majore $A$. fasciatae habui. Serius (in Obs.bot. anni 1822) ut species propria, sub nomine erroneo tamen $A$. subulatae descripta est, et huc usque imperfecte cognita remansit. Maximis in sectione $\boldsymbol{A}$. Margariliferarum cum praecedente adnumeranda est, et pulcherrimis. 



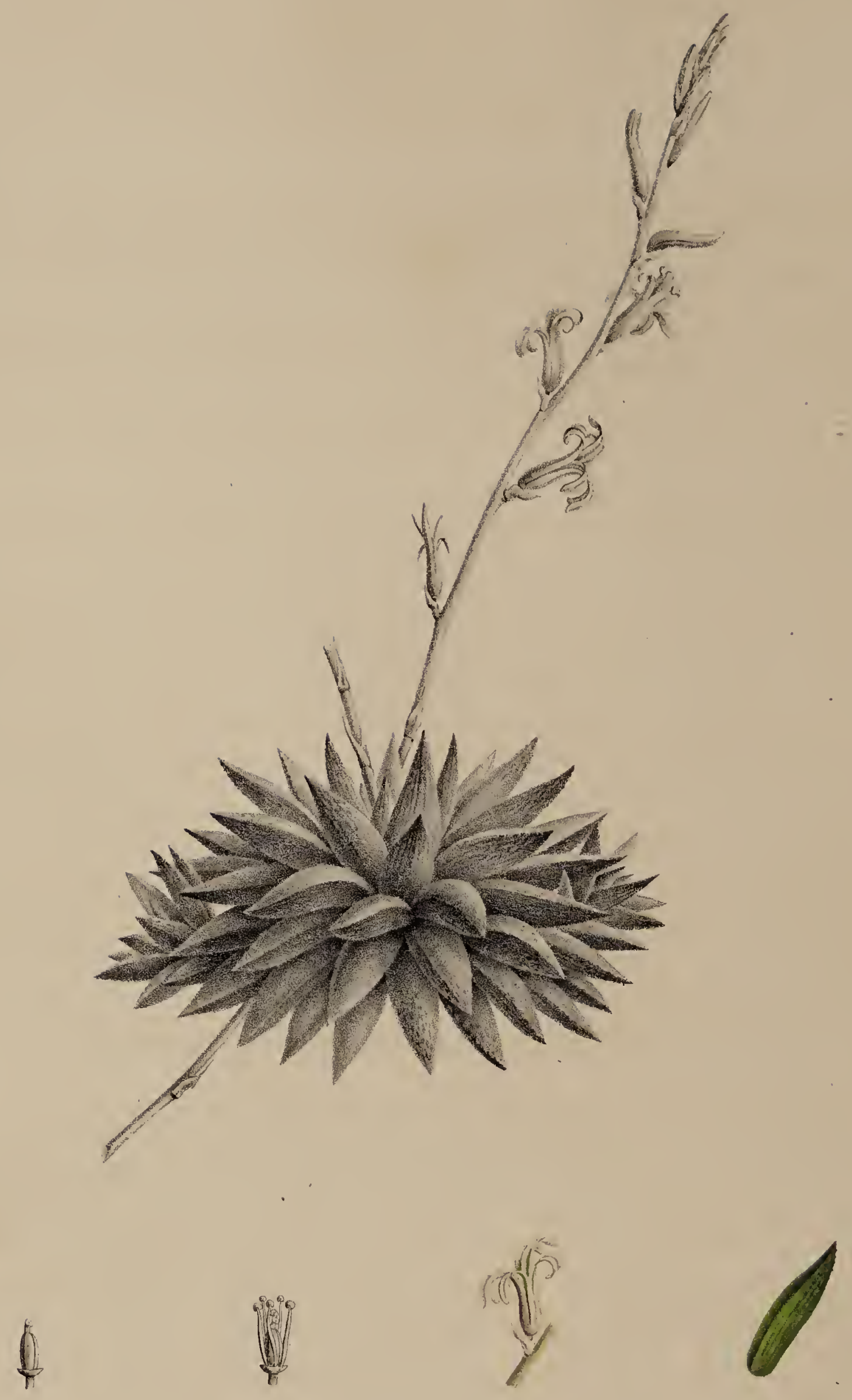

A.

(\$.10. - Fig. 1.) 
(\$. 10. Fig. 1.)

\section{A L O E R E T I C ULA T A Han. (HAWORTHIA Duval.)}

ALOE reticulata; acaulis vel subacaulis, foliis rosulatim multifariis patulis oblongo-acutis farctim triquetris pallide viridibus pellucidis valde reticulatis laevibus, superne ad margines carinamque obsolete denticulatis.

A. reticulata; foliis triquetris patulis obtusiusculis glaucescentibus subreticulatis margine carinaque denticulatis. spreng. Syst. 2. p. 68.

A. herbacea; acaulis, foliis caespitosis oblongis acutis apice triquetris, angulis imprimis carinali tenuiler denticulatis. DC. Cat. Hort. Monspet. p. 76.

HAWORTHIA reticulat $a$; foliis multifariis aequilateri-triquetris obtusiusculis glaucescentibus reticulatis supra subconcavis. Haw. Synop. p. 9. - in Lim. Soc. Trans. 7. p. 9. Ait. Kew. ed. 2. Vol. 2. p. 299. - Nob. Cat. rais. p. 2. - Schutl. Syst. 7. p. 639.

APICRA reticulata; subcaulescens, foliis oblongo-triquetris patulis obtusiusculis tenuissime reticulatis glabris, junioribus supra planis, senioribus convexiusculis, apice carina obsolete subdenticulata. Willd. Mrag. p. 272.

ALOE arachnoides $\gamma$ reticulala; foliis crassioribus oblusioribus pallidioribus glabris, margine tantummodo carinaque rotmdata obsolete denticulatis. Bot. Mag. t. 1314.

APICRA Pumilio; acaulis, foliis erectiusculis lanceolatis triquetris acutis glaucescentibus glabris, apice, margine, et carina cartilagineo-dentatis. willd. Mag. p. zzl.

ALOE Pumilio ; foliis trigonis, apice et carina cartilagineo-dentatis; floribus subspicatis breviter pedunculatis patulis, supra medium expansis. Jacq. Hort. Schönb. 4. p. 11. t. 421.

RADIX cylindracea, carnosa, fibrosa.

CAULIS in plantis jumioribus nullis, in adultis e superpositione foliorum quandoque pollicaris.

FOLIA numerosa, mullifaria, in rosulam disposita, lin. 12-13 longa et lin. 3-4. basi lata, suberecto-patentia, laevissime incurvula, acuta, subrigida, laevia, vix nilida; juniora supra planiuscula seniora comexa, subtus semicylindracea, apice farctim triguetra angulo carinali subproducto, pallide viridia, pellacida, lineolis 10-12 opacis, reticulalim anastomosantibus notata, ad nargines superne et ad carinam obsolete denticulata.

PEDUNCULUS floralis seu scapus simplex, luridus, bracteis sterilibus remotis: amplexicaulibus, longe cuspidatis, integris instructus.

FLORES spicati, erecli, subsessiles. Bracteae albido-roseae, latae, perianthii lubum basi imolventes.

PERIANTHIUM ad $1 \frac{1}{2}$ tubulosum, obclavatum, tubo recto rosen, limbo bilabialo, labiis subrevolutis; laciniae oblusulae, subaequales, basi viridulae apice pallidissime roseae.

STAMINA perianthii tubo breviora, alternation inaequalia. Filamenta subulalu viritula. Antherae flavae. 
PISTILLUM. Ovarium cylindraceo-trigomm. Stylus filamentis brevior. Sligma obtusum.

CAPSULA cylindraceo-trigona; maturam non vidi.

Habitat in Prom. b. spei. Floret a mense Februario ad Aprilem.

Observ. Haec species jam ante annum 1794 in Anglia culta erat, et Cl. Haworth eam descripsit sub nomine $A$. reticulatae. Serius in hortum Schönbrunnensem et in hortum Monspeliensem advecta, Cl. Jacquin sicut et Cl. De Candolle eam pro specie nova habuerunt, cui primus nomen $\boldsymbol{A}$. Pumilionis et secundus $\boldsymbol{A}$. herbacene tribuerunt. Cl. Willdenow, quoque in errorem inductus, Haworthii et Jacquinii species ut distinctas descripsit, et inde haec planta triplici nomine donata, dubiosa remansit. Sobolibus ad basin plantae frequentibus facile propagatur. 



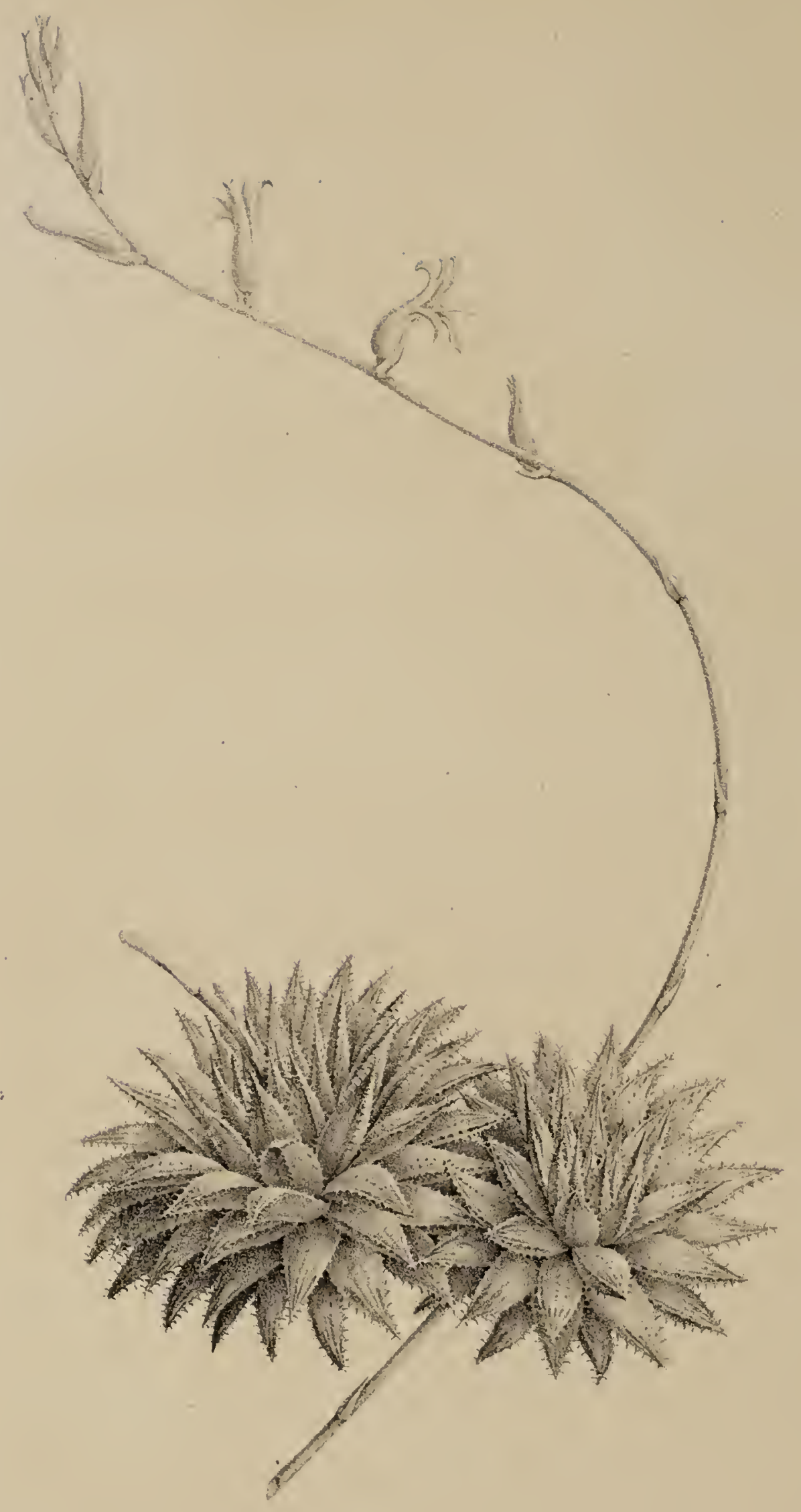

6

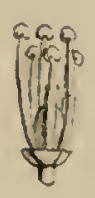
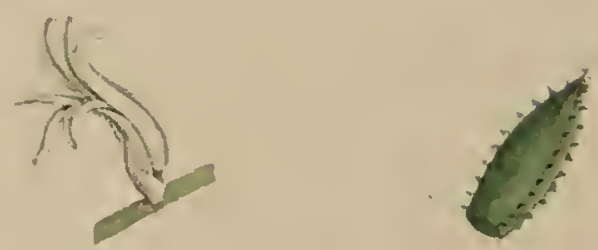

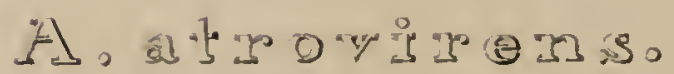

$$
\text { (s. (1). - F . 2.) }
$$


(§. 10. Fig. 2.)

\title{
A L O E A T R O V I R E N S DC.
}

\author{
(HAWORTHIA Dival.)
}

ALOE atrovirens; acaulis vel subacaulis, foliis rosulatim multifariis patulis oblongoacutis in setulam exeuntibus triquetris supra convexis atroviridibus obscure pellucentibus tuberculatis, ad margines carinamque dentatis, dentibus brevibus subulatis herbaceis.

A. atrovirens; foliis patulis lanceolatis trigonis margine carinaque dentatis, dentibus brevissimis subulatis, tuberculis confertis. Spreng. Syst. 2. p. 69.

II aworthia atrovirens; foliis atroviridibus supra valde turgidis, setulis marginalibus exiguis, tuberculisque undique numerosis. Haw. Revis. p.57. - Schutt. Syst. \%. pay. 610. (Stib. sitir.)

Apicra atrovirens; acaulis, foliis patulis lanceolatis trigonis tuberculatis, margine carinaque dentatis, dentibus subulatis brevissimis, corollis pedicellatis, bracteis pedicelio brevioribus. Willd. Mag. p. 268 .

Alö̈ atrovirens; acaulis, foliis patulis ovatis trigonis, margine carinaque dentatis, dentibus subulatis brevissimis, corollis pedicellatis infundibuliformibus, bracteis pedicello brevioribus. Willd. Enum. p. 385.

Alo $\ddot{e}$ atrovirens; foliis caespitosis patulis atroviridibus apice trifariis, 'angulis spinis herbaceis brevibusque munitis, lateribus subtuberculosis. DC. Pl. grass. 1. 51. - Nob. Cat. rais. p. 2.

Il aworthia pumila; foliis perviridibus, spinis marginalibus herbaceis tuberculisque numerosis. Haw. Synop. p. 95. Linn. Transact. 7. p. 10.

Aloë arachnoides pumila. Willd. Spec. pl. 2. pag. 188. - Ait. Kew. ed. 1. Vol. 1. p. 468. ed. 2. Vol. 2. p. 301. - Bot. Mag.t. 1361.

Aloë herbacea. Mill. Dict. No. 18.

Alo ë pumila $\varepsilon_{0}$ foliis ovato-lanceolatis carnosis apice triquetris, angulis inerme dentalis. Lin. Hort. Cliff. p. 131. Hort. Upsal. p. 86. - Roy. Lugd. bat. p. 24. - Bradt. Succ. 3. p. 12. 1. 30.

RADIX cylindracea, carnosa, fibrosa.

CAULIS nullus, aut in plantis adultis e superpositione foliorum quandugue pollicaris.

FOLIA numerosa, multifaria, in rosulam disposita, lin. 6-8 longa, et 4-5 basi latı, acuda, apice subaristata, subrigida, nitidu, supra convexu, subtus curinata, perviridia, pellucida, lincis longitudinalibus $\mathbf{3 - 5}$ opacis subunustomosuntibus notatu, quibus incidunt tot series tuberculorum, ad margines et ad curinum inerme aculeuta; aculeis conferlis subcurtilagineis, brevibus, subpellucentibus.

PEDUNCULUS Roralis seu seapus simplex, huridus, bracteis remotis semiumplexicaulibus, cuspidatis instructus. 
FLORES spicati, erecti, subsessiles. Bracteate albido-roseae, latiusculae, perianthii fubum basi involventes.

PERLANTHIURI ad \% tubulosum, obclavalum, tubo incurvulo viridi-albo, limbo bilabialo; labiis subrevolutis; laciniae aculae, subaequnles, exteriores albidae, interiores viridulne.

STAUINA perianthii tubo breviora, alternatim inaequalia. Filtumenta subulata viridula. Antherac Raune.

PISTIELLUH. Ovarium cylindracen-trigomum. Stylus filamentis brevios. Sligme obfusum.

CAPSULA cylindraceo-trigona; maturam non ridt.

Uabitat in Prom. bon. Spei. - Floret mensibus Julio et Augusto.

Observ. Haec planta jam diu culta, recenter solum, et cura Cl. Decandollii bene cognita est. Vulgatissima in hortis occurrit, et a pracectente foliis perviridibus, ad margines incrme aculeatis, omnino recedit. 

(\$. 11. Fig. 1.)

\section{ALOE CYMBAEFOLIA schral. (HAWORTHIA Dural)}

ALOE cymbaefolia; subcaulescens, foliis rosulatim-multifariis patento-incurvulis ovatoacutiusculis integerrimis mollibus glaucescenti-viridibus pellucentibus, supra concavis subtus convexis, apicem versus obtuse carinatis.

Alö̈ cymba formis; foliis ovatis concavis glaucescentibus apice carinatis obtusis mucronatis subreticulato-lineatis. spreng. Syst. 2. pag. 68.

A. cymbaefolia; acaulis, foliis lato-ovatis concavis mucronatis dorso apicem versus carinatis, floribus racemosis erectis cylindricis bilabiatis. Sclrad. Neues Journal. Vol. 2. 1. p.17.८ 2.

Apicra cymbaefolia; acaulis, foliis ovatis concavis mucronatis glaucescentibus supra lineatis, apice carinatis. Willd. May. p. 271.

Haworthia concava; foliis excavato-cymbiformibus obtusis glaucis valde concavis: superne carinatis obsolete reticulatis: propaginibus cespitosis. Haw. Revis $p$. 58. (excl. var. $\beta$. foliis erectioribus.)

Aloë cymb a efolia; acaulis, foliis patentibus ovatis concavis subtus apice carinatis, corollis pedunculatis erectiusculis infundibuliformibus. Will. Enum. p. $38 \%$.

I aworthia cymbiformis; foliis cymbiformibus obtusis glaucis; supra valde concavis, apicibus carinatis obsolete reticulatis: propaginibus numerosis. Haw. Synop. pag. 93. Linn. Soc. Trans. 7. pag. 8. - Nob. Cat. rais. pag. 1. - Schult. Syst. 7. pag. 637. (sıb Aloë) - Ait Kew. ed 2. Vol. 2. p. 299. - Bot. Mag. t. 802. - Jacq. Fragm. 1. 112. Fig. 1.

\section{RADIX cylindracea carnosa, fibrosa.}

CAULIS aetate pollicaris et ultra, crassus, subcarnosus.

FOLIA multifaria, subconferta, in rosulam disposita, sesquipollicem longa, et pollicem medium versus lata, infime et superne ovoideo-attenuata, apice acutiuscula, mutica, juniora erecto-incurvula, seniora patentia, herbacea, mollia, glauco-viridia, laevissima, supra concava aut plano-concuviuscula, subtus convexu, superne incrassatu et carimulatim producta, apice aquoso-pellucida, et lineis subreticulatis viridibus opacis striata, ad margines curinamque integerrima.

PEDUNCULUS floralis simplex, crassiusculus, luridus, bracteis sterilibus instructus.

FLORES subspicati, erecti, breve pedicellati. Bracteae lanceolatue, spurco-roseae, pedicello paulo longiores.

PERIANTHIUM ad 1/2 tubulosum, obclavatum, pallidissime roseum, viridi-striahum, limbo bilabiato revoluto; laciniae latiusculue, obtusae, subaequales, albido-roseae, linea basi sordide viridi et apice rosea notulae. 
STAMINA perianthii tubo breviora, alternatim imaequalia. Filamenta viridula, subulala. Antherae flavae.

PISTILLUM. Ovarium cylindraceo-trigomum. Stylus filamentis brevior. Stigma obtusum.

CAPSULAM maturam non vidi.

Habitat in Prom. bon. Spei. Floret mense Junio.

Observ. Dom. Masson hanc speciem anno 1795 in Anglian advexit, el sobolibus frequentissimis celeriter in hortis nostris vulgatissima evasit. Varielıs B. foliis ereclioribus a Cl. Haworthio ei adscripta vix notatu digna est. 



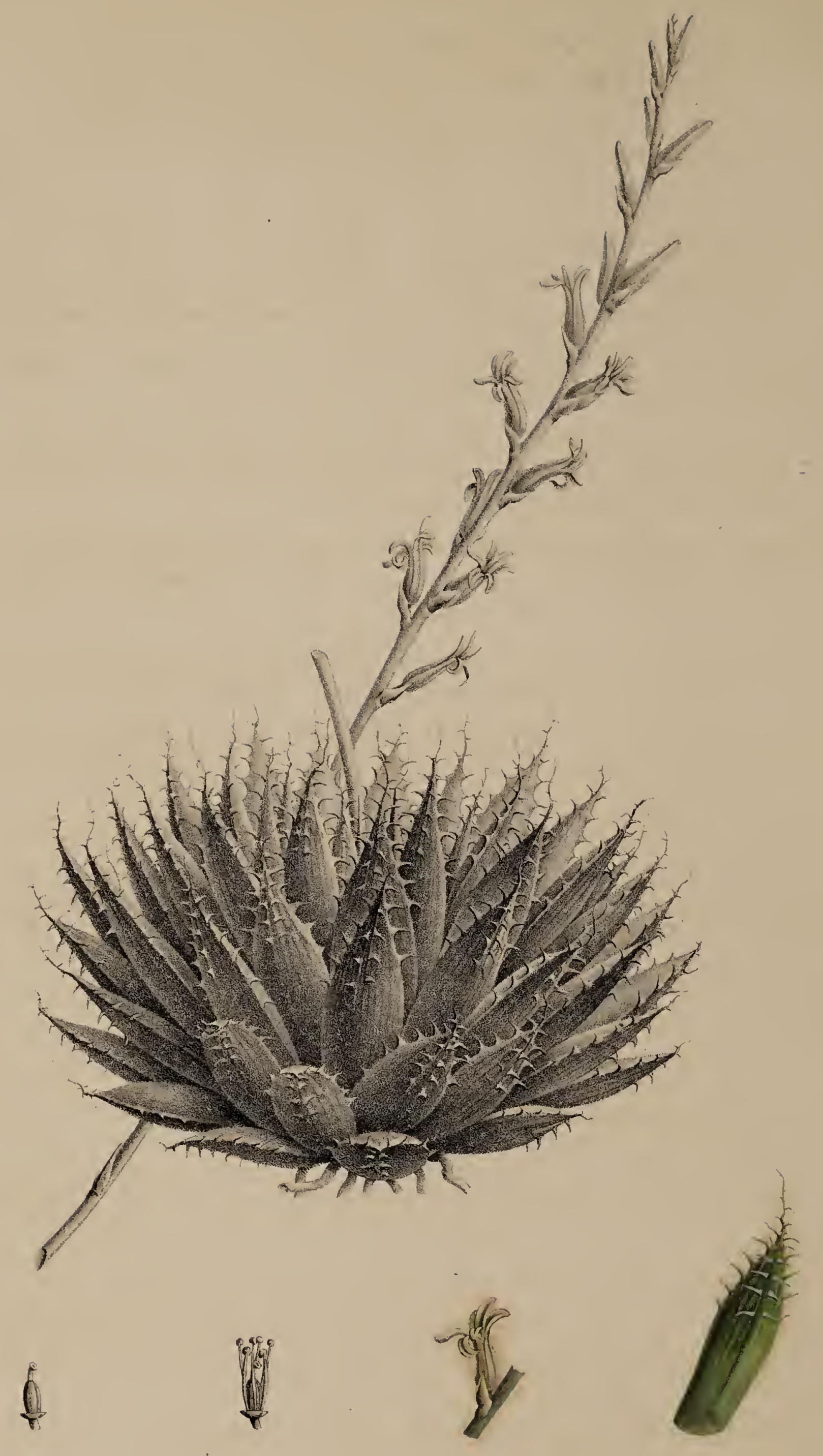

A

(\$.12. - Fig. 2.) 
(\$. 12. Hig. 2.)

\section{1. O E A $\mathrm{C}$ A C H N O I D E S Thmb.}

\section{(HAWORTHIA Din.ul.)}

ALOb, arac/enoides; acaulis, foliis rosulatim multifariis incurvalu-patulis lanceolato-acuminatis in setan dentatam exemntibus, planiusculis apice carinatis pellucide glaucescentibus, arl margines carinamque selosis, setis longis subulatis cartilagineis.

A. ar aclınoides; foliis adscendentibus lanceolatis striatis apice trigonis margine carinaque dentatis, dentibus cartilagineo-setaceis. symeny. syst. 2. p. tis

J picra arachnoides; acaulis, foliis adscendentibns lanceolatis striatis apice trigonis, margine carinaque dentatis, dentibus cartilagineo-setosis, corollis subsessilibus bracreis pedicello longioribus. Willd. Mag. p. 268 .

A. arachnoides; acaulis, foliis adscendentibus ovatis apice trigonis, margine carinatule dentatis, dentibus cartilagineo-setosis, corollis subsessilibus infundibuliformilus. hracteis pedicello longioribus. Willd. Emm, m. 38.5 .

A. "rrelunoides; foliis cespitosis coarctatis glancescentibus apice pellucido-corneis trifariis, angnlis spinis inermibus Iongisque mmitis, lateribus laevibns. DC. Pl. grass. 1. oo.

Ilaworthia arachnoides; foliis expansis lanceolatis, smpra planinsculis marginibns car-

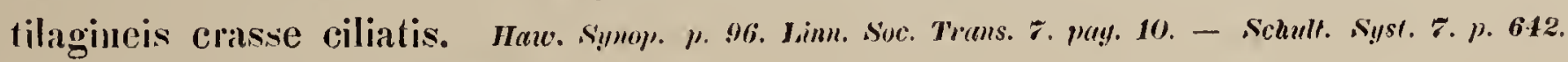
- Nob. Cat. rais. p. 3. (excl. vur. B.)

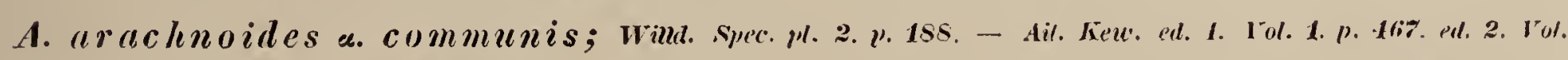
2. 11. 301. - Bol. May. 1. 756 .

A. arachnoides; acaulis, foliis trigonis cuspidatis ciliatis; forilus subspicatis crectis cylindricis. Thenb. Diss. n. 7. Fr. Cap. ed. schult. p. 311.

A. Mumila arachnoides; Mill. Dict. n. 1r. Lim. Sper. ed. 1. p. 392.

A. africana humilis arachnoidea. Commer. Prael. 1. 2⿰.

RADIX cylindracea, cumosa, fibrosa.

CAULIS mullus.

FOLIA memerosa, mullifaria in rosulam disposilu, poll. 2 el ullra longa el lin. 6-F medio latu, basin versus prauhum angustata, apice acuminala, in setcum filiformem lomgum dentalam mox marcescentem exeunlia, incurvula, jumino evecto-palula, seniora patrmlia, herbaceo-mollia, supra plana-convexa luevia, subhus basi convexu, superne carinato-lriquetio, glauco-laeteviritia, pellucida, lineis longitudinalibus 8-9 opacis subreliculatim anastomosanlibus molata, ad margines basin revsus laevia, superne al anl carinam setis cartilayineis validis, remolinsculis, subulatis, rectis, niveis instructa.

PEDUNCULUS floralis sen scapus simplex, cressinsculus, phembuginern-rividis, bracleis slerililus instructus.

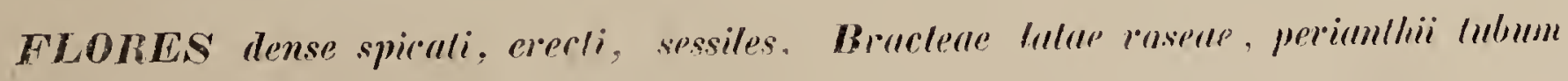
hrrei imolventes. 
PERIANTHIUM ad \% tubulosum, obchwatum, spurco-roseum, saturatius striatum, limbo bilabiato, labiis revolutis; laciniae subaequales pallide roseae linea saturatiore notatae, obtusae, media in labio inferiore magis revoluta.

STAMINA perianthii tubo breviora, alternutim inaequalia. Filamenta subulata

ralbida. Antherae luteae.

PISTILLUM. Ovarium cylindraceo-trigonum. Stylus filantentis brevior. Stigma obfusum.

CAPSULAM maturam non vidi.

Habitat in Prom. bon. Spei. - Floret aestate.

Obsere. Haec antiqua hortorum incola a praecedente foliis lanceolatis planiusculis sicut et multo minus pellucentibus satis differt. Var. B. minor ei a Cl. Haworthio (Suppl. p. 52) adscripta, serius ab auctore ipso ad $\boldsymbol{A}$. setosum relata est; et Vur. pellucens Nob. (Cat. rais. p. 3.) nilil nisi annosior planta in caldario culta. Hae varietates ergo delendae sunt. 



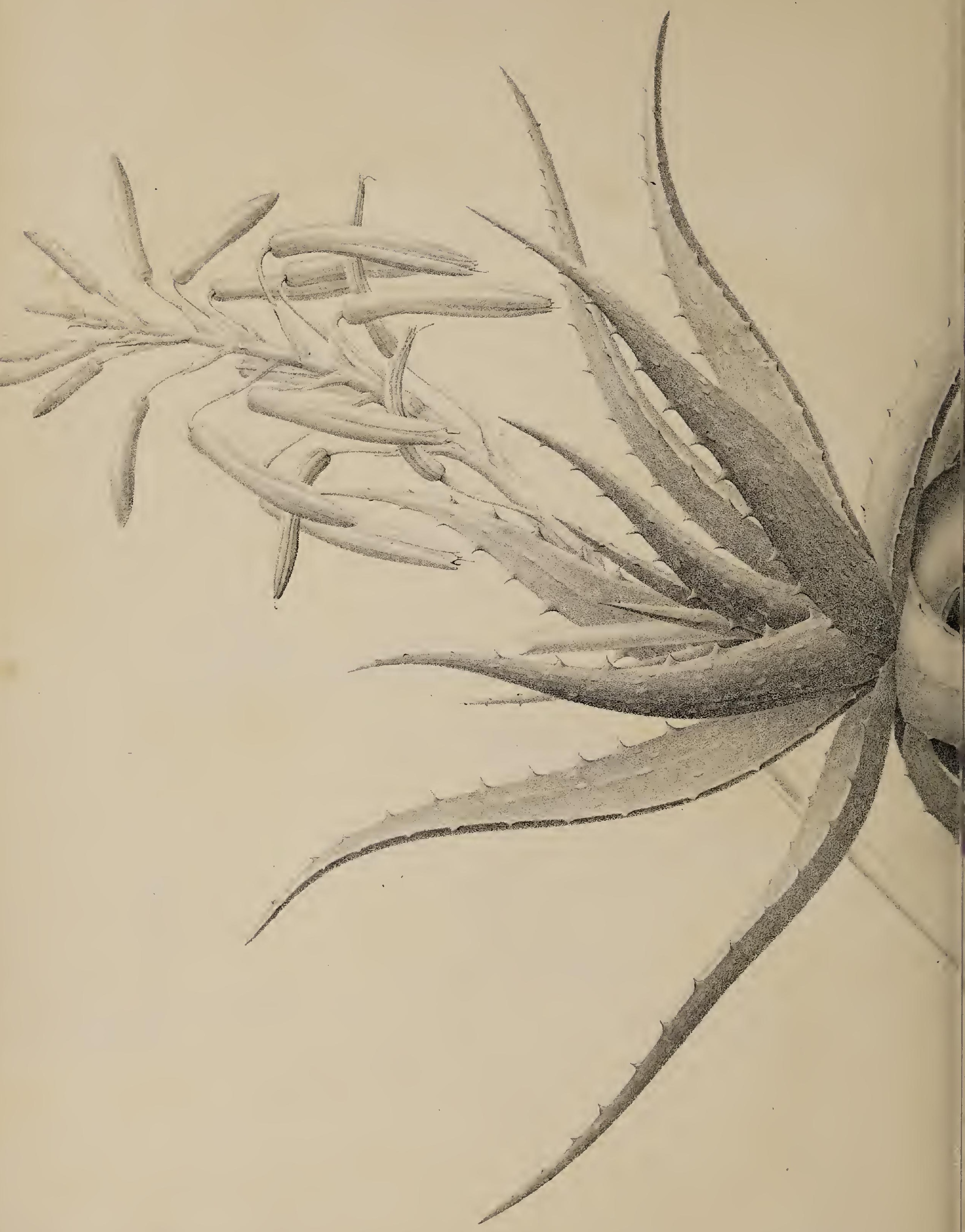




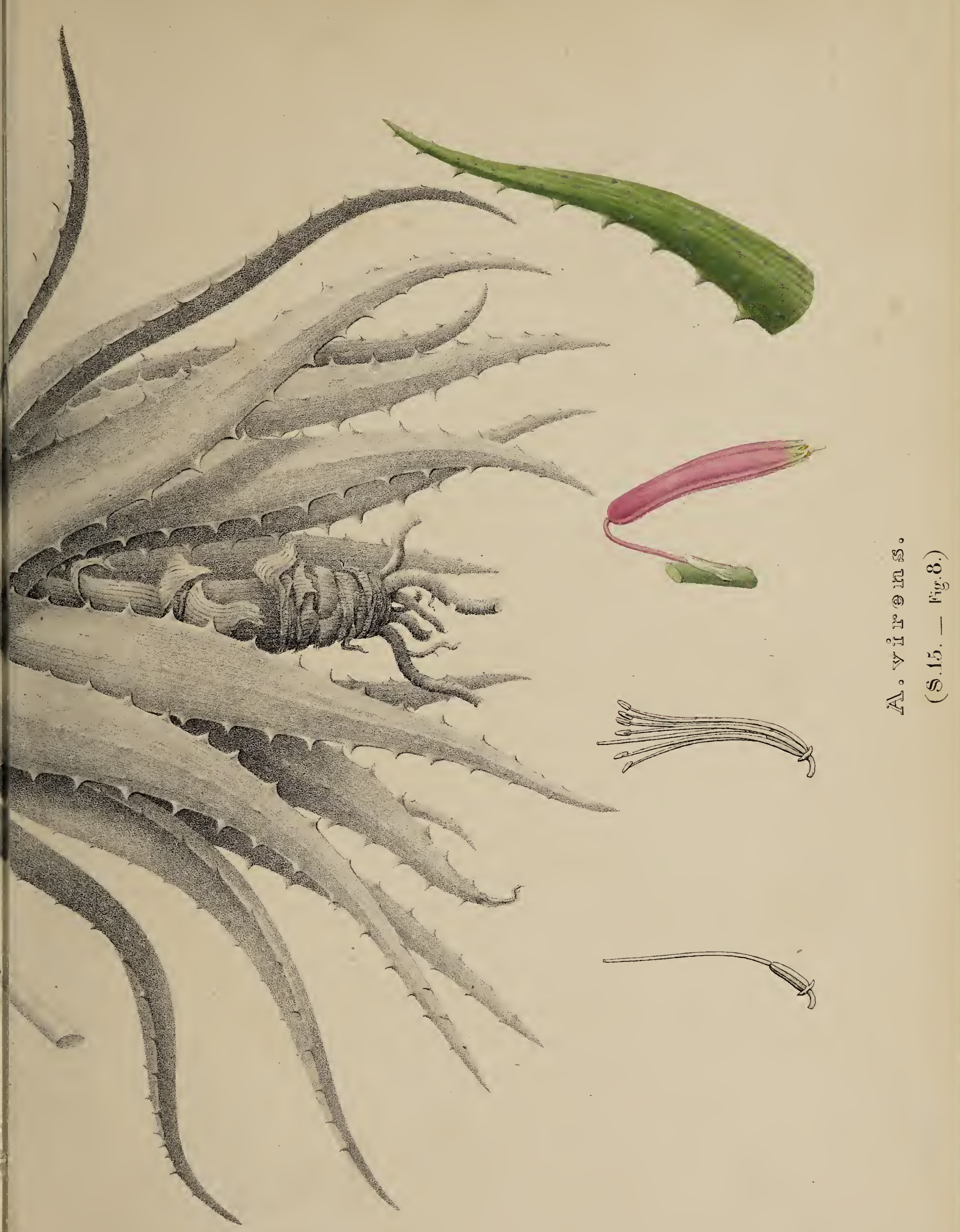





\section{(\$. 15. Fig. 8.)}

\section{A L O E V V R E N S Hav.}

ALOE virens; subcaulescens, foliis divaricatis lanceolato-oblongis acuminatis laevibus viridibus parce albo-maculatis, ad margines remote ac subinerme aculeatis, scapo basi nudo.

A. virens; subacaulis, foliis oblongo-lanceolatis viridibus parce maculatis, marginibus remote spinosis, spinis viridibus uncinatis, floribus thyrso-spicatis. Spreng. Syst. 2. p. 72.

A. virens; subcaulescens, foliis oblongo-lanceolatis patentibus laete viridibus glabris utrinque albo-maculatis, margine remote spinosis, spinis uncinatis. Willd. Mag. p. 25.9. n. 15.

A. virens; saubacaulis, foliis oblongo-lanceolatis viridibus, parce maculatis, marginibus remote spinosis, spinis viridibus, floribus thyr'so-spicatis. Baw. Suppl. p. S3. Limn. Soc. Trans. 7. p. 17. - Nob. Cat. rais. p. 22. - Bot. Mlag. t. 1355. - Schult. Syst. 7. p. 686.

\section{RADIX cylindracea, carnosa, fibrosa.}

CAULIS aetate spithameus, cicatrisatus, diametro pollictri.

FOLIA in apice caulis conferta, multifuria, juniora recurvato-patentia, seniora patentissima aut omnino deflexa, apice varie flexa, poll. 9-11 longa, et lin. 15 basi lata, sensim attenuata, acuminata, supra plana, subtus cunvexiuscula, laete viridia, utrinque substriata, laevia, nitidula, et albo parce maculata, maculis in pagina infera mumerosioribus in lineas longitudinales dispositis, et imo apice spinulescenti-prominulis, ad margines aculeata, aculeis remotis mollibus basi viridibus apice subuncinatis albidis.

PEDUNCULUS foralis pedalis, simplex, crassus, virens, basi nudus et superne bracteis quibusdam sterilibus, latiusculis, semiamplexicaulibus instructus.

FLORES in racemum laxum dispositi, longe pedicellati; pedicellis miniatis, bracteis duplo longioribus.

PERIANTHIUM cylindraceum, lin. 20-23 longum, laevissime trigonum vix ventricosum, sub forescentia mutans, profunde sexfidum; laciniis in tubum conniventibus, miniatis, apice coarctatis lineaque viridi notatis, exterioribus latioribus aculiusculis.

STAMINA periunthii tubum aequantia, atternatim subinaequalia. Filamenta subulato-filiformia, albida. Antherae laterales, basi emarginalae, croceae.

PISTILLUM. Ovarium cylindraceo-trigonum. Stylus filamentis longior, subulatofiliformis. Stigma inconspicuum.

CAPSULAM maturam non vidi.

Habitat in Prom. bon. Spei. - Floret liyeme ad verem usque.

Observ. Haec species propaginibus frequentibus in hortis nunc vulgatissima, jam ante annum 1790 in Anglia culta fuit. Primo intuitu a Sectione Echinatarum propter folia utrinque laevia discedere videtur; hae vero maculis quibusdam sunt adspersa, quae in linea media paginae superae et subtus imo apice subspinulescentes evadunt, et ergo pro echinis oblitteratis haberi debent. A plurimis hujusce sectionis speciebus pedunculo florali basi ebracteato solum recedit. 

- 



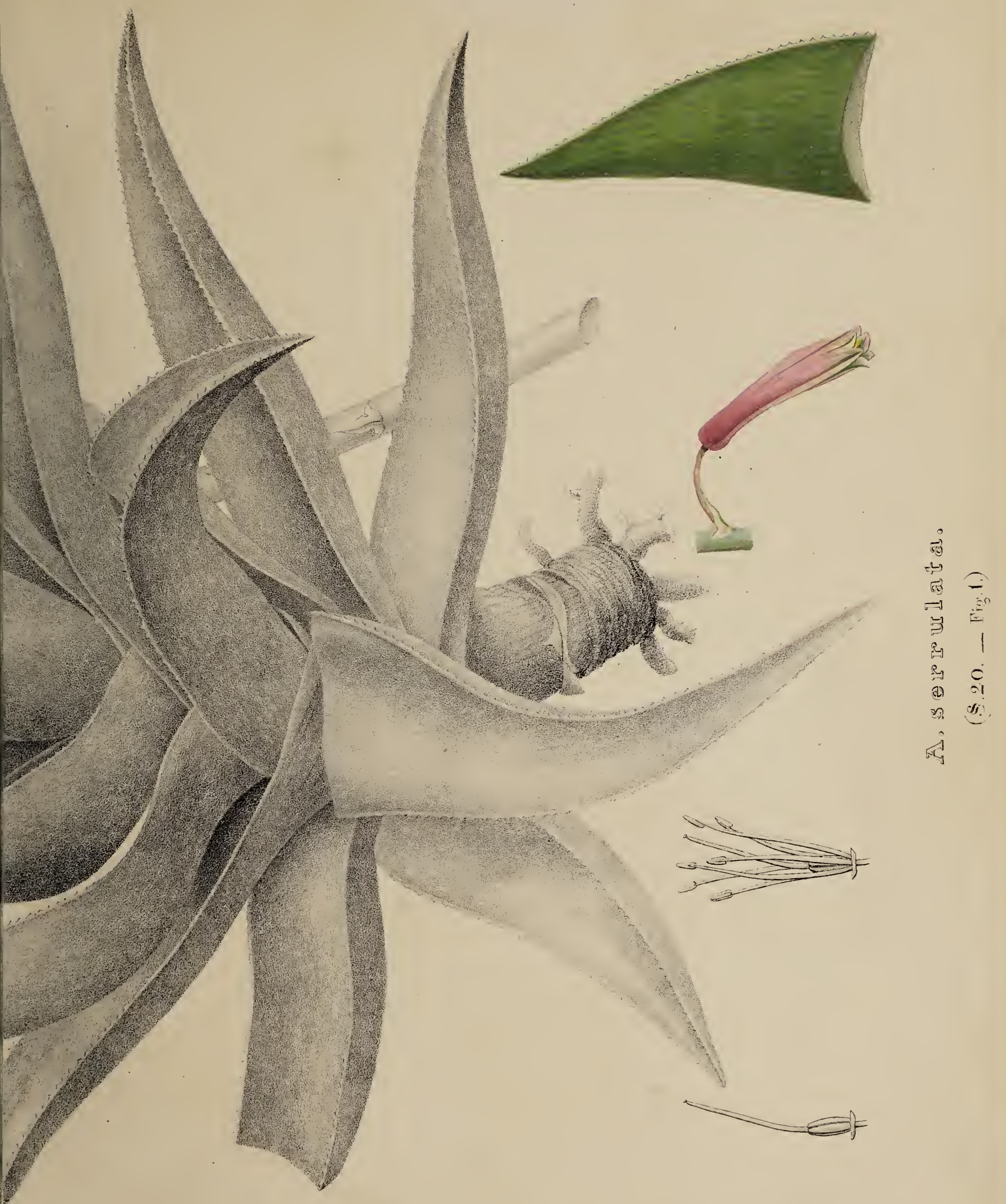



(S. 20. Fig. 1.)

\section{ALOE SERRULATA Haw.}

ALOE serrulata; caulescens, foliis perspiraliter trifariis patentibus ovato-lanceolatis, acutis, laete viridibus obscure albo fasciatim maculatis laevissimis nitidis, supra plano-concavis subtus convexis, imo apice carinatis, ad margines carinamque cartilagineo-serrulatis.

A. serrulata; foliis ovato-lanceolatis apice subtriquetris seriatim maculatis margine carinaque apice serrulatis. Spreng. Syst. 2. p. 72.

A. serrulata; foliis maculatis, marginibus carinaque apice serrulatis. Haw. Synop. p. 82. Linn. Soc. Trans. 7. p. 18. - Ait. Kew. ed. 2. Vol. 2. p. 295. - Bot. Mag. t. 1415. - Nob. Cat. rais. p. 26. Schult. Syst. 7. p. 697 .

A. perfoliata $\lambda$. serrulata Ait. Kew. ed. 1 .

RADIX carnosa, cylindracea, fibrosa.

CAULIS aetate subbipedalis, inferne nudus, cicatrisatus, diametro pollicari.

FOLIA in apice caulis conferta, trifarium in linea spirali disposita, et inde fere multifaria, juniora erecto-recurvata, seniora patentissima, apice in-vel recurvula, poll. 7-8 longa, et poll. 2 basi fere lata, carnosa, laetissime viridia, utrinque maculis albidis oblongis superne fasciatim dispositis, ad basin vero sparsis, mumerosissimis ac confluentibus notata, laevissima, nitidula, supra planiuscula, medium versus concaviuscula, et apice triquetrocompressa, ad margines carinamque cartilaginea, imo basi integerrima, superne sensim denticulata et aspere serrata.

PEDUNCULUS floralis sesquipedalis, simplex, strictus, crassus, lividus, bracteis quibusdam sterilibus instructus.

FLORES in racemum densum dispositi, pedicellati; pedicellis miniatis bractea viridula duplo longioribus.

PERIANTHIUM cylindraceum, sesquipollicem et ultra longum, laevissime trigonum, subventricosum, mutans, ad medium usque sexfidum; laciniis subaequalibus conniventibus miniatis, apice patulis flavido-roseis lineaque obscure viridi notatis.

STAMINA longitudine perianthii tubo, alternatim inaequalia. Filamenta subulata, filiformia, pallidissime carnea. Antherae laterales basi enurginutae, favidae.

PISTILLUM. Ovarium trigonum. Styhus longitudine filamentorum. Stigma vix conspicuum. 
CAPSULAM muturam non vidi.

Habitat in Prom. bon. Spei. Floret mense Majo.

Observ. Haec species in Anglia jam ante annum 1789 culta, rarissime adhuc in hortis occurrit, et Cl. Willdenow eam cum $\boldsymbol{A}$. Serra confudit. Sectionem propriam cum A. variegata constituere debet, propter folia trifarie disposita, fasciatim maculata, ad margines crenulato-serrulata, et propter pedunculum floralem nunquam ramosum. 


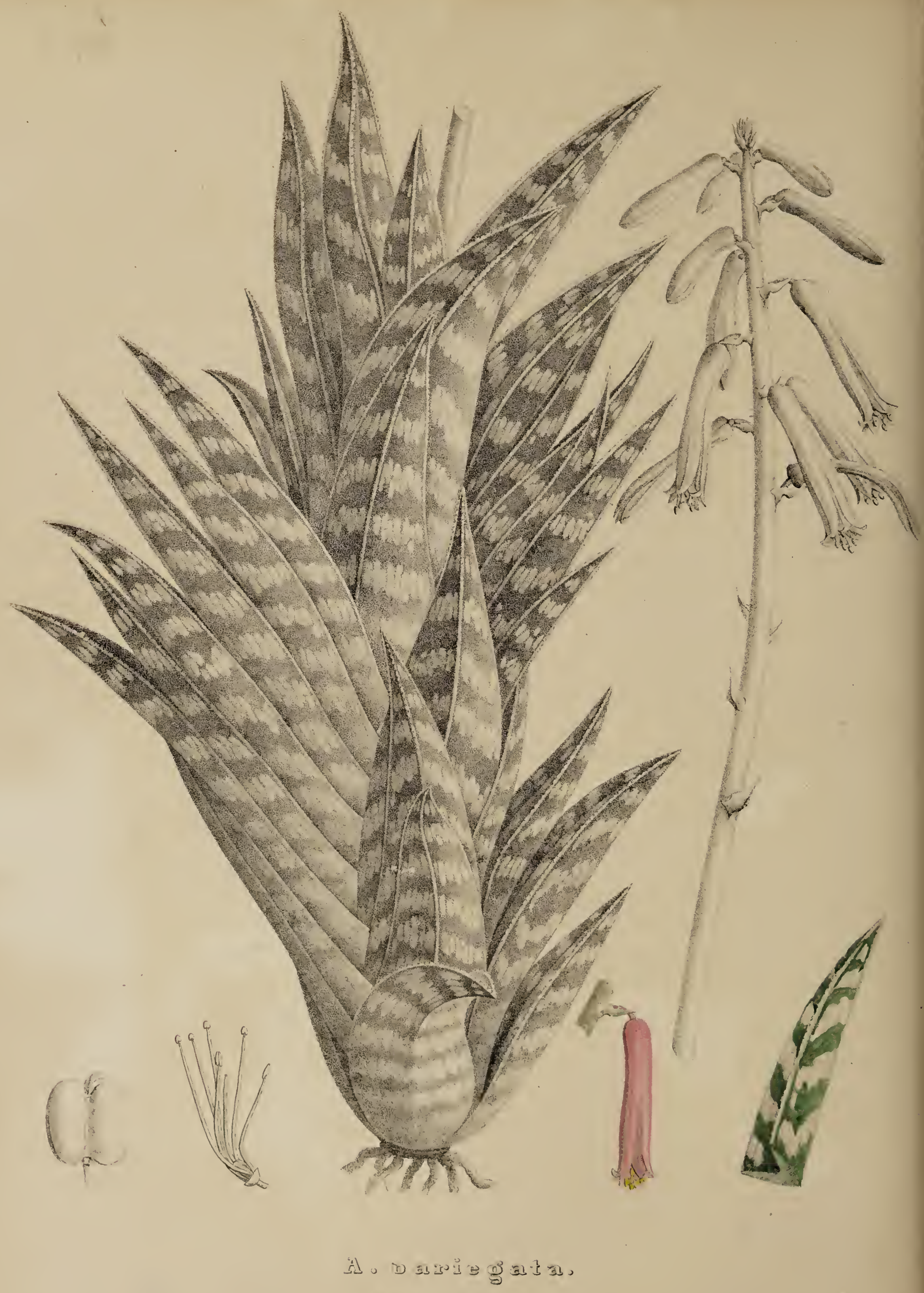

5. 20 - Fin. 
(ङ. 20. Fig. 2.)

\section{A L O E V A R I E G A TA Lir.}

ALOE variegata; subcaulescens, foliis subspiraliter trifariam imbricatis erectis lanceolatoacutis perviridibus albo-fasciatim maculatis laevissimis nitidis, supra excavatis subtus valde triquetro-compressis, ad margines carinamque cartilagineo-crenatis.

A. varie gata; foliis imbricato-patulis trifariis ovatis canaliculato-trigonis fasciato-maculatis margine carinaque cartilagineo-crenatis. spreng. Syst. 2. p. za.

A. variegata; subcaulescens, foliis imbricato-patulis trifariis ovatis trigonis, supra concavis, glabris, maculatis, margine carinaque cartilagineis crenatis. Will. Mag. p. 27. .

A. variegat ; foliis trifariis pictis fasciis albis, canalicnlatis, angulis cartilagineis obsolete serrulatis. Haw. Synop. p. 81. - Schull. Syst. 7. p. 696. - Nob. Cat. rais. p. 16.

A. variegata; subcaulescens, foliis imbricato-patulis subtrifariis oblongis trigonis maculatis angulis cartilagineis crenatis, racemo simplici, corollis cylindricis pendulis. willd. Euum. p. 384.

A. variegata; subacaulis, foliis trifariis pictis canaliculatis, angulis cartilagineis, floribus racemosis cylindricis. Thunb. Diss. N. 12. Prodr. 61. Fl. Cap. ed. Schult. p. 312. - Will. spec. pl. 2. p.190. - Ait. Kew. ed. 1. Vol. 1. p. 470. ed. 2. Vol.2.p.296. - DC. Pl. succ. p. 21. t.21. - Bot. Mag. t. 513.

A. punctata; subacaulis foliis imbricatis carinatis incurvatis undique albo maculato-punctatis. Haw. Lin. Soc. Truns. 7. p. 26. Reris. p. 44.

A. variegata; foliis canaliculatis trifariam imbricatis radicatis erectis: angulis cartilagineis ternis. Lin. Hort. Cliff. p. 132. Hort. Upsal. p. 87. - Roy. Lugd-bat. p. 24.

A. variegata; floribus pedunculatis cernuis racemosis prismaticis: ore patulo aequali. Lin. spec. pl. ed. 1. p. 321. - Mill. Dict. N. 9.

A. africana humilis, folio ex albo et viridi variegato. Comm. Prael. t. 28. (sine fure) - Till. Hort. Pis. t. 7. (cum flore Aloes margaritiferae minoris in Tab. 8 depictae, erroneo transposito.)

\section{RADIX carnosa, cylindracea, fibrosa.}

CAULIS poll. 6-9 altus, simplex, foliis tectus, basi quandoque mudus.

FOLIA conferta, dense trifariam in linea subspirali imbricata, juniora erecta, seniora evecto-patula, laevissime recurvata, poll. 3-4 longa et pollicem basi lata, sensim attenuata, parum carnosa, perviridia, utrinyue maculis albis elongatis subconfluentibus fasciatim notala, unde folia ex albo et viridi variegata, laevissima, nitida, supra canaliculation excuvata, subtus a basi fere trifuetro-compressa, lateribus planis et carina acuata, ad margines carinamque cartilaginea, inferne integerrima, superne denliculato-crenata.

PEDUNCULUS floralis subpedalis, simplex, strictus, crussus, tividus, bracteis quibusdam sterilibus instructus.

FLORES in racemum dispositi, pedicellati; pedicellis miniatis bractea rosea parum brevioribus. 
PERIANTHIUM cylindraceum, sesquipollicem longum, laevissime trigonum, vix ventricosum, mutuns, profunde sexfidum, laciniis subaequalibus conniventibus miniatis, apice putulis roseis lineaque viridi notutis.

STAMINA perianthii tubo parum longiora alternatim inaequalia. Filamenta suImelata, filiformia, carnea. Antherae laterales, basi marginatae, croceae.

PISTILLUM. Ovarium trigonum. Stylus filımentis brevior. Stigma vix conspicuntm.

CAPSULA matura magna, trialatim compressa, basi et apice emarginata.

Habitat in Aethiopia et in Prom. bon Spei. Floret aestate.

Observ. Antiqua et in hortis vulgatissima species. Varietas viridior a Cl. Haworthio ei adscripta notatu non digna est. In tabulis Horti Pisani n. 7. et I1. 8., errore gravi, pedunculi florales transpositi sunt, et ita flos $\boldsymbol{A}$. variegatae in tab. 7 tributus ad tab. 8 pertinet, et vice versa. Capsula in lac specie peculiari modo ad valvulas alatim compressa, et utrinque auriculatim producta est. 


(5. 21. Fig. 1.)

\section{A L O E M I C R A C A N T H A Haw.}

ALOE micracantha; subcaulescens, foliis linearibus canaliculatis macris utrinque albo maculatis, maculis subtuberculiformibus elongatis sparsis, aculeis marginalibus minutis rectis albis, floribus umbellato-racemosis.

A. micracantha; foliis linearibus canaliculatis cuspidatis maculatis, margine spinulosociliatis. spreng. Syst. 2. pag. 7 1.

A. microcantha; acaulis, foliis canaliculatis linearibus maculatis, spinis marginalibus minutis debilibus. Link et otto Abbild. auserl. Gewächse. fasc. 7. p. 87. t. 40.

A. microcantha; foliis lineari-loratis canaliculatis marginibus spinulosis, racemo umbellato laxo, pedunculis corolla longioribus. Sims. Bot. Mag. t. $22 z 2$.

A. microcantha; foliis anguste ensiformibus inferne albo maculatis, maculis saepe tulerculaeformibus oblongis sparsis numerosis, spinis marginalibus rectis albis minutissimis, Haw. Suppl. p. 105. - Schult. Syst. \%. p. 697.

RADIX cylindracea, carnosa, fibrosa.

CAULIS aetate brevis, crassitie digiti majoris, cicatrisatus.

FOLIA juncea, collecta, basi valde vaginantia, vaginis membranaceis allis fusco striatis, juniora erecta, seniora flaccido-recurvata, sesquipedem et ullra longa, basi ad vaginas lin. 8-9 lata, sensim attenuata, acuta, supra marginibus inflexis canaliculatim concava, subtus convexa, laete viridia albo-maculata, maculis oblongis in pagina infera praecipue promimulis subspinulescentibus, ad margines tenuissime cartilaginea, aculeis remotiusculis minutis, rectis, subinermibus instructa.

PEDUNCULUS floralis seu scapus simplex, pedulis, teres, viridis, basi nudus, superne bracteis quibusdam sterilibus instructus. Bracteae latae, semiamplexicuules, acuminatae, roseo-albidae, fusco-striatulae.

FLORES in racemum densum subumbellatim dispositi, longe pedicellati; pedicellis miniatis bracteis fere duplo longioribus.

PERIANTHIUM latum, cylindricum, fere sesquipollicem longum, luevissime trigonum, subventricosum, profunde sexfudum, laciniis subaequalibus, latiusculis, miniulis, apice acutis, patulis . virescentibus lineisque 3-1 suturatioribus notatis.

STAMINA longitudine perianthï tubo, alternatim inaequalia. Filamenta subulata, crassa, alba. Antherae laterales, miniatae. 
PISTILLUM. Ovarium obclavato-trigonum. Stylus longitudine filamentorum, pallide carneus. Stigma obtusum.

CAPSULAM maturam non vidi.

Habitat in Prom. bon. Spei. Floret mensibus Augusto et Septembri.

Observ. Jam ante annum 1819 vigebat in Horto Kewensi haec species anomala in hortis adhuc valde infrequens, quia nec soboles, nec semina profert matura. Aloes habitum nullo modo refert, et foliis angustissimis canaliculatis junceis flaccido-recurvatis a caeteris speciebus tantum recedit, ut absque flore pro Aloë vix agnoscenda sit. 



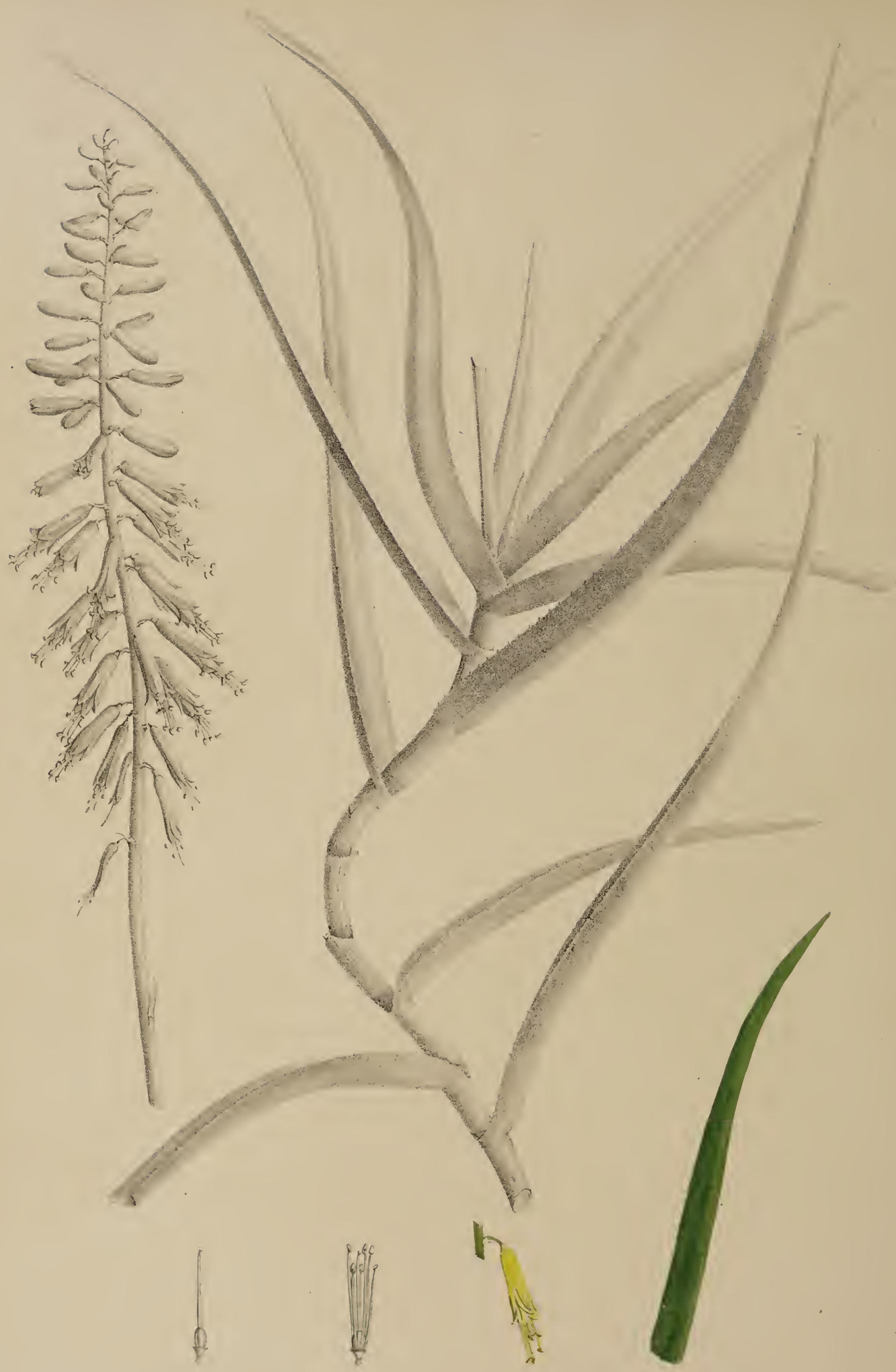

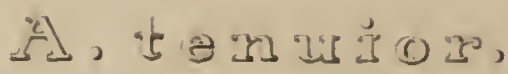

$(\$ 2.5-F i j)$ 
(\$. 25. Fig. 3.)

\section{A L O E T E N U I O R Haw.}

ALOE tenuior; caule gracillimo erecto-decumbente, foliis lineari-lanceolatis carnosis supra planis subtus convexis valde vaginantibus, ad margines tenuissime dentatis, pedunculo florali terminali.

A. tenuior; foliis lorato-acuminatis, vaginis viridibus; spinulis marginalibus minutissimis numerosissimis unifornibus; caudice gracillimo. Haw. in. Phil. Mag. et Journ. 1825. p. 281. - Schult. Syst. \%. p. 704 .

RADIX tuberosa, carnosa, fibrillis instructa.

CAULIS 6-8 pedalis, vix crassitie digiti minoris, teres, debilis, decumbens nisi suffultus, saepe ramosus, nodosus, internodiis lin. 6-9 longis.

FOLIA sparsa, subremota, erecto-patentia, poll. 6-7 longa, et lin. 3-4 ad vaginas lata, carnosula, laevia, laete viridia, nitida, basi amplexicaulia et in vaginam decurrentia, supra planiuscula apicem versus involuto-concava, subtus convexa, ad margines dentibus seu aculeis minutissimis ac mumerosissimis instructa; vaginate laevissimae, foliis concolores, internodiis vix breviores.

PEDUNCULUS foralis terminalis, poll.9-10 lıngus, gracilis, basi nudus, superne bracteis quibusdam sterilibus instructus, simplex, teretiusculus, viridis.

FLORES in racemum densum disposili, numerosi, pedicellati; pedicellis viridibns longitudine bractearum; Bracteae ungustae, acutue, Ravidae.

PERIANTHIUM subcampanulato-cylindricum, lin. 7-8 longum, sub anthesi nutans, sexfidum; laciniis exterioribus coalitis, interioribus liberis paulum longioribus, onnibus apice patulis acutiusculis favescentibus, linea viridi notatis.

STAMINA perianthii tubo longiora, alternatim inaequalia. Filamenta filiformia, favida. Antherce laterales, croceae.

PISTILLUM. Ovarium cylindraceo-trigonum. Stylus filamenta adcequans, filiformis: Stigma obtusum.

CAPSULA matura olivaeformis, rugosa, stylo emarcido persistente instructa.

Habitat in Prom. bon. Spei. - Floret aestate.

Observ. Caule debiliore et radice tuberosa differt haec species a praecedentibus, sicut ac foliis angustioribus ad margines numerosissime et minutissime denticulatis. 





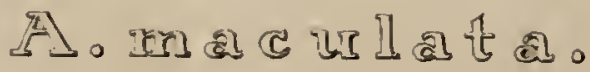

$(\$ \cdot 20 .-\mathrm{Fig} \cdot 1)$ 
(\$. 29. Fig. 1.)

ALOE MACULATA Thmb.

(G.ASTERIA Duval)

ALOE maculata; caulescens, foliis spiraliter distichis anguste linguaeformibns oblique flexis laevissimis nitidis uno latere crassiore, apice obtusis cum mucrone, utrinque convexiusculis maculisque albis confluentibus fasciatim pictis.

A. obliqua; caulescens, foliis subdistichis linearibus inaequilateri-trigonis integerrimis obtusis mucronatis maculatis, maculis confluentibus. spreng. syst. 2. p. zo.

Gasteria maculata; foliis anguste linguaeformibus oblique subundatis obtusis (cum mucrone) floribus grossis pedunculo longioribus. Haw. Phil. Mag. 1827. p. 348.

Alö obliqua; caulescens, foliis spiraliter distichis angustis oblique flexis, uno latere truncatis apice obtusis cum mucrone, glabris nitidis atroviridibus, maculis confluentibus albis fasciatis, margine integerrimis. Nob. obs. bot. 1821. p. 42. - Schutt. Syst. 7. 1.661.

A. maculata; canlescens, foliis subdistichis linearibus inaequilateri-trigonis, glabris, integerrimis, maculatis, maculis confluentibus, apice obtusis mucronatis. Willd. Mag. p. 2z9.

Gasteria obliqua; caule senecto sesquipedali subdichotomo; foliis spiraliter multifariis pictis anguste linguaeformibus obtusissimis cum mucrone. IIav, Synop. p. 85. - Nob. Cat. rais. p. 11.

Alö obliqua; foliis anguste linguaeformibus obtusissimis cum mucrone. Haw. Limn. Sac Truns. 7. p. 1.

A maculalu B. obliqua; foliis obusis cum acumine. Ait. Ker. ed. 1. Vot. 1 1. 469. ed. 2. Vol 2.p. 29\%. - Willd Spec. pl. 2. p. 18.

A. Lingua a. Bot. Mag. t. 979 .

A. maculata; foliis lingnaeformibus glabris pictis, floribus racemosis cermis curvatis Thunb. Diss. n. 10. Prodr. 61. Fl. Cap. ed Schuet. 311.

B. angustior; partibus omuibus minor, foliis albidioribus el angustioribus.

Gasteria maculata fallax; candidior, foliis quasi ad oculun unberculato-exasperatis, sed vere tactı laevissimis. Haw. Plit. Mag. p. $\mathbf{3 1 8}$.

RADIX cylindracea, carnosa, filrosa.

CAULIS pedalis et ultra, foliis seu foliorum reliquiis ıectus, busi prolifer.

FOLIA spiruliter disticha, erecto-palula, poll. 5-7 longa, et pollicem lala, (in varietate lin. 7-8 lala,) post medium oblique Rexu, linguueformin, supra pluno-convexa, uno latere truncula, sublus oblique convexiuscula, apice cultruta obtusissina cum mucromulo, glaberrima, nilida, perviridlu, utrinque maculis albis elongatis confluenlibus, in magina infera numerosioribus, fasciatim picta, ad margines carlilaginea inlegerrima, "picem versus quandoque tachu scubra.

PEDUNCULUS foralis tripedalis, simplex, raro ramosus, basi anceps, superne teres, lividus, nudus. 
FLORES dense rucemosi, longe pedicellati; pedicellis braclea acuta albida duplo longioribus.

PERIANTHIUM lin 9 longum, obclavatum, recurvatum, parte ventricosa valde inflatum, roseum, parte tubulosa sexfidum; laciniis latis apice obtusis, patulis, ad margines pallide roseis lineisque viridibus tribus comfluentibus notatis.

STAMINA longitudine perianthii tubo, subaequalia. Filamenta subulala albida. Antherae laterales, luteat.

PISTILLUM. Ovarium cylindraceo-trigonum. Stylus filamentis paulo brevior, albidus. Stigma obtusum.

\section{CAPSULAM maturam non vidi.}

Habitat in Prom. bou. Spei. Floret a mense Martio ad Majum.

Observ. Haec species jan tempore Milleri cum sequente cognita, melius fortè nomen $\boldsymbol{A}$. obliquae servavisset; attamen Cl. Willdenowii et Haworthii quoque exemplum hic secutus sum. Quamvis Thumbergius speciem suam acaulem foliisque radicalibus dixerit, dubium non est quin sit eadem ac ıostra, quae in hortis culta semper caulescens provenit. Varietas huic speciei adscripta partibus omnibus gracilior est, et constans se praebet. 



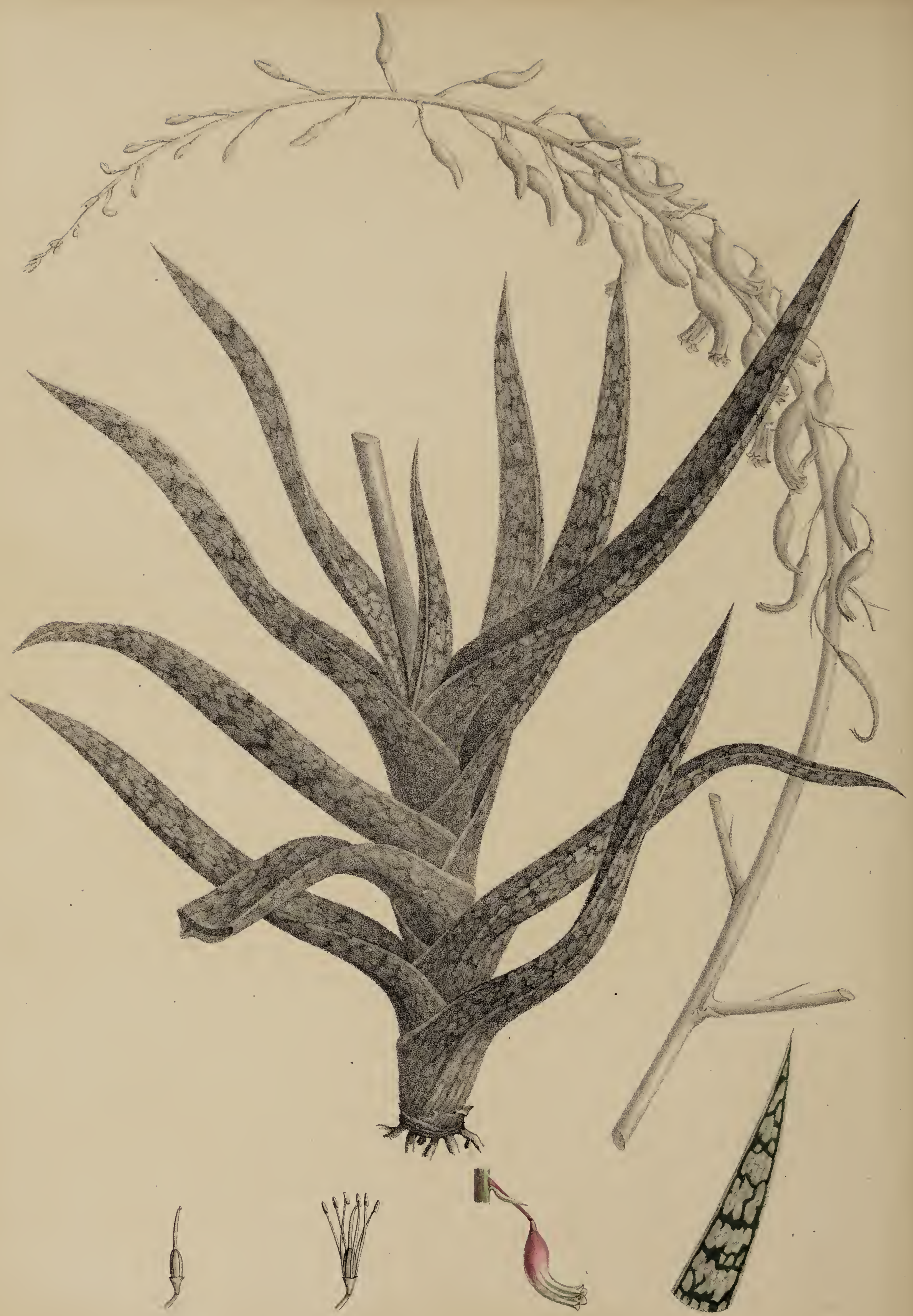

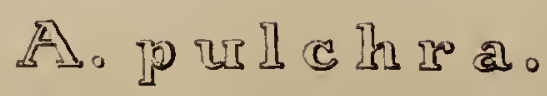


(\$. 29. Fig. 2.)

I L O E P U L C H R A Jacq.

(GASTERIA Duval.)

ALOE pulchra; caulescens, foliis spiraliter distichis anguste ensiformibus attennatis acutis laevissimis nitidis uno latere truncatis, supra concavis subtus inaequilateri-carinatis, utrinque maculis confluentibus albis fasciatim pictis.

A. pulchra; caule subdichotomo, foliis subdistichis linearibns inaequilateri - trigonis glabris integerrimis acuminatis cuspidatis distincte maculatis. syreny. syst. 2. p. zo.

Gasteria pulchra; foliis acute ensiformibus; pedunculo floribus subangustis sublongiore. Haw. Phil. Mag. 1827. p. 318.

Gasteria pulchra; caule senecto sesquipedali subdichotomo; foliis spiraliter multifariis pictis ensiformibus acutis. Haw. Synop. p. 86. - Nob. Cat. rais. p. 12.

Aloё pulchra; canlescens, foliis spiraliter distichis angustis, subcanaliculatis, uno latere truncatis, apice attenuatis acutis glabris nilidis atroviridibus, maculis confluentibus albis subfasciatis, margine integerrimis. Nob. Observ. bot. anno 1821. p. 43. - Schult. Syst. 7. p.660,

A. pulchra; subcaulescens, foliis subdistichis, linearibus inaequilateri-trigonis, glabris, integerrimis, maculatis, maculis distinctis, apice attenuatis acutis mucronatis. Willd. Mag. p. 279.

A. pulchra; subacaulis foliis acinaciformibus glabris maculatis, floribus racemosis cernuis, curvatis. Jacq. Hort. Schönbr. 4. p. 10. $t a b .419$.

A. obliqua; foliis junioribus distichis, tandem sparsis, inaequaliter trigonis, acutis, patentilus pictis; corollis ventricosis, cernuis. DC. Pt. grass. 1. 91.

A. pulchra; foliis ensiformibus aculis. Haw. Lin. Soc. Trans. 7. p. 14.

A. maculala a. pulchra; foliis aculis. Ait. Hort. Kewew. ed. 1. rol. 1. p. 469. ed. 2. col. 2. p. 297. Willd. Spec. Pl. eol. 2. p. 189.

A. Muculata; Bot. Mag. t. 765 .

Alö foliis linguiformibus variegatis, floribus pedunculatis cermuis, ore imaequali. Mill. Icon. 195. t. 292.

RADIX cylindracea, carnosa, fibrosa.

CAULIS pendalis et ultra, foliis seu foliorum religuiis tectus, basi prolifer.

FOLIA spiraliter disticha, patentia, pedem ad sesquipedem longa, el pollicem basi lata, sensim attenuata, acuminata, ensiformia, supra canaliculatim concava, uno latere valde Inuncala, sublus basi inaequilateri-trigona, medio oblique convexa, imo apice cullrulu, glaberrima, nitida, perviridia, utrinque maculis albis elongatis confluentibus, in pagina infera numerosioribus, fasciatim picta, ad margines cartilaginea, integerrima ant laevissime tuberculata.

PEDUNCULUS foralis tripedalis, ramosus, basi anceps, superne teres, mudus, lividus. 
FLORES dense racemosi, longe pedicellati, pedicellis miniatis, bractea acuta viridi-albida longioribus.

PERIANTIIIUM lin. 9 longum, obclavatum recurvatum, purte ventricosa parum inflatum, miniatum, parte tubulosa sexfudum; laciniis latis apice obtusis patulis, ad margines pallide miniatis lineaque viridi lata medio notatis.

STAMIN.A longitudine periunthii tubo, subaequalia. Filamenta subuluta, albu. Antherae laterales lutene.

PISTILLUM. Ovarium cylindraceo-trigonum. Slylus filamentis paulum brevior, albidus. Stigma obtusum.

CAPSULAM maturam non vidi.

Habitat in Prom. bon Spei. Floret a mense Martio ad Majum.

Observ. A praecedente differt haec species foliis duplo Iongioribus attenuatis àcuminatis, supra concavis et uno latere magis truncatis. Flores quoque diversi sunt, et pedunculus floralis semper ramosus. Cl. Jaquinius recte igitur judicavit hanc plantam esse pro specie propria habendan. Propaginibus radicalibus, sicut et praecedens, facile propagatur. 



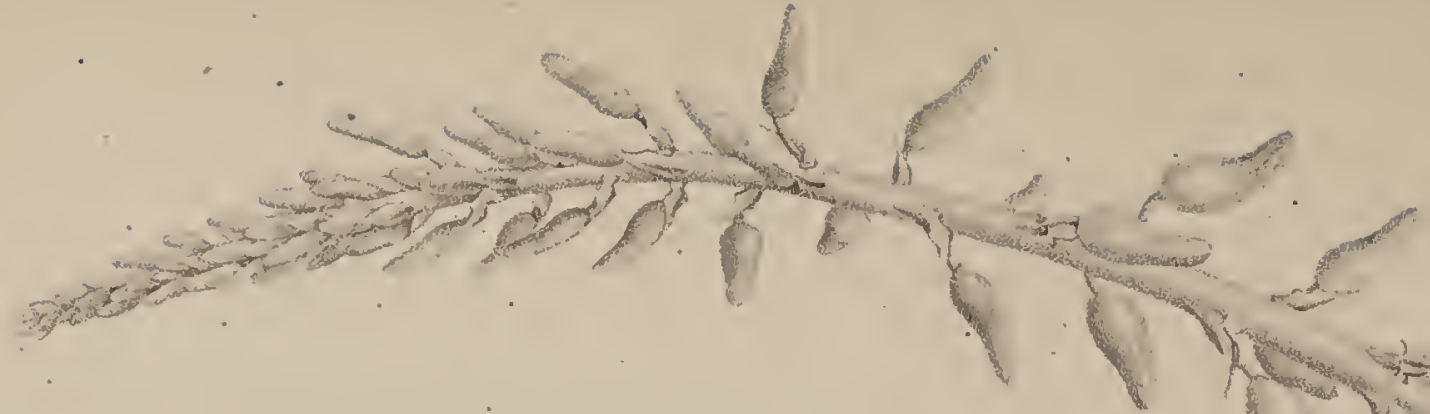

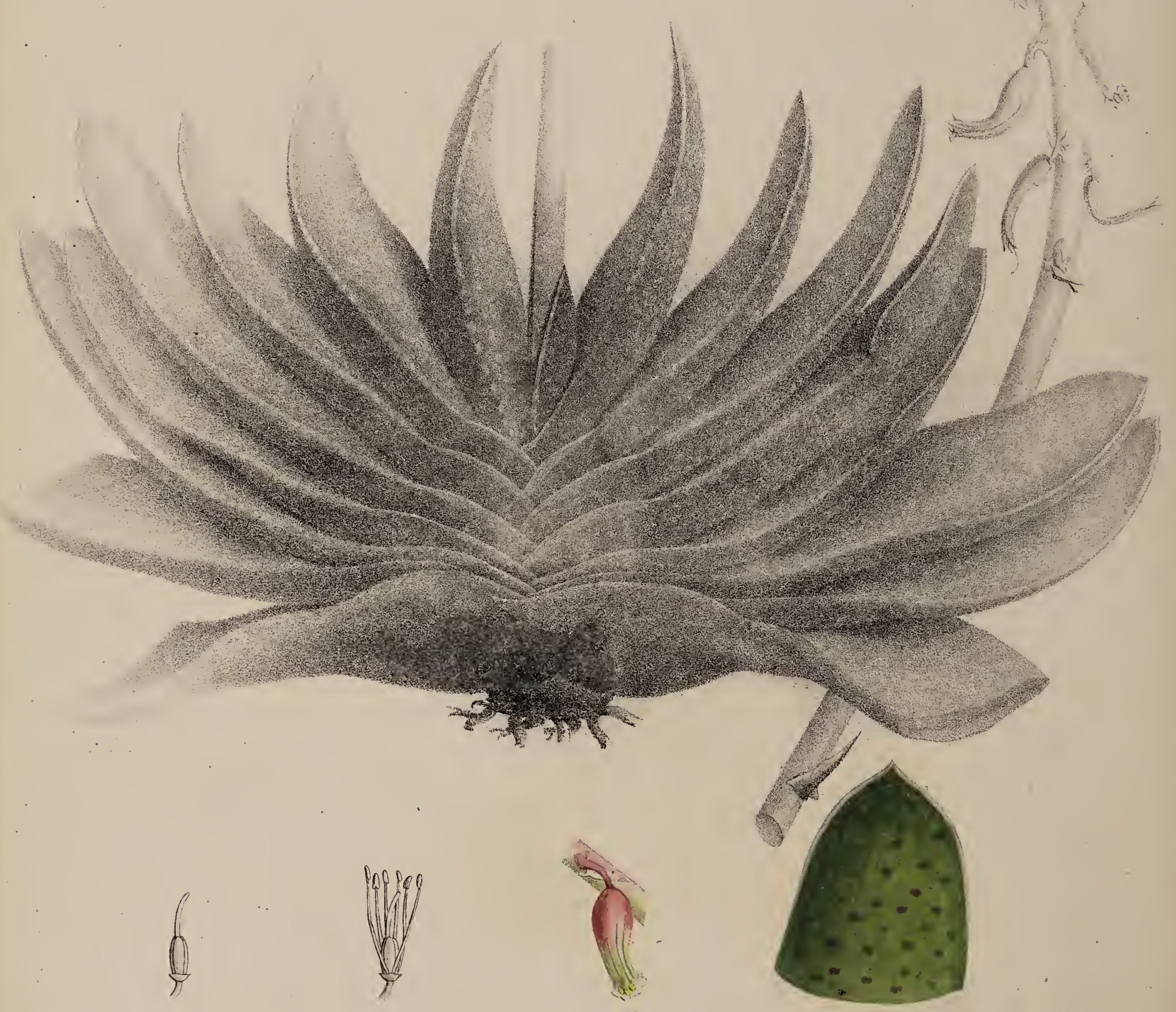

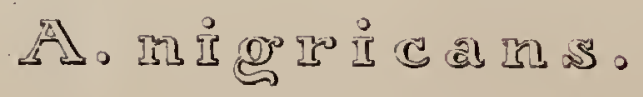

(\$.29. - Fig. 7.) 
(\$. 29. Fig. 7.)

\title{
A L O
}

\author{
(GASTERIA Duval.)
}

ALOE nigricans; subacaulis, foliis distichis erectis late linguacformibus crassissimis utrinque convexis apice obtusiusculis cum mucrone, atro-viridibus albido-subserialiter maculatis glaberrimis nitidis, ad nargines basi obtusis apice cultratris cartilagineis integerrimis. Nob. Observ. bot. anno 1821. p. 63. - Schutt. Syst. 7. p. 663.

a. latifolia. Foliis latioribus, longioribus, apice obtusis, margine integerrimis. Nob. observ. l. $c$.

A. nigricans; caule simplicissimo, foliis exacte distichis linguaeformibus abbreviatis margine cartilagineis integerrimis obsolete maculatis. spreng. syst. 3. p. $z$.

Gasteria nigricans; foliis linguiformibus brevibus obtusis nigro-viridibus, obsolete maculato-punctatis; marginibus cartilagineis integris. IIau. Phil. May. 1827. p. 349.

A. nigric ans; acanlis, foliis distichis patentibus linguiformibus atroviridibus albo-maculatis glabris, apice obtusissimis mucronatis, margine acutis cartilagineis integerrimis, scapo ramoso. Willd. Mag. p. 287.

A. obliqua; subacaulis, foliis linguaeformibus, obtusis cum mucrone, integerrimis, floribus racenosis curvatis cermuis. Jacy. IIort. Schönb. Vol, 4. t. 9. p. 418. (excl. Symon.)

Gusteria nigricans; caule senecto subpedali simplicissimo tecto, foliis exacte distichis imbricatis late linguaeformibus brevibus obtusis obsolete maculatis, marginibus cartilagineis integris. Haw. Synop. p. 86. - Nob. Cat. rais. p. 16.

A. nigricans; foliis imbricatis hifariis late linguaeformibus obtusissimis nigricantibus laevigatis obsolete maculatis, marginibus integerrimis. IIaw. Lin. Soc. Trans. 7. 1. 13.

A. Lingua ß. crassifolia; foliis latioribus brevioribus. Ait. It. Kew. ed. 1. Vol. 1. 1 . 169. Willd. Spec. Pt. 2. p. 190. - Ait. Kew. ed. 2. Vol. 2. p. 297. - Dot. Mag. t. 838.

B. crassifolia; foliis angustioribus, crassioribus, usque ad medium fere cylindraceis, apice minus obtusis, et margine laevissime crenulatis. Nob. t. c.p. 64. Cat. rais. p. 17.

Gasteria crassifolia; foliis anguste linguiformibus brevissimis, deorsum subcylindraceis, obsoletissime marmorato-punctatis. IIav. Phil. Mag. 1827. p. 350. - Schult. Syst. 7. 1. 661.

$\gamma$. marmorata; foliis angustioribus brevioribus, naculis obsoletis albidis et roseis marmoratim confluentibus, apice obtusinsculis vel oblique acntis. Nob. t. c. m. 64 .

RADIX cylindracea, camosa, fibrosa.

CAULIS aelate e superposilione foliorum subpedalis, foliis tectus quandoque in linea subspirali disposilis.

FOLIA bifarie per paria $8-10$ disposila, jumiora erecto-imcurvula, senecla patentia, in var. a. poll. G-8 longa, el poll. 2 lala, (in var. B. et r. semper Ireviora 
et (ungustiora) linguaeformia, crassa, utrinque convexa, apice obtusa cum mucrone, glaberrima, nitida, nigricantia, in var. $\alpha_{\text {. et }} \beta$. obscure albido serialiter picta (in var. $\gamma$. ex albido et roseo omnino marmorata) ad latera ima basi valde membranaceo-dilatata rosea, medio obtusissima rotundata, superne cultrata margine cartilagineo laevissime crenulato et apicem versus integerrimo cincta.

PEDUNCULUS floralis tripedalis, simplex vel quandoque ramosus, basi mullus, superne bracteis sterilibus quibusdam latis, acutis, linea media nigricante notatis instructus, teres, lividus.

FLORES dense racemosi, breve pedicellati; pedicellis miniatis bractearum longitudinem adaequantibus.

PERIANTHIUM lin. 10-11 longum, obclavatum, recurvatum, parte ventricosa inflatum, roseo-miniatum, parte tubulosa sexfidum, laciniis latis apice obtusis patulis, ad margines albis lineaque media viridi lata notatis.

STAMINA longitudine perianthii tubo, subaequalia. Filamenta subulata, albida. Antherae laterales, luteae.

PISTILLUM. Ovarium cylindraceo-trigonum. Stylus filamentis paulum brevior, albidus. Stigma inconspicuum.

CAPSULA matura mugna, trigona, obtusa, basi attenuata.

Habitat in Prom. bon. Spei. - Floret aestate.

Observ. Aloë nigricans jam tempore Milleri (anno 1731) cognita et, ut videtur, cum $\mathbf{A}$. linguaeformi Willd., (sed secundum Cl. Aiton cum $\boldsymbol{A}$. intermedia) confusa, bona est et distinctissima species. Var. $\beta$. foliis solum paulum angustioribus et crassioribus differt, quae ad formam normalem saepe redeunt, et vix ergo notatu digna est. Var. $\gamma$. constans se praebet, sed semper aegrota remanet, et pro varietate peculiari modo picta haberi potest. Propagines rarissime profert haec species. 



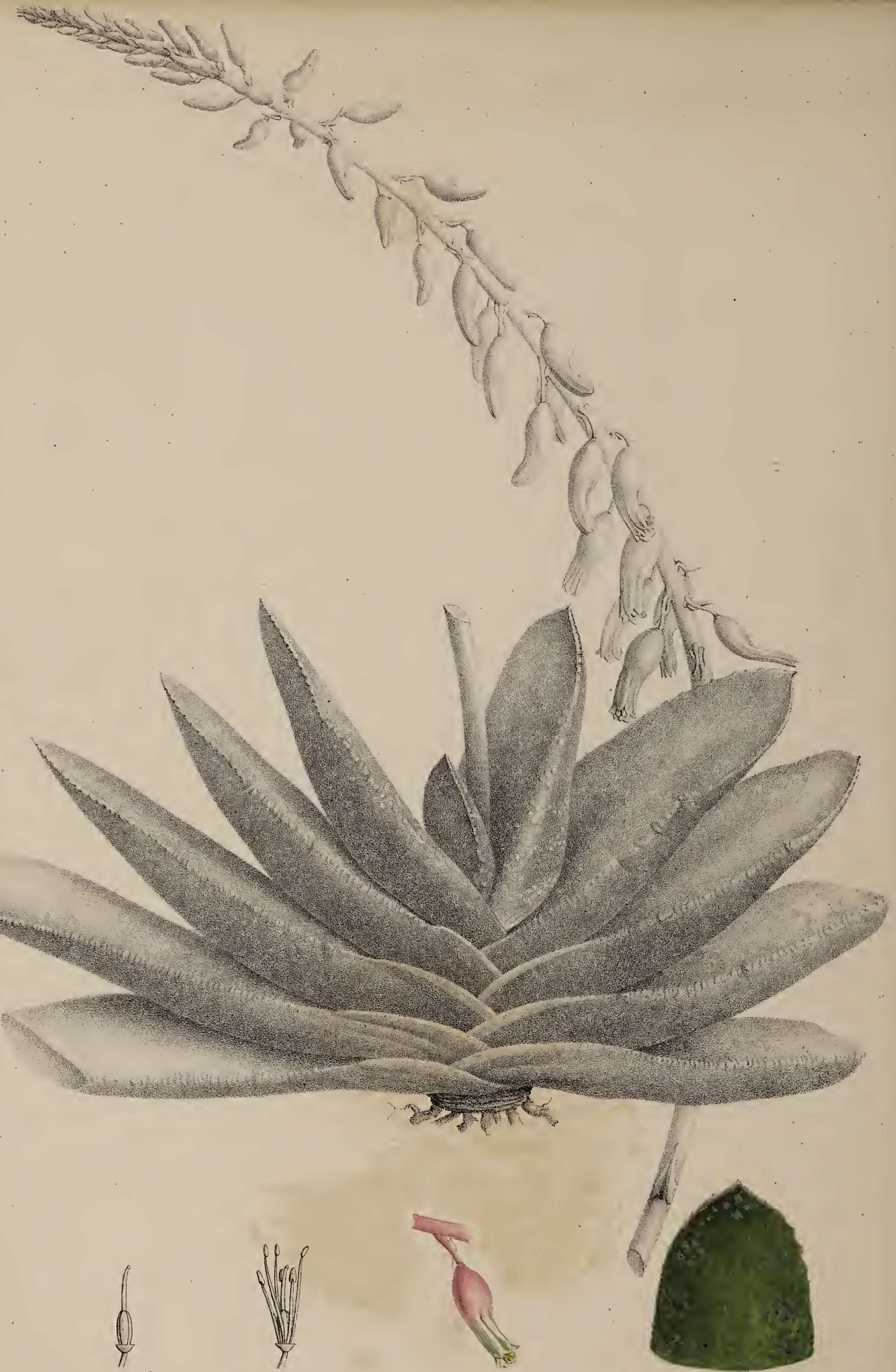

A

$(\$ .29 .-F i g .8)$ 
(\$. 29. Fig. 8.)

ALOE BRACHYPHYLLA Nob.

\section{(GASTERIA Ihwal.)}

ALOE brachyphylla; acaulis, foliis distichis erecto-patentibus late linguaeformibus crassis uitidis supra plano-concaviusculis subtus convexis, apice obtusis cum mncrone albo, serialiter maculatis maculis subprominulis, ad margines basi obtusis superne cultratis cartilagineo-tuberculatis ino apice integerrimis.

Gasteria brevifolia; foliis parabolico-linguiformibus brevissimis, punctis pallidis, floribus partul abbreviatis. Haw. Phil. Mag. 182\%. p. 350. - Schult. Syst. 7. p. 664.

Gasteria brevifolia; foliis exacte distichis paraholico-linguaeformilbus brevibus obtusis, marginibus superne laevibus. Haw. synop. p. 89.

Aloë nigricans $\gamma$. denticulata; marginibus tuberculatis. Nob. Cat. rais. p. 1\%.

RADIX cylindracea, carnosa, fibrosa.

CAULIS unllus ant superpositione foliorum aelate brevissimms.

FOLIA bifarie per paria $6-7$ disposita, juniora erecta, seniora patentissima, poll. 5-6 longa el poll. 2 cum dimidio lata, linguaeformia, crassa, superne plano-concava, sublus comvexa, apice obhusa cum mucrone, nitida, viridia, maculis subpromimalis albis distinctis seu confucntibus scrialiter picla, ad latera ima basi roseo-membranacea, medio obusa, superne cultrata, huberculisque instructa primo distinctis el sensim in marginem carlilagineum ino "pice integervimum, comfuentibus.

PEDUNCULUS foralis sulpedalis, simplex, basi mulus, superne bructeis sterilibus quilmsalum latis acutis, linea media fusca notatis instruchus, teres, lividus.

HLORES dense racemosi, breve pedicellali; pedicellis miniatis, bractearum longitudinem adaerpumtibus.

PERIANTHIUN lin. 10 -11 longum, obclavalum, recurvatum, parle ventricosa inflatum, rosen-miniahum, parte tubulosa sexfulum; laciniis latis rupice obtusis patulis, ad margines albis lineaque media viridi lala nolatis.

STAMINA Inngihudine periunthii tubo, alternatim inuequeliu. Filımenta subuluta alba. Anthercue laterales, huteae.

PISTILLUM. Ovarium cylindraceo-trigonum. Styhus longitudine filamentorum breviorum, albirlus. Stigma inconspicunem. 
CAPSULAM maturam non vidi.

Habitat in Pront. bon. Spei. Floret aestate.

Olsere. Haec species in Anglia apud Dom. Hill jam anno 1809 culta erat. Proxime accedit ad $\boldsymbol{A}$. nigricantem, sed foliis planioribus plus minusve laeteviridibus et subtuberculato-punctatis satis differt. Parum variat colore intensiore aut pallidiore, et propagines profert infrequentes. 


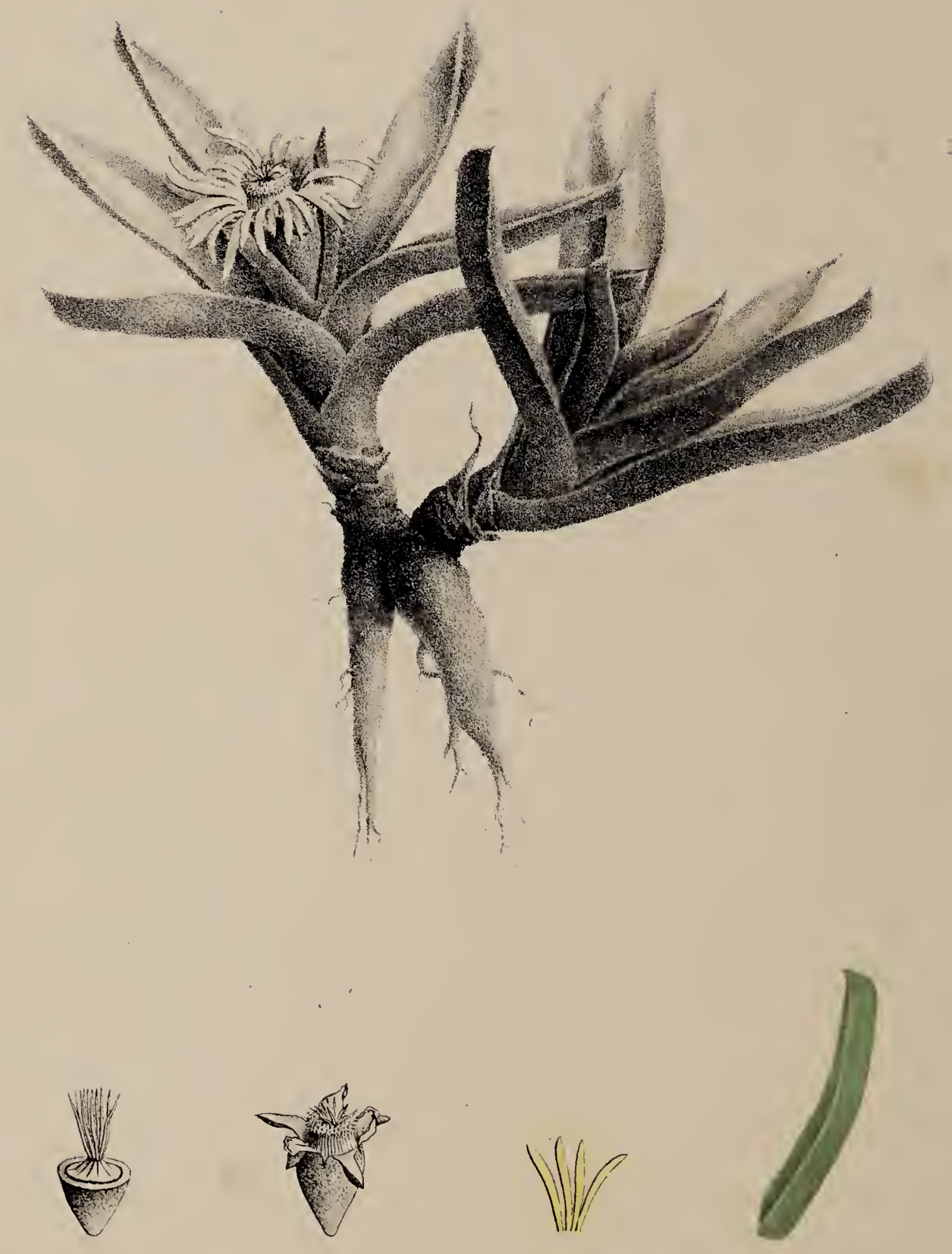

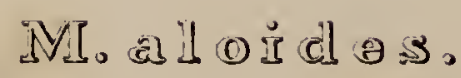

$$
(\$ .4 .-F i g . j)
$$


(s. 4. Fig. 3.)

\section{MESEMBRYANTHEMUM ALOIDES Haw.}

MESEMBRY ANTHEMUM aloides; acaule vel subacaule, foliis erecto-patulis elongatis anguste subrhombeis integerrimis, albo-punctatis, supra plano-concaviusculis, subtus convexis, apice carinato-triquetris mucronatis.

M. aloides; acaule, foliis integris semiteretibus virescentibus albo-marmorato-punctatis, sursum acutis supra concavis, apice carinato-triquetris. Haw. Revis.p. 87.-DC.Prodr. 3.p. 419.

M. aloides; foliis patentissimis rigidis semiteretibus acutis apice triquetris calloso-punctatis. Spreng. Syst. 2. p. 515.

M. al oides; acaule, foliis integris semicylindricis submargaritaceo-punctatis; superne concavis sensimque auctis apice triquetris, radice fusiformi. Haw. Suppt. p. 88 .

RADIX carnosa, fusiformis, fibrillis instructa.

CAULIS nullus, aut aetate brevis, ramosus.

FOLIA 6-8 basi connuta, rigidiuscula, integerrima, nitidula; juniora erecta, seniora patentia, perviridia crebre albo-punctatu, punctis vix prominulis, pollices 2 longa, et basi lineas 4 lata, paulum ultra medium rhombeo-dilatata, supra pluna superne concaviuscula, subtus basi convexa sensim carinulata, et apice incurvulo triquetro-compressa, obtusiuscula cum mucrone.

FLORES diametro pollicari, solitarii, ante meridiem expansi, sessiles.

CALYX turbinatus, quinquefidus, albo-punctatus, laciniis longitudine aequalibus, duabus triquetro-acutis, tribus maryine membranaceis, sub apice carinato-mucronatis.

PETALA uniserialia, divaricato-expansa, lineari-lanceolata, lutea.

STAMINA numerosa, collecta, erectu. Filamenta ulba. Antherae flavidae.

PISTILLUM. Ovarium turbinatum. Styli 10, erecti, subulati, staminibus longiores, flavidi.

CAPSULA decemloculuris; maturam non vidi.

Habitat in Prom. bon. spei. Floret mense Majo.

Observ. Hanc speciem Dom. Burchell in Africa australi legit, et anno circiter 1819 in Angliam advexit. A praecedentibus hujusce sectionis foliis albo-marmoratis, et a sequentibus foliis rhombeo-dilatatis differt. 



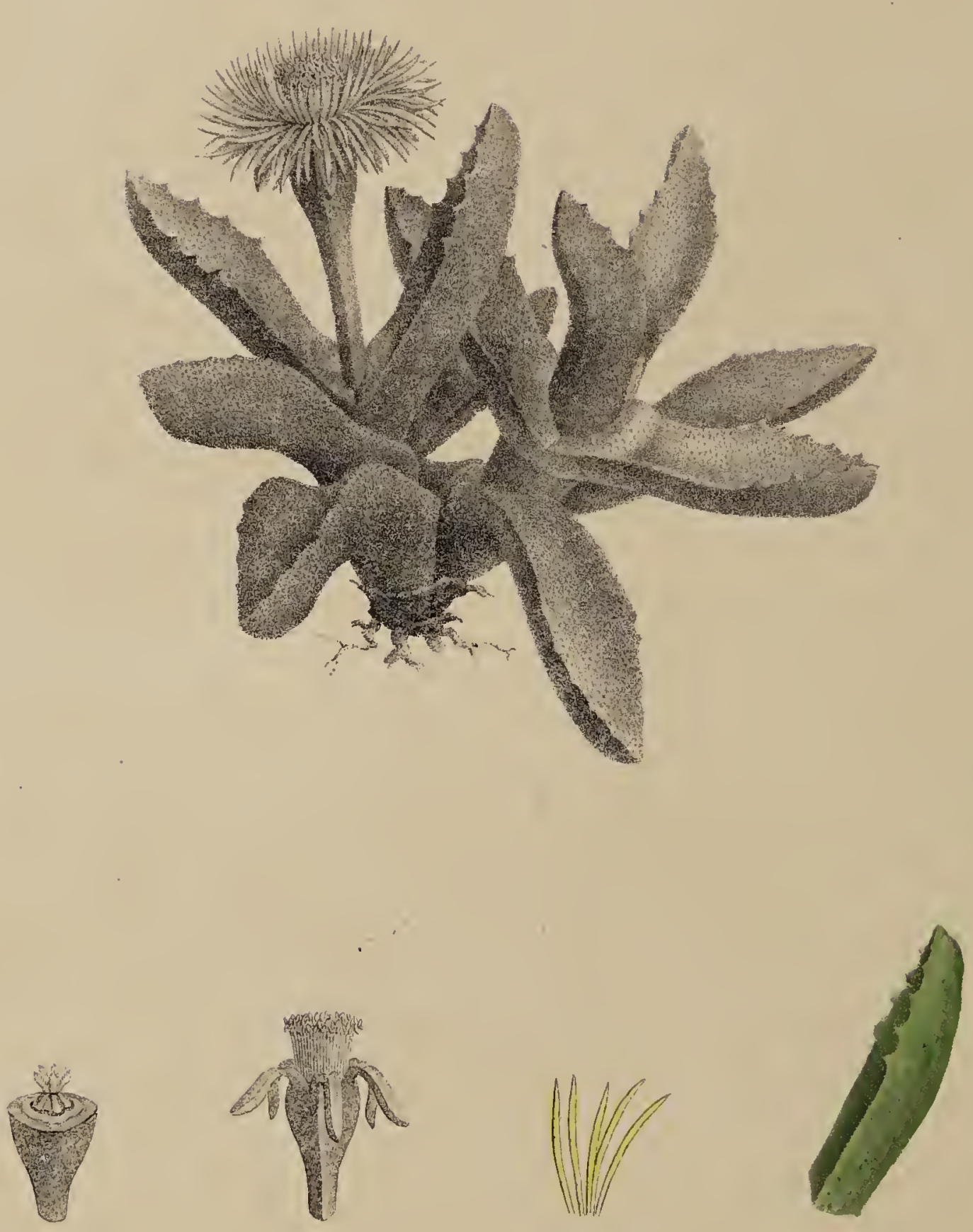

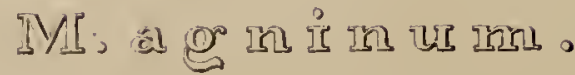

$$
\text { (\$.5. Fig.8.) }
$$




\section{(\$. 5. Fig. 8.)}

\section{MESEMBRYANTHEMUM AGNINUM Haw.}

MESEMBRY ANTHEMUM agninum; subcaulescens ranulosum, foliis oblongis canescenti-laeteviridibus creberrime papuloso- punctatis, supra planis basi interme pustulatis, subtus carinato-convexis, ingulis lateralibus apicem versus parum dentatis vel integris, flore pedunculato.

a. denticulatum; foliis apice grosse dentatis.

B. integrifolium; foliis paulo minoribus apice integerrimis.

M. agninum; subacaule, canescens, punctato-rugulosum: foliis semiteretibus puncto-serrulatis, subinde dentatis; basi intus pustulatis. Haw. Phil. Mag. et Journ. Auyust 1826. p. 128.

$\boldsymbol{R A D I X}$ sublignosa, ramosa, fibrosa.

CAULIS brevis, ramosus, ramulis adscendentibus, folionum rudimentis exsiccatis onustus.

FOLIA decussata, erecto-patentiu, vulde connata, carnosa, subrigida, sesquipollicem ad polices 2 longa, a basi ad medium lineas 5-6 lata, superne sensim attenuata, oblusiuscula, canescentia, laete seu lutescenti-viridia, munctis permultis prominulis ad lucem suldpellucidis rugosa; supra planiuscula, ima basi pustula grandi instructa, subtus convexo-triquetra angulo carinali inlegerrimo, vix apice producto; angulis lateralibus in var: a. superne denticulatis, dentibus in singulo latere 3-5 grossis, muticis; in var. B. omnino integerrimis.

FLORES solitarii, diametro 14 lineari, pedunculati, noctu expansi, suave fragrantes. Pedunculus pollicaris, compressus, apice incrassatus.

$\boldsymbol{C A L Y X}$ subcompressus, munctatus, sexfidus; lobis aequalibus, elongutis, triquetris, obtusiusculis, deflexis.

PETALA pluriserialia, numerosa, lineariu, lutea.

STAMINA mumerosa, erectu. Filamenta lutea. Antherae flavae.

PISTILLUM. Ovarium turbinatum, supra conicum. Styli sex, parvuli, erectopatuli, ramentacei, lutei.

CAPSULA sexlocularis; Maturam non vidi.

Habitat in Prom. bon. spei. Floret mense Junio.

Observ. Haec species, (sicut et duae praecedentes) a Dom: Bowie in Angliam advecta, anmo 1826 in horto Kewensi primo, sed imperfecte floruit. Locus huic speciei in sectione tribuendus non facile decernitur; foliis rugosis, basi intus pustulatis, valde accedit ad $\boldsymbol{M}$. muslellinum; sed propter florem pedunculatum rectius ante $\boldsymbol{M}$. caninum locandam esse videtur. 




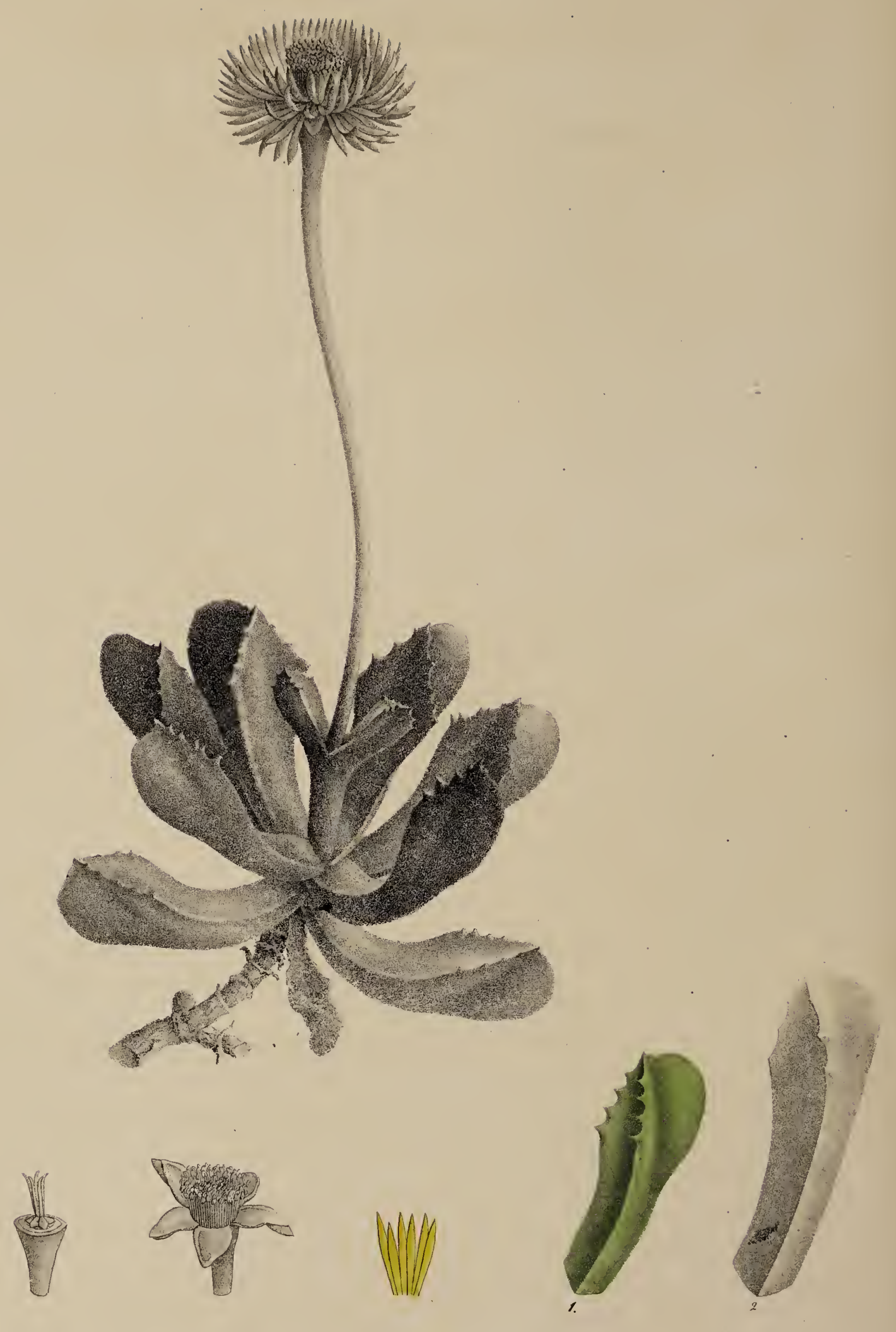

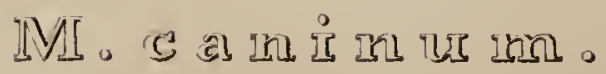

$$
\text { (s.5. - Fig. .) }
$$




\section{MESEMBRY A NTHEMUM CANINUM Haw.}

MESEMBRYANTHEMUM c aninum; subcaulescens ramulosum, foliis triquetris elongatis dilatato-subclavatis impunctatis glaucescentibus, angulo carinali producto illtegerrimo, lateralibus superne plus minusve dentatis; flore longe pedunculato.

a. pluridentatım; floribus minoribus erectioribus viridioribus, angulis lateralibus valde denticulatis.

M. caninum; subacaule, foliis glancis carinato-triquetris subclavatis apicem versus bracteisque dentatis subincurvis, pedunculis folio longioribus. DC. Prodr. 3. pag. 419. - Haw. neris. p. 87.

M. caninum; foliis oblongis apice dilatatis triquetris epunctatis, angulis binis obtuse dentatis, floribus longe pedunculatis. spreng. Syst. 2. p. 515.

M. caninum; subacaule, foliis impunctatis glaucis, apicein versus bracteisque denticulatis incurvantibus; pedunculis longitudine foliorum. Haw. Synop. p. 217.

M. caninum; subacaule, foliis impunctatis oblongis, apice triquetris; angulis duobus superis ohtuse dentatis; florum pedunculis folio duplo longioribus. DC. Pl. grass. t. 95.

M. caninum; subacaule, foliis impunctatis glaucis apicem versus grosse bifariam dentatis, pedunculis folio duplo longioribus. Haw. Miscel. nat. p. 81. - Ait. Kew. ed. 2. vol. 3. p. 218.

M. caninum; acaule, foliis impunctatis oblongis apice triquetris et dentatis, dentibus obtusis, floribus pedunculatis; pedunculis foliis multo longioribus. Will. spec. 2. p. $102 s$.

Ficoide gueule de chien. M. subcaulescens, foliis impunctatis apice triquetris et latioribus angulis internis subdentatis, floribus longe pedunculatis. Lam. Encycl. 3. p. 159.

M. ringens a. caninum Lin. Spec. pl. p. 298. - Ait. Kew. ed. 1. vol. 2. p. 194.

M. s ub a ca ule foliis ciliato-dentatis. Lin. Hort. Clif. p. 218. .- Roy. Lugd. bat. 283. - Mill. Dict. No. 39 . Icon. t. 7\%. Fig. 2.

M. rictum caninum referens. Dill. Euth. 241. t. 188. Fiy. 231.

Ficoides capensis lumilis, folio triangulo prope summitatem dentato, flore luteo. Bradl. Succ. 2. t. 8. p. 17.

ß. paucidentatum; foliis majoribus magis expansis, albidioribus; angulis lateralibus obsolete dentatis.

M. vulpinum; subacaule, foliis 'glancis carinato-triquetris subclavatis apicem versus grandidentatis integrisve, senectis horizontalibus, bracteis integris, pedunculis folio longioribus. DC. Prodr. 3. p. 420. - Haw. Revis. p. s8.

M. vиlpinum; subcaulescens, foliis elongatis glaucescentibus triquetris, angulis obsolete denticulatis, floribus longe pedunculatis. syreng. Syst. 2. p. 515.

M. vulpinum; subacaule, foliis impunctatis glaucis apicem versus grandidentatis integrisve, senectis horizontalibus, bracteis integris, pedunculis folio longioribus. Haw. synop. p. 217.

M. caninum B. vulpinum Haw. Miscel. nat. p. 32. 
RADIX sublignosa, ramosa, fibrosa.

CAULIS lignosus, brevis, aetate ramosus; ramulis prostralis vel suberectis, foliorm rudimentis desiccatis omustus.

FOLIA in apice ramorum collecta, decussata, connata, incurvato-erecta, seniora (in var. B. patenlia,) crassa, rigidla, impunctata, laevia, nilidula, glaucescentia (in var. $\beta$. allicantia), poll. 2 longa (in var. B. poll. 3,) basi lin. 4-5, et superne parte rhombeodilatata lin. 7-8 latu, apice acutu, supra plana, basi interne pustulata, subtus triquetroconvexa; angulo carinali integerrimo apicem versus valde compresso gibboso-dilatato, margineque rubro suepissime cincto, angulis lateralibus a basi ad $\% \frac{3}{3}$ integerrimis, superne denticulatis, denticulis cartilagineis incurvulis, confertis, parvulis saepe mbicundis, (in var. B. remotis grossis.)

FLORES plerumque solitarii, qucudoque bini, rarissime terni, mediocres, post meridlien expansi, longe pedlunculati. Pedunculus poll. 4. longus, teres, apice incrissutus, cauliculo subcompresso suffultus. Cauliculus hic e foliis duobus summis mimutis ac valde connatis oriens, et apice al insertionem pedunculi bracteis duabus triquetro-acutis integerrimis instructus, primo brevissimus et inter folia inclausus, post anthesin vero quandoque sesquipollicaris evadit.

CALYX in pedunculum attenuatus, laevis, quinquefidus, lobis subaequalibus latiusculis obtusis, tribus sub apice corinatis.

PETALA phariserialia, lanceolato-acuta, incurvato-expansa, inhus lutea, extus aurcantiaca.

STAMINA mumerosa erecta. Filamenta lutea. Anthercue flavae.

PISTILLUM. Ovarium obconicum, supra conicum. Styli 5 subulati, erecti, apice recurvuli, staminibus paulo breviores.

CAPSULA quinquelocularis; maturam non vidi.

Halbitat in Prom. bon. spei. Floret mensibus Junio et Julio.

Observ. Haec species Dillenii tempore jam culta a $\boldsymbol{M}$. felino omnino recedit. E commixtione pollinis cum $\boldsymbol{M}$. albido duae varietates ortae sunt, una magis ad $\boldsymbol{M}$. caninum, altera ad $\boldsymbol{M}$. albidhom spectans. Cl. Haworth primam sub nomine $\boldsymbol{M}$. vulpini, et secundam sub nomine $\boldsymbol{M}$. hybridi descripsit; sed duae hae species certissime delendae sunt. M. vulpinum Haw: a $\boldsymbol{M}$. canino statura solum paulo majore et foliis albidioribus apice minus denticulatis differt. Flores saepissime aboriuntur. Tabula sistit plantam florentem $\boldsymbol{M}$. canini Haw, et in explicatione partium addidi cauliculum bracteatum post anthesin enatum. Folium No. 1. ad M. canimum $\alpha_{0}$ pluridentatum, et No. 2 . ad Var. B. paucidentatum pertinet. 



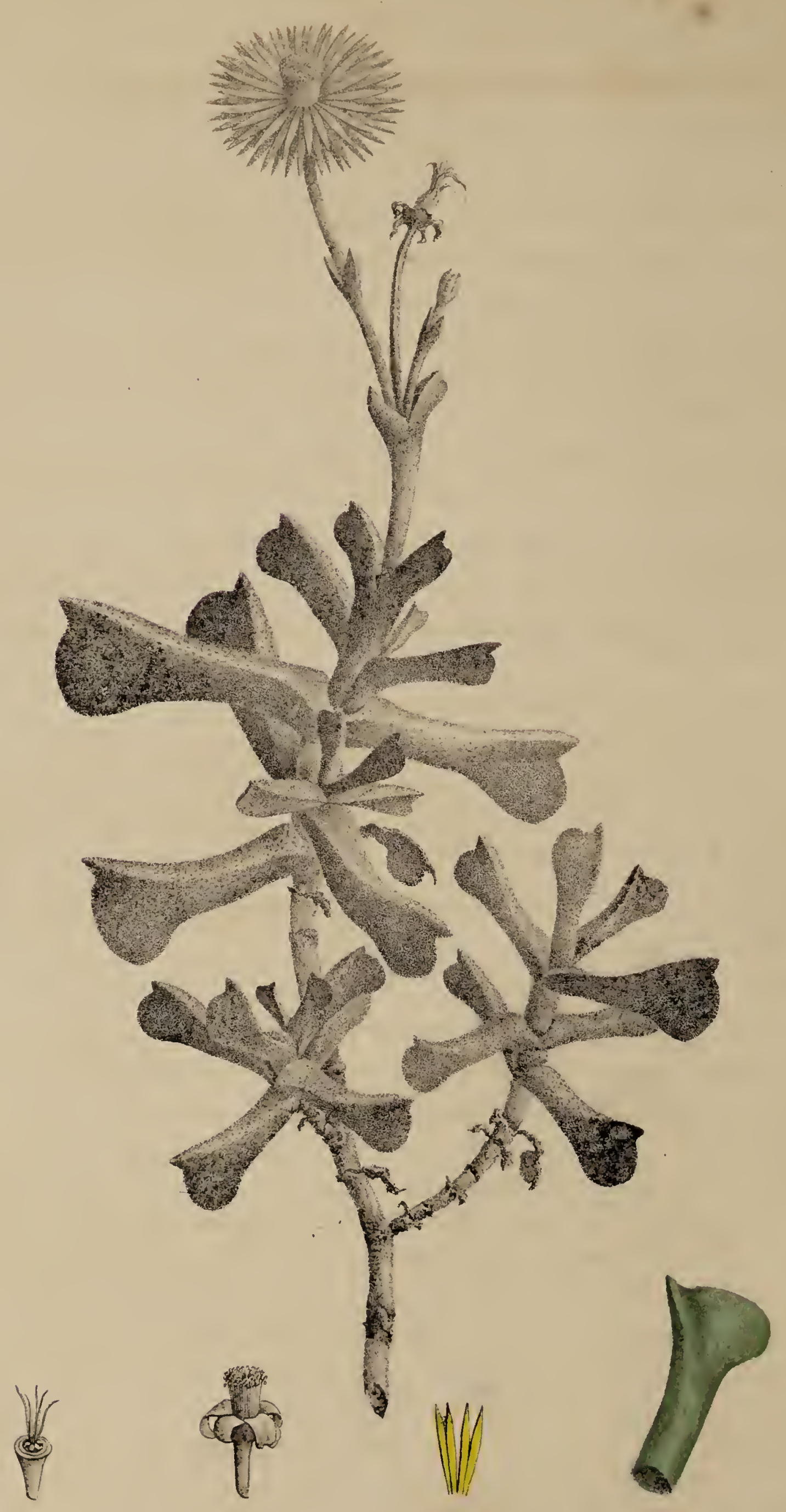

Mo s ol a

$$
(\$ .6 .-\mathrm{Fig} .3 .)
$$




\section{MESEMBRY ANTHEMUM DOLABRIFORME Lin.}

MESEMBR YANTHEMUM dolabriforme; caulescens ramosum, foliis confertis incurvatis multipunctatis glaucescentibus integris, basi subcylindraceis superne compressissimis obtuse acutis, carina sub apice dolabriformiter dilatata.

M. dolabriforme; junius acaule demum caulescens erectum, foliis glaucis puitictatis exacte dolabriformibus i. e. 'basi depressis apice comipressis 'obtusis subemalginatis, floribus breviter pedicellatis. DC. Prodr. 3. $\boldsymbol{p} . \mathbf{4 2 3}$.

M. dolabriforme; foliis glaucescentibus punctatis basi tereti-compressis apice dilatatis breviter acinaciformibus. spreng. Syst. 2. p. 516 .

M. dol abriforme; subcaulescens, foliis dolabriformibus triquetrisve carina ipicem versus valde dilatata. Haw. Synop. p. 219. Miscell. nat. p. 37. - Ait. Kew. ed. 2. Vol. 3. p. 221.

M. dolabriforme; subacaule, foliis punctatis triquetro-carinatis, carina apice dilatata biloba. Willd. Spec. 2. p. 1030.

Ficoide dolabriforme. Lam. Dict. Encycl. No. 18.

M. dolabriforme; foliis dolabriformibus punctatis. Lin. sp. m. p. 699. Horl. cliff. p. 218. - Roy. Lugd bat. p. 284. - Mill. Dict. No. 11. - Ait. Kew. ed. 1. eot. 2. p. 191. - DC. Pl. grass. t. 6. - Curt. Bot. Mag. t. 32.

M. Folio dolabriformi. Dill. Ellh. p. 218. 1. 191. Fig. 237.

Ficoides capensis humilis, foliis cornua cervina referentibus, petalis luteis, noctiflora. Bradl. Succ. 1. p. 11. t. 10.

$\boldsymbol{R A D I X}$ lignosa, ramosa, fibrosa.

CAULIS in plantis junioribus brevis, in adultis subpedalis, ramosus; rami cylindracei primo carnosuli lutescentes, dein lignosi tortuosi, cortice cinereo valde cicalricoso.

FOLIA conferta, connata, rigida, glaucescenti-pallide viridia, nitidula, punclis permultis pellucidis subprominulis adspersa, apice saepe rubro marginata, basi intus pustulata, patentia, subcylindracea, superne incurvato-erecta apice recurvulo, obtusiuscula cum mucronulo, valde triquetro-compressa, angulo carinali maxime dilatato, dolabriformiter usque sub apice producto (unde folium quasi crenalum aut bilobum,) pollicem ad sesquipollicem longa, basi lineas 2 et parte dilulata lineas 7 lata

FLORES ternatim aut quinatim disposili, uno alterove saepe abortivo, pedicellati, pedicellis in pedunculum communem seu cauliculum incidentibus, vespere expansi. Pedunculus communis quandoque geminus, subcompressus, superne bracteaius, bracteis subfoliiformibus compressis decurrentibus; e quibus oriuntur pedicelli tres, pollicem aut sesquipollicem longi, leretes, superne incrassati, intermedio breviore praecociore semper unifloro mudo, lateralibus (post anthesin floris centralis enascentibus) quandoque bifloris, ad medium bracteis duabus minoribus, carinatis, acutis instructis.

CALYX in pedicellum attenuatus, brevis, profunde quinquefidus; laciniis lanceolatis superne carinatis, revolutis, duabus margine submembranaceis. 
PETALA biserialia, lanceolata, integerrima, expansa, lutea.

STAMINA conferta, erecta. Filamenta et Antherue flavae.

PISTILLUM. Ovarium obconicum, supra convexiusculum. Styli 5 filiformes longitudine staminum, lutei, primo erecti apice recurvuli, dein flexuoso-patentes.

CAPSULA 5 locularis; naturam non vidi.

Habitat in Prom. bon. spei. Floret mensibus Julio et Augusto.

Observ. Haec antiqua species, peculiari foliorum forma nullae aliae vere affinis, propter caulem subpedalem anomala quoque in subdivisione $\boldsymbol{M}$. Subacaulium esse videtur. Variat attamen caule lumiliore, partibusque omnibus minoribus, et ratione inflorescentiae a M. scapigero et carinante separari non potest. Cl. Haworthii sectiones M. Dolabriformium et Carinantium in unam ergo collegi, cui locus inter sectiones $\boldsymbol{M}$. Ringentium et Difformium sine dubio tribuendus. 


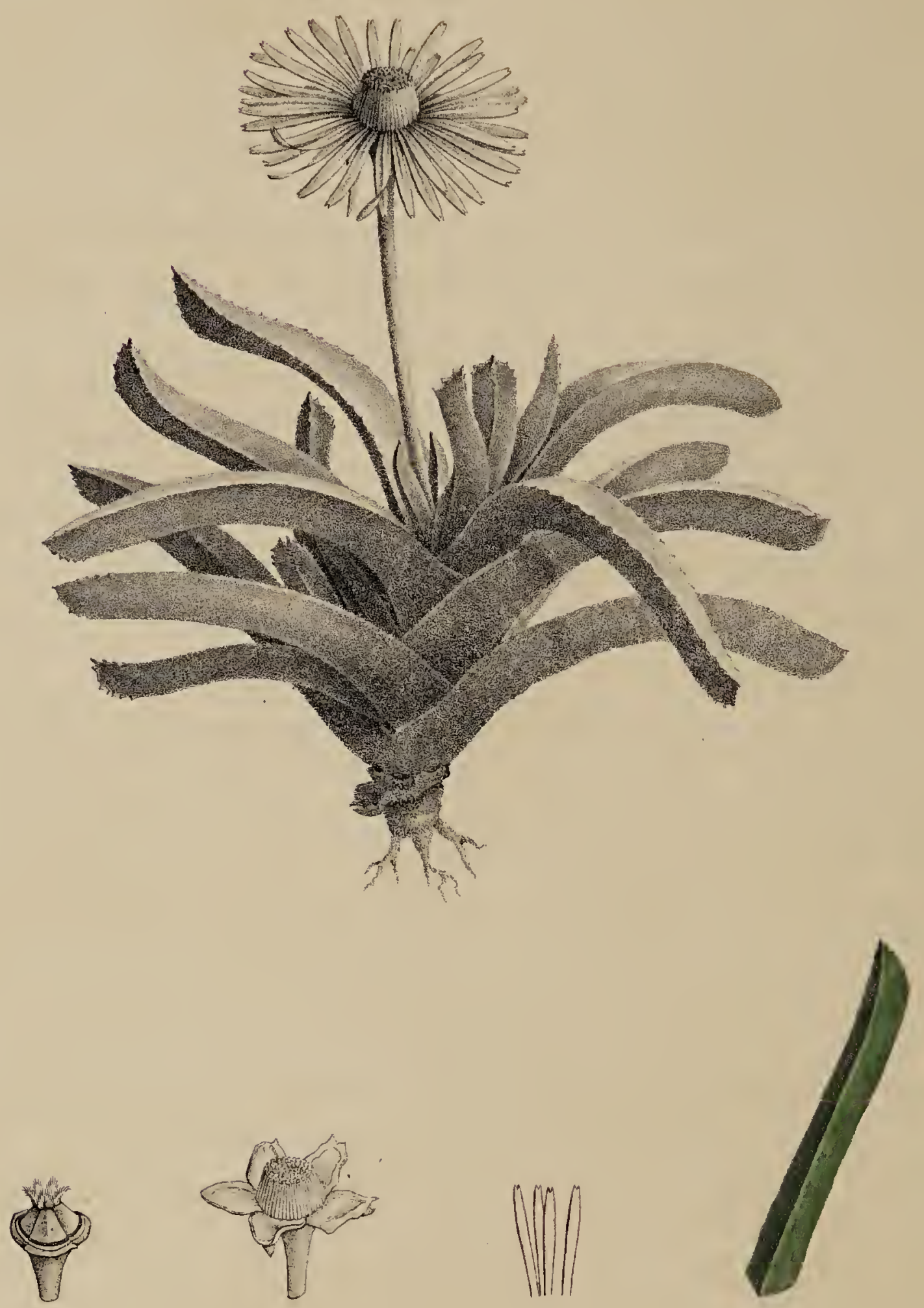

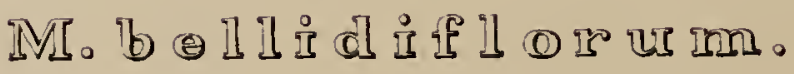

$$
\text { (\$.12. - Fig.1) }
$$




\section{MESEMBRYANTHEMUM BELLIDIFLORUM Lin.}

MESEMBRYANTHEMUM b ellidiflor um; acaule vel subacaule, foliis glaucescentibus triquetris compressis apice trifariam denticulatis impunctatis laevissimis, pedunculo basi bracteato, stigmatibus 5 ramentaceis.

M. bellidiflor um; caudice brevi suffruticoso, foliis triquetris compressis subacinaciformibus apice denticulatis, pedicello brevi. Dc. Prodr. 3. p. 42.

M. bellidiflorum; acaule, foliis triquetris impunctatis apice trifariam vel inferne dentatis, stigmatibus numerosissimis. DC. Pl. grass.

a glaucum; foliis patentibus glaucis compresso-triquetris, apice trifariam dentatis.

M. bellidiflorum a glaucescens; foliis subglaucis apice saepius trifariam dentatis. DC. Prodr. 3. p. 12.

M. bellidiflorum a glaucescens; laevigatum, foliis subglaucis. Haw. neris. 1. 106.

M. bellidiflor um; acaule, foliis triquetris linearibus impunctatis apice trifarian dentatis. Lin. Sp. pt. ". 690. - IIort. Cliff. p. 218. - Roy. Lugd. bal. p. 283. - Mill. Dict. No. 9. - Lam. Encycl. No. 16. - Willd. Syst. 2. p. 1029. - Haw. Mesembr. p. 143. No. 27. Synop. p. 207. - Ail. Kew. ed. 1. Vol. 2. p. 185. - ell. 2. Vol. 3. p. 217.

M. bellidiflor um. Dill. Elll. 244. Fig. 233.

RADIX sublignosa, ramosa, fibrosa.

CAULIS mullus aut aetate brevis, subdichotomus.

FOLIA triquetra, conferta, deccussata, comata, impunctata, lnevissima, rigida, in var. a. glauca, sesquipollicem ad pollices 2 longa, basi fere aequilateralia, patentia, superne compresso-triquetra, latere supero angustiore, per paria uno incurvalo altero recurvato, apicem versus triplici margine denticulatu, denticulis cartilagineis albidis.

FLORES solitarii, diametro sesquipollicari, meridie expansi, pedunculati. Pedunculus fere bipollicaris, teres, basi bracteis duabus parvulis folliformilus instructus.

CALYX quinquefidus, laciniis lutiusculis subaequalitus, trilus margine memlranaceis sul apice mucromatis.

PETALA biserialia, expansa, anguste lanceolata, apice bidentata, alba, margine et medio subtus linea spurco-rubra notatu.

STAMINA collectu, filamentis sterilibus basi albis superne roseis circumdatu. Filamenta brevia. Antherae spurco-roseae.

PISTILLUM. Ovarium clavatum supra pyramidato-convexum. Slyli 5 erectrrecurvuli, crassiusculi, acuti, ramentacei, viride purpurascentes, longitudine staminum.

CAPSULA subgloboso-pentagona, quinquelocularis.

Habitat in Prom, bon. spei. Floret hyeme.

Observ. Adsunt tres varietates hujusce speciei, omnes antiquae hortorum incolae. Dillenius hanc primam solum cognovit, et ad eam referri debent synonyma omnia in figuran 233 Horti Eltham: imnixa; caetera vero Bradleyi, Pluckenetii, Boerhavii et Tournefortii ad var. $\beta$ et $\gamma$. spèctare videntur. Haec planta foliis glancissimis recurvatopatentibus, et evidenter triplici margine dentatis facile agnoscitur. 


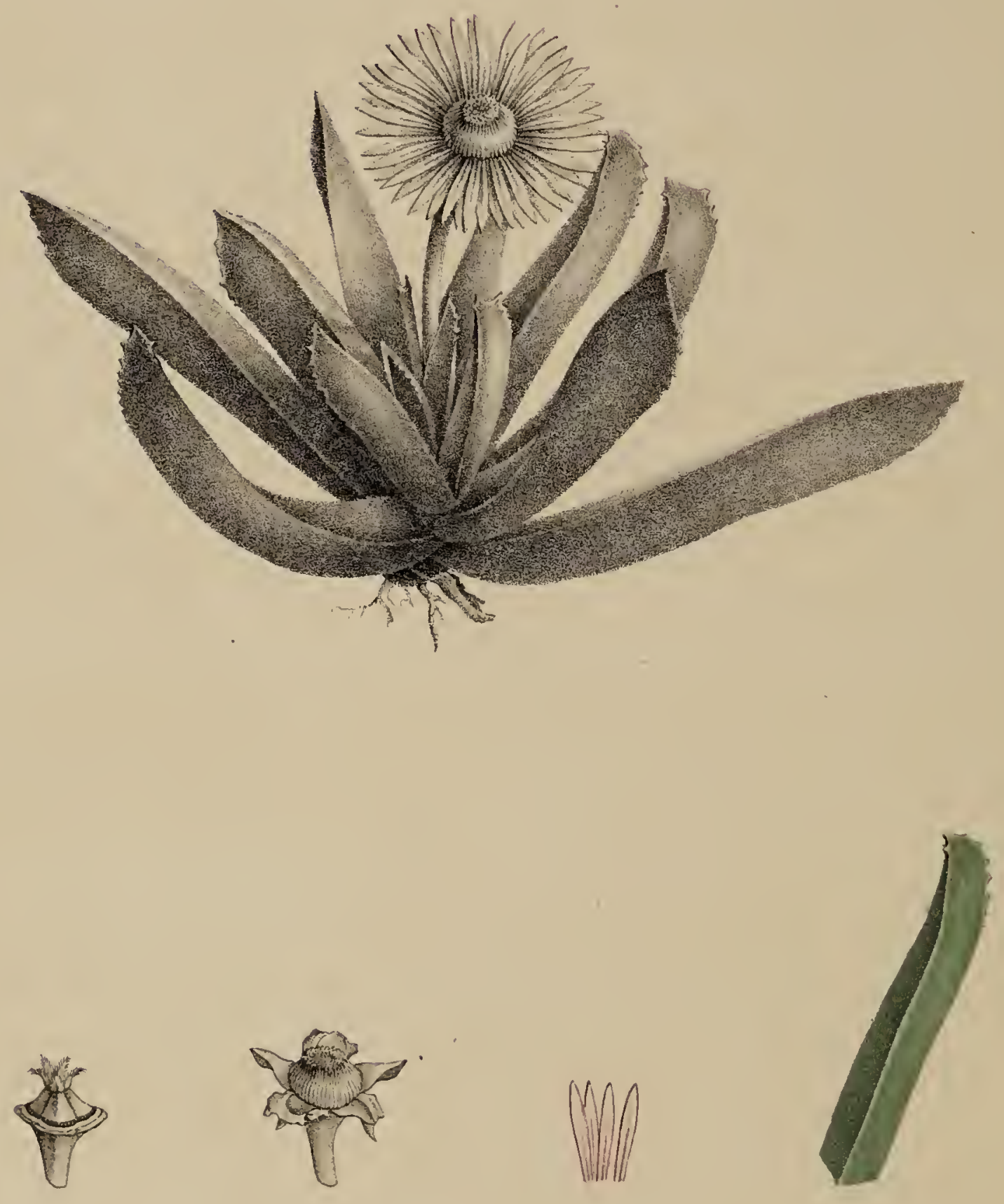

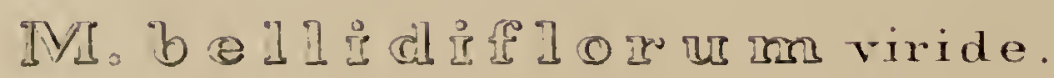

$$
\text { (\$.12...Fig. I. ) }
$$


(S. 12. Fig. 1. B.)

\section{MESEMBRY A NTHEMUM HELLIDIFLORUM. B. viride Haw.}

MESEMBRYANTHEMUM bellidiflor um $\beta$. viride; foliis suberectis virescentibus triquetris valde compressis, angulis lateralibus integris.

M. bellidiflo rum $\gamma$. viride; foliis laete viridibus subtus ad carinam dentatis. Dc. Prodr. 3 p. 424.

M. bellidiflorum $\gamma$. viride; foliis laete viridibus, petalis roseis costa saturatiore. Haw. Revis. p. 106.

M. bellidiflor um; foliis triquetris viridibus apice dilatatis trifariam denticulatis mucronatis. Syreng. Syst. 2. $p, 515$.

Ficoides seu Ficus aisoides africana humilis folio crasso viridi ad extrema spinoso, flore violaceo. Boerh. Ind. pl. 1. p. 123. N. 12?

Ficoides capensis humilis folio triangulari in summitate dentato, flore minore purpurascente. Bradl. Succ. 2. p. 9. t. 18 ?

RADIX, CAULIS ut in var. $\alpha$.

FOLIA viridia, laevissime glaucescentia, suberecta, angulo curinali magis producto magisque denticulato, denticulis longioribus, angulis lateralibus vero saepe integris.

FLORES ut in var. a, sed diametro pollicari, et pedunculo fere duplo breviore.

CALYX ut in var. a.

PETALA latiora ac breviora, apice acuta, dilutissime rosea, margine et medio. linea purpurea notata.

STAMINA ut in var. a. Filamenta basi barbata alba. Antherae purpurascentes.

PISTILLUM ut in var. a; sed styli flavo - purpurascentes.

Habitat in Prom. bon. spei. Floret aestate.

Observ. Raro occurrit in hortis haec varietas, quae foliis erectioribus, latioribus, viridioribus, et floribus purpurascentibus a praecedente differt. 

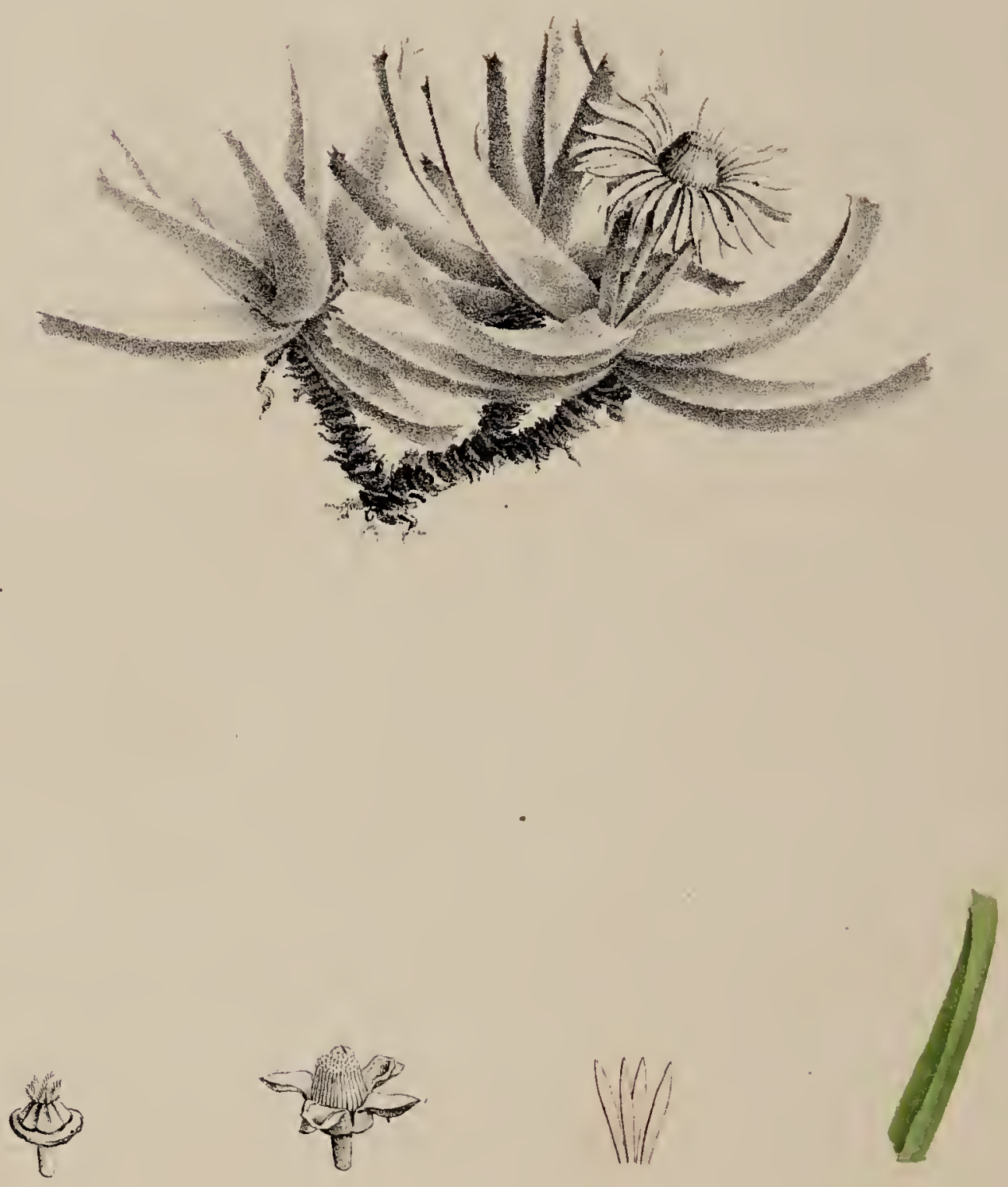

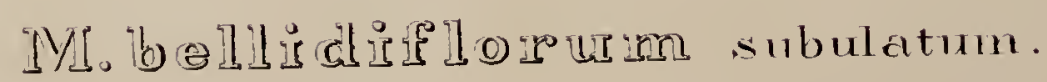

$$
(\$ .12-F i g .1 \%)
$$


(\$. 12. Fig. 1. $\gamma$.)

\section{MESEMBRYANTHEMUM BELLIDIFLORUM ${ }_{\gamma}$. subulatum Haw.}

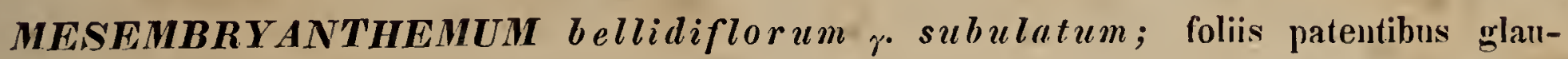
cescentibus attenuato-triquetris, angulo carinali imo apice dentato.

M. subulatum; caudice ranuloso, foliis subglaucis triquetro-subulatis apice denticulatis. DC. Prodr. 3 p. 424.

M. subulatum; foliis triquetris subulatis dorso superne serratis. Spreng. Syst. 2. $p, 515 .-$ Haw. Synops. p. 208. - Mill. Dict. N. 10.

M. bellidiflorum B. simplex; foliis latere infero tantum apice dentato. DC. Pl. grass. t.41.

M. bellidiflorum ß. subulatum; foliis viridibus duplo majoribus. Haw. Revis. p. 106.

Ficoides a fric an a; folio triangulari incurvo et dentato. Tournef. Act. Acad. Scient. 1705. p. 240. N. 20.

Ficoides africana Mesembryanthemum triquetro folio, flore albo parvo, polyantlo. Pluck. MIant. p. 7\%. - Ray. Hist. 3. p. 364. N. 2.

Ficoides afra, folio triangulari longo, marginis inferioris supremo aculeato, flore violaceo. Boerh. Ind. alt. pl. p. 290. N. 15?

RADIX, CAULIS ut in var. a.

FOLIA glauca, patenti-incurvula, pollicem longa, sensim attenuata, angulo carimali imo apice grandidentato, dentibus $3-4$.

FLORES vix diametro pollicari. Pedunculus semipollicaris.

CALYX ut in var. $\alpha$.

PETALA breviora, apice acuta, alba, margine et medio busin versus linea rosea

nolata.

STAMINA ut in var. a; sed Filamenta subburbata.

PISTILLUM ut in var. a; sed Styli pallide lutei.

Habitat in Prom. bon. spei. Floret aestate.

Observ. Haec tertia varietas in hortis est frequentissima. A praecedentibus differt statura minore, foliisque incurvulis subulato-attenuatis, apice subuncinatis, et angulo carinali solum dentibus quibusdam instructis. Pro genuina specie haberi non potest, ut e tabula et descriptione patet. 




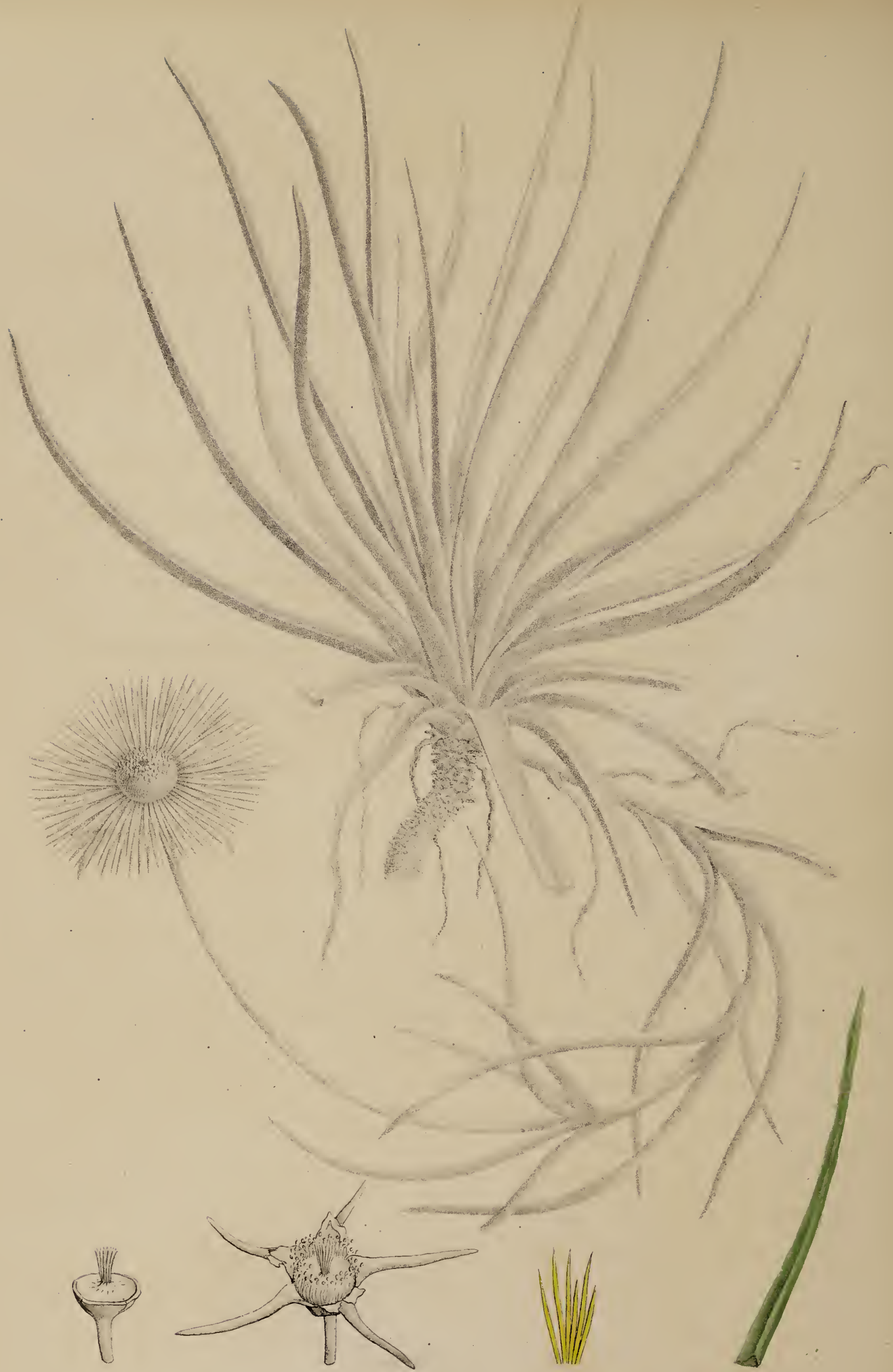

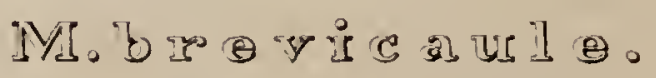

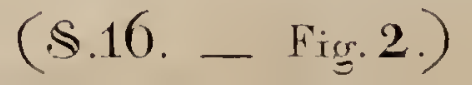




\section{(\$. 16. Hig. 2.) \\ MESEMBRYANTHEMUM BREVICAULE Haw.}

MESEMBRYANTHEMUM brevicaule; caudice suffruticoso simplici erecto, foliis ad apicem congestis alternis longissimis laeteviridibus, laciniis calycinis petala longitudine aequantibus.

M. Urevicaule; caudice suffuticoso simplici erecto, foliis ad apices congestis alternis virescentibus triquetris. DC. Prodr. 3. p. 426.

M. Urevicaule; foliis triquetris strictis viridibus laevissimis patulis, caule humili. spreng. Syst. 2. p. 519 .

M. Urevicaule; candice $2-3$ unciali, foliis triquetris $2-3$ uncialibus pugioniforuibus viridibus, ramorum floriferum patulis. Haw. Sumpl. p. 91.

M. Lrevicaule; foliis virescentibus 3-4 uncialibus triquetribus: caudice senecto biunciali simplice erecto. Haw. neris. p. 113.

Chrysanthemum aizoides africanum minus flore flavo. Breyn. Cent. 165?

RADIX sublignosa, ramosa, fibrosa.

CAUDEX carnoso-lignosus, simplex, erectus, vix 4-5 pollices altus, cicutrisutus, corlice subsuberoso, fulvo-ciner(uscente.

FOLIA in apice caudicis capitatim conferta, alterna, juniona suberecta stricta, seniora recurvato-patula, lineari-elongata, aequilateri-lriquetra, pugioniformia, poll. 4-5 longa, et lin. 2 lata, basi parum dilatata, semiamplexicaulia, subcanaliculata, mollia, impunclata, laeteviridia ima basi pallidiora.

FLORES in ramulo porali proprio, foliis allernis remotis instructo et inter folia infimn enascente, post anthesin marcescente, terminules, solitarii, pedunculati. Pedunculus 1-5 poll. longus, teres.

CALIX amplus, urceolutus, quinquefidus; laciniis inferne lalo-ovatis, superne cylindraceis elongatis, tribus paulo brevioribus basi membranaceis.

PETALA pluriserialia, expansa, basi vix ciliata, splendide sulphurea, linearilanceolata, attemuta, lin. 10-12 longa, longiludine calycis laciniarum.

STAMINA erecta, filamentis sterilibus primo capitatim collectis, dein expansis varie flexis sulphureis, circumedata. Filamenta brevia, et Antherae parvulae luteae.

PISTILLUM. Ovarium basi planiusculum, supra vix conicum. Slyli 12 filiformes, erecti, stigmate inconspicuo.

CAPSULA 12 locularis, magna, conica.

Habitat in Prom. bon. Spei. Floret aestate.

Observ. Dom. Burchell hanc plantam versus annum 1818 in Angliam advexit, et dubium milii est, an sit Breynii Chrysanthemum aizoides minus flore flavo, quia in locis habitat Breynii tempore vix cognitis. Bona est species quae in hortis uostris semina matura profert, et e seminibus renata non variat. A $\boldsymbol{M}$. elongato differt caudice perenni, foliis capitatim collectis, floribus minoribus, laciniisque calycinis longioribus. 




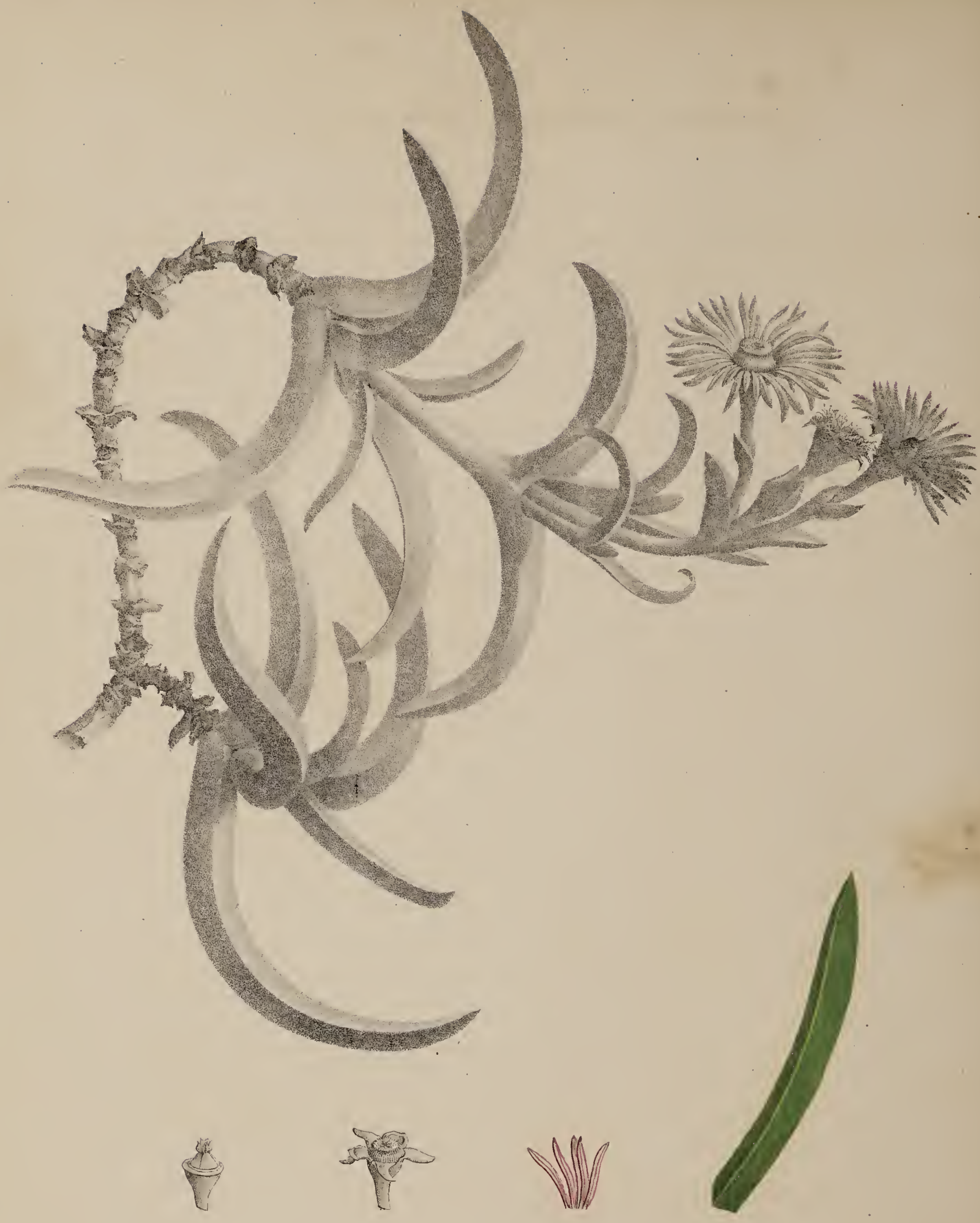

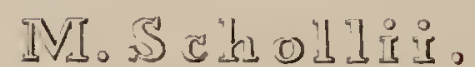

(\$.17. Fig.1.) 
(\$. 17. Fig. 1.)

\section{MESEMBRYANTHEMUM SCHOLLII Nol.}

MESEMBRYANTHEMUM Schollii; canle diffiso ramisque subsarmentoso-decumbentibus, foliis connatis patenti-recnrvatis punctatis elongatis attenuato-triquetris ad angulos serrulatis, pedicellis bigeminatim ternatimve dispositis basi et medio bracteatis.

M. Schollii; caulibus firmis decumbente-sarmentaceis, foliis connatis compresso-triquetris patenti-recurvatis ad angulos laterales et carinam superne sermlatis, perlunculis termis medio bibracteatis, stigmatibus 5. DC. Prodr. 3. p. 427.

M. recurvum; foliis triquetris recurvis glaucescentibus punctatis, angulis serrulatis asperis spreny. Syst. 2. p. 523.

M. recurvum; foliis quadriuncialibus triquetris recurvis glancescentibus pumctatis ad angulos laterales exasperatim crebre sermlatis. Haw. sumpl. p. go.

M. Schollii; sarmentoso-canlescens, foliis connatis triquetris patento-recurvatis, punctatis, angulis lateralibus et carinali superne semrulatis; floribus ternatis, pallide rubicundis, bibracteatis. Nob. Observ. 1820. p. 10.

II. Schollii; foliis compresso-triqnetris magnis recurvis serrulato-asperrimis; senectis canlibus firmis decumbenti-sarmentiformibus. Haw. Reris. p. 116.

M. aduncum Jacq. Fragm. t. 51. Fig. 2.

RADIX liguosa, ramosa, fibrosa.

CAULIS ramosus, diffusus, rumique conferti, lignosi, rigidi, juniores compressi cortice cineren, foriferi sarmentoso-prostrali, sed nom radicantes, seniores tortuosi folionm rudimentis desiccalis onusti, senectissimi corlice rimoso, cinereo.

FOLIA in ramulis sterilibus conferta, in vamis forentibus subremota, valde connata, rigida, glancescenti-perividia, poll. 2-3 longa, basi lin. G lata, sensim altemuala, oblusiuscula cum mucromulo rubro, patenti-recurvata, triquetra, lateribus subfarctis, punctis pellucidis permullis subprominulis, et basi interne pustula lata instructa, ad angulos cartilaginenservulata.

FLORES in ramis floriferis terminales, mediocres, rite bigeminati cum intermedin tertio pracociore brevinsque pedicellato, sed abortu saepe termati, ante meridiem expansi, pedicellati. Pedicelli pollicem longi, basi et medio bracteali, superne incrassati, in pedunculum communem sesquipollicarem compressum geminatim affixi. Bracteal latae, aculae, carinatae, vaginatim comutate.

CALYX quinquefidus, laciniis subaequalibus latiusculis acutis, duabus margine membranaceis.

PETALA uniserialia, lin. o longa, lineari-lanceolatu, patentia, mallide rosea, linea saturatiore medio notata.

STAMINA collecta, filamentis sterilibus albis apice mubicundis circumdatu. Filamenta ulba. Antherae lutere.

PISTILLUM. Ovarium obconicum supra convexum. Styli .5 erecti, ressinsenti, acuti, subramentacei, lutei. 
CAPSULA quinquelocularis; maturam non vidi.

Habitat in Prom. bon. spei. Floret mense Aprili et Majo.

Observ. Haec species in Horto Schönbrunnensi versus anmm 1800 e seminibus Capensibus enata, et ibi sub nomine peregrimatoris Schollii culta, erroneo serins a Cl. Jaquinio pro M. adunco Haw. habita erat. Cl. Haworth in Supplemento Plantarum succulentarun lnic speciei nomen M. recurvi imposuit, sed ei serius in Revisionibus suis nomen Schollii restituit, quod servari debet. Rami non vere sarmentosi sunt, et flores rite bigeminatim dispositi, cum intermedio tertio, sacpissime abortu binorum inferiorum ternati apparent. 



\section{(\$. 17. Fig. 2.) \\ MESEMBRY ANTHEMUM RIGIDICAULE Hav.}

MESEMBRYANTHEMUM rigidicaule; caule subramoso ramisque firmis erectodecumbentibus, foliis connatis erecto-patentibus punctatis elongatis aequilateri-triquetris ad angulos asperiusculis, pedicellis bigeminatim ternatimve dispositis, basi et medio bracteatis.

M. rigidicaule; caule firmo procumbente (nec pendulo), foliis longis aequilateri-triquetris rectis margine asperiusculis. Dc. Prodr. 3. p. 427.

M. rigidicaule; foliis longis aequilateri-triquetris rectis, margine asperiusculo; caule firmo procumbente (non pendulo). Haw. Revis. $n .116$.

$\boldsymbol{R A D I X}$ lignosa, ramosa, fibrosa.

CAULIS subramosus ramique subflexuoso-erecti, lignosi, remoti, rigidi, juniores subconıpressi, cortice ferrugineo, floriferi erecto-decumbentes, seniores foliorum rudinentis desiccatis onusti; senectissimi corlice luevi cinereo.

FOLIA in ramulis sterilibus subconferta, in ramis forentibus remota, comata, rigilla, viridia, poll. 2-3 longa, et lin: 3 lata, obtusa cum mucronulo rubente, erecto-patentia, varie in-aut recurvula, aequilateri-triquetra, lateribus laevissime farctis, punctis pellucidis permultis et basi interne pustula planiuscula instructa, ad angulos praecipue carinales subserrulata.

FLORES in ramulis floriferis terminules mediocres, rite bigeminati cum internedio tertio praecociore, sed abortu saepe ternati, ante meridiem expansi, pedicellati. Pedicelli pollicares et ultra, basi et medio bracteati, superne incrassati, in pedunculo communi sesquipollicari, compresso, geminatim affixi. Bracteae latiusculae, acutae, carinatae, vaginatim connatae.

$\boldsymbol{C A L Y X}$ quinquefidus, laciniis subaequalibus latiusculis, acutis, duabus margine membranaceis.

PETALA uniserialia, lin. $\boldsymbol{6}$ longa, lineari-lanceolata, patenti-recurvula, rosea, linea saturatiore medio notata.

STAMINA collecta, filamentis sterilibus roseis apice saturatioribus circumdata. Filamenta alba. Antherae luteal.

PISTILLUM. Ovarium obconicum, supra convexum. Styli 5 erecti, crassiusculi, acuti, lutei.

CAPSULA quinquelocularis; maturam non vidi.

Habitat in Prom. bon. spei. Floret hyeme.

Observ. Proxime accedit haec species, in horto Kewensi anno 1819 e seminibus Capensibus enata, ad M. Schollii; sed caule erectiore foliisque nec attenuatis nec recurvis satis differt, ut pro propria specie haberi debeat. Flores quoque fere semper ternatim dispositi sunt. 




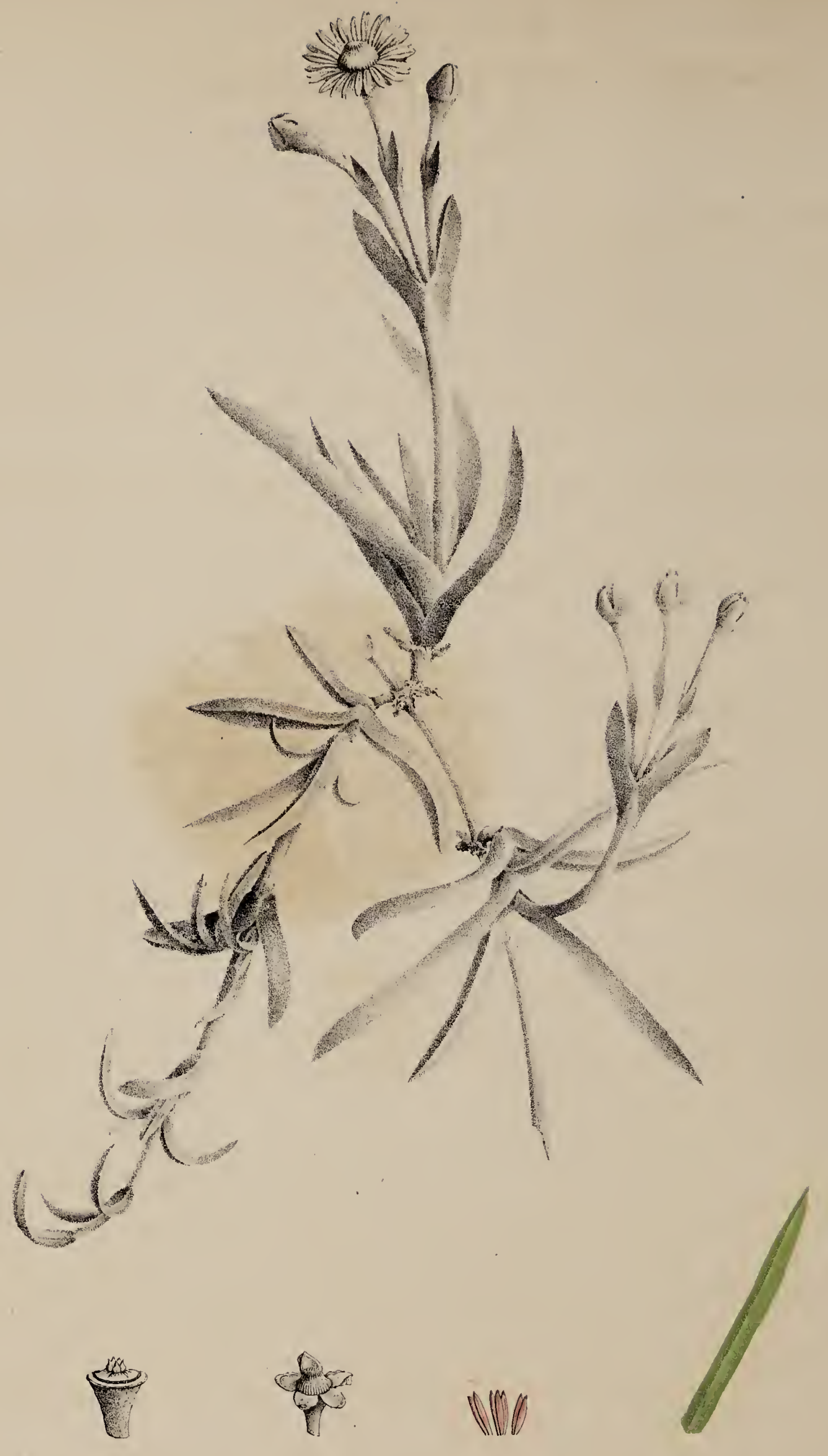

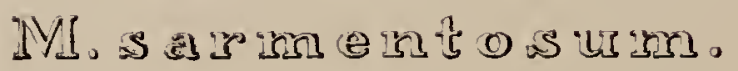

(\$.17. - Fig. 3.) 


\section{MESEMBRY NTHEMUM SARMENTOSUM Haw.}

MESEMBRYANTHEMUM s armentosum; caule diffuso ramisque gracilibus sarmentaceis ad nodos radieantibus, foliis vaginato-connatis suberectis aequilateri-triquetris obtusiusculis ad angulos sublaevibus, pedicellis bigeminatim ternatinve dispositis basi et medio bracteatis.

M. sarmentosum; caule suffuticoso diffuso, ranis prostratis radicantibus sarmentaceis, foliis confertis compresso-triquetris laeteviridibus ad margines exasperatis, pedunculis superne clavatis, stigmatibus 5. DC. Prodr. 3 p. 127 .

M. sarmentosum; satmentis radicantibus, foliis confertis triquetris pumctatis glaberrimis, pedunculis ternatis bibracteatis clavatis, floribus rubris. spreng. Syst. 2. p. 5*3.

M. sarmentosum; sarmentis sesquipedalibus gracilibus laxulis radicantibus, foliis confertis compresso-triquetris laete viridibus, marginibus minime exasperatis. Inw. Revis. \%. 11.5.

M. sarmentosum; sarmentis sesquipedalibus, foliis confertis aequilateri-triquetris, pedumculis ternatis e ramis lateralibus. Haw. Synop. p. 23s.

ß. rigidius; caule robustiore, internodiis brevioribus foliisque paulo gracilioriluss.

M. simile; caulibus fruticosis firmis procumbentibus, foliis aequilateri-triquetris glancescentibus punctatissimis apice rectis internodio longioribus margine non serrulatis. $\boldsymbol{D C}$. Prodr. 3. p. 427.

M. simile; foliis aequilateri-triquetris glaucescentibus punctatissimis apice rectis internodiis longioribus, marginibus minime serrulatis, caulibus firmis procumbentibus. Iraw. Revis. p. 115 .

$\boldsymbol{R A D I X}$ lignosa, ramosa, filrosa.

CAULIS ramosus ramipue graciles, decumbentes, nodosi, angulosi, rigidi, (ine var: B. paulo crussiores, erectiores, intemodiisque brevioribus,) cortice prino ferrugineon dein cinesren, sarmentoso-extensi, ad nodos radicantes.

FOLIA ad nodos fasciculatim collecta, patenti- errecta, vaginato-conmala, subrigida, lacte viridia, poll. 2 ad $2 \frac{1}{12}$ longa, et lin. 3 (in var. $\beta$ lin. 2) lata, obtusì cume mucromulo rubente, aequilateri-triquetra, lateribus laevissime farctis, punctis temissimis pellucidis et basi interne rustula parva instructa, ad angulos laevia aut apicem versus solum minime aspera.

FLORES in ranulis floriferis terminales, parvuli, rite bigenuinati cum intermedio tertio praecociore, sed abortu (praecipue in specie) sctepe ternati, ante meridiem expansi, pedicellati. Pedicelli pollicares et ultra, basi et medio bracteati, superne incrassati, (in var. B. graciliores,) el in pedicellum communem sequipollicarem compressum geminutim affixi. Bracteae latiusculae, acutae, carinatae, decurrentes.

$\boldsymbol{C A L Y X}$ quinquefidus, laciniis subaequalibus, latiusculis, margine membranaceis, obtusiusculis, (in var. B. acutiusculis.)

PETALA uniserialia, lin. 3 longa, lanceolata, acuta, patentia, rosen, linea saturatiore medio notata. 
STA.MINA collecta filamentis sterilibus albis apice rubicumdis circumduta. Filamenta alba. Antherae luteae.

PISTILLUM. Ovarium obconicum, suma planiusculım, (in var. ß. comvexiuscuhem;) Styli 5 erecti, crossiusculi, aculi, lutei.

CAPSULA incinquelocularis; maturam non vidl.

Habitat in Nova Hollandia? Floret mensibus Martio et Aprili.

Observ. Dom. Dom anuo $1806 \mathrm{Cl}$ : Haworthio M. scrmentosum communicavit, quod e seminibus Australibus ortum esse dicitur. $\boldsymbol{M}$. simile vero in Horto kewensi anno 1819 certissime e seminibus Capensibus enatum est; unde patria M. sarmentoso tribuenda mili dubia remanet. Hae duae plantae separari non possunt, ut e descriptione patet. Statura minore et graciliore a $\boldsymbol{M}$. rigidicculli differt, et magis ad $\boldsymbol{M}$. geminiflorum accedit. 


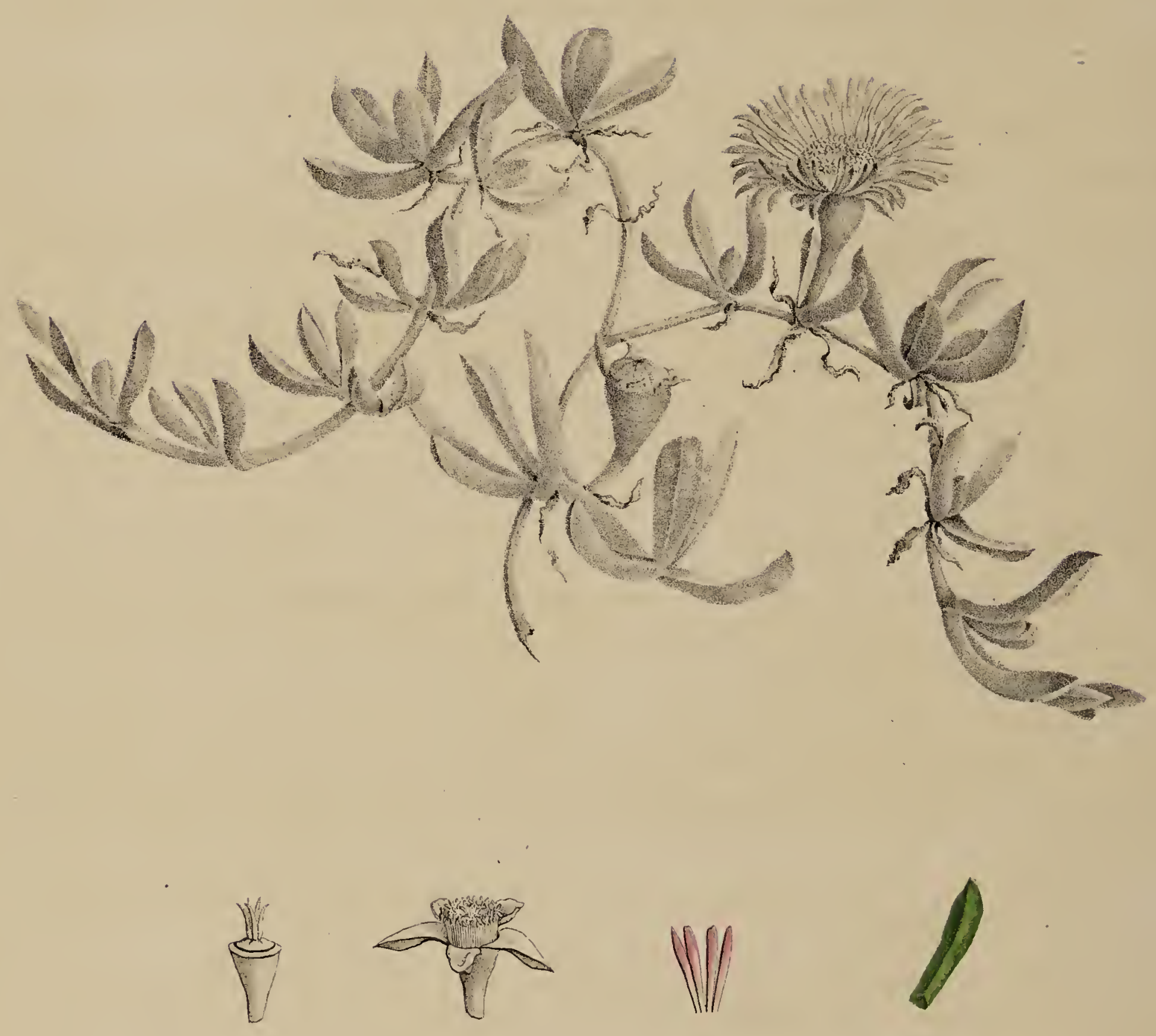

MD。 US Us

$(\$ .18 .-F i g .2$. 
(§. 18. Fig. 2.)

\section{MESEMBRYAN'THEMUM AUSTRALE Ail.}

MESEMBRYANTHEMUM australe; caule prostrato reptante semitereti, foliis erectopatentibus incurvulis glaucescenti-laeteviridibus laevissimis triquetris, lateribus farctis, petalis roseis.

M. australe; caule semitereti reptante, foliis triquetris glaucescentibus punctulatis laevibus incurvartibus, pedunculis obtuse ancipitibus basi bibracteatis, stigmatibus 5 subulatis. DC. Prodr. 3. p. 428.

M. australe; foliis triquetris laevibus glaucis punctulatis, caule reptante semitereti, pedunculis ancipitibus, floribus rubris. spreng. Syst. 2. p. 522.

M. australe; foliis glaucescentibus punctato-triquetris incurvantibus laevibus. Haw. Revis. p. 122.

M. australe; foliis glaucescentibus punctulatis triquetris laevibus, caule semitereti reptante, pedunculis ancipitibus. Haw. Synop. p. 241. - Ait. Kew. ed. 2. vol. 3. p. 211.

M. australe; foliis subtriquetris punctulatis connatis obtusiusculis, caule tereti repente pedunculis obtuse ancipitibus solitariis. Ait. Kew. ed. 1. Vol. 2. p. 18\%. - willd. sp. Plant. 2. p. 1047. Enum. 1). 536.

M. Uemissum; Willd. Emum. Sump. p. 36.

\section{RADIX ramosa, fibrosa.}

CAULES humifusi, pedales et ultra, crassitie pennae columbine, flexiles, nodulosi, ad nodos radicantes, ramosi, juniores sicut et rami semiteretiusculi, primo herbacei rosei, dein sublignosi, cortice stramineo-cinereo.

FOLIA in ramis junioribus subremota, sed in vetustioribus ud nodos capitutim collecta, busi subvaginato-comnata, erecto-patentia, lin. 8-10 longa, et lin 2 latu, triquelru, luterilus furctis angulisıue laevissime curtilagineis, basi intus tumidulu, glancescenti-lueleviridiu, obscure punctulula.

FLORES solitarii, terminales, meridie expansi, pedunculati. Pedunculi mudi, subcompressi, superne incrassıti.

CALYX turbinutus, carnosus, quinquefuhus; laciniis duabus triquetro-aculis subfoliiformibus, tribus planiusculis margine memlranaceis.

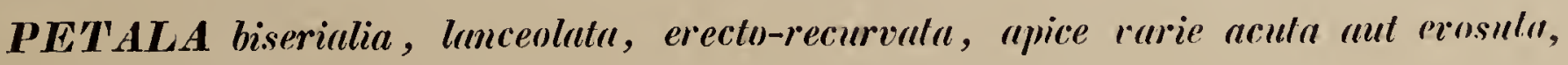
pullide roseu.

STAMINA mumerosa, erecta. Filamentu albida. Aulleren flaridue. 
PISTILLUM. Ovarium hurbinatum, supra convexum. Styli 5 subulati, erecti, flavo-virides, longitudine staminum.

CAPSULA quinquelocularis; maturam non vidi.

Habitat in Nova Hollandia. Floret aestate.

Observ. Cl. Banks hanc speciem in Nova Hollandia reperit et anno 1773 in Angliam advexit. A praecedente, iisdem locis nascente, differt statura majore, foliis triquetris petalisque roseis, et magis accedit ad sequentem, quae in Promontorio bonae Spei habitat. Primo intuitu tamen foliis laeteviridibus, brevioribus, confertioribus, et flore roseo ab illa satis discernenda est. 


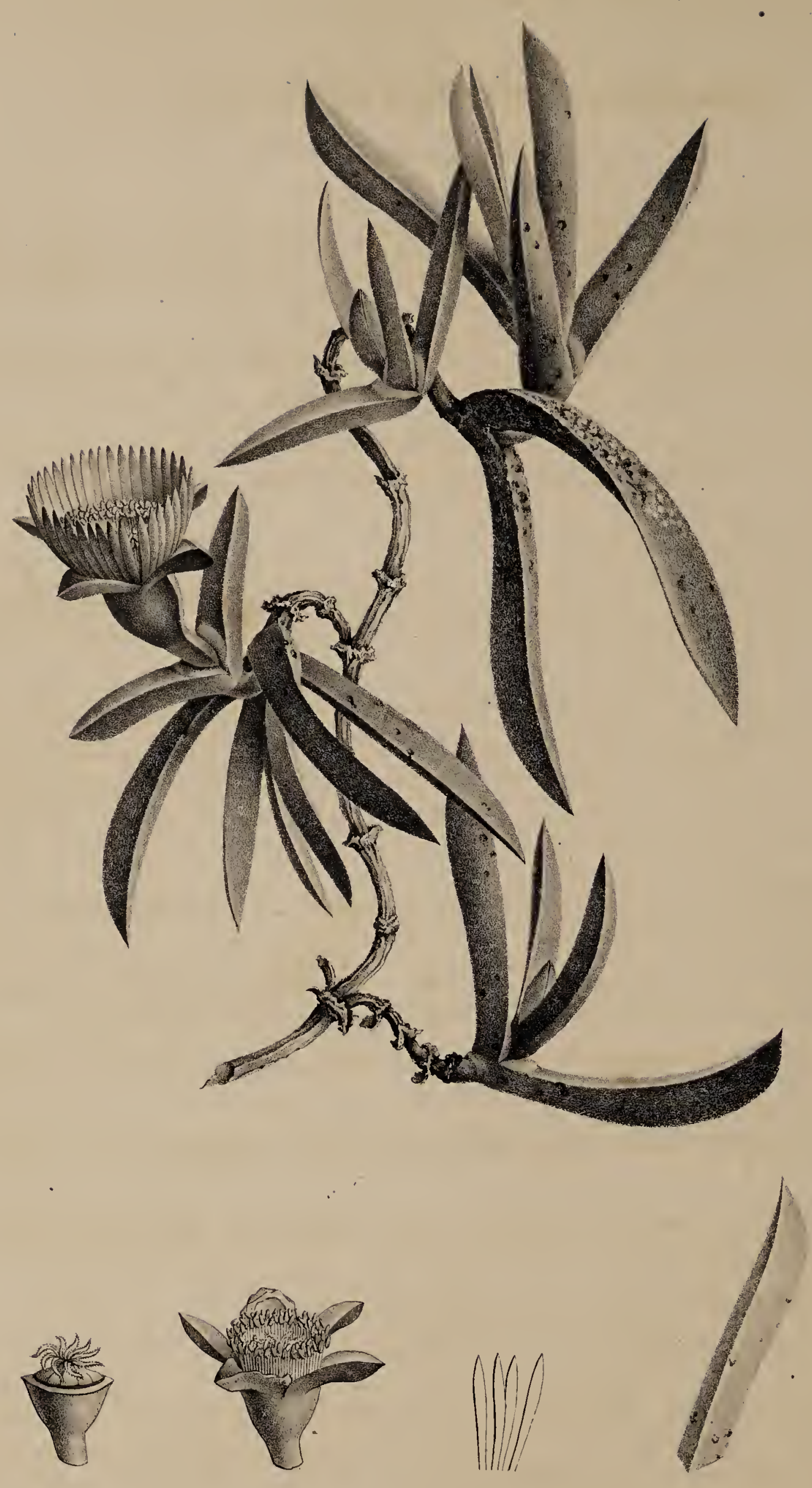

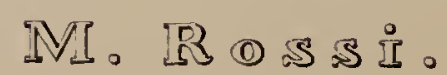

(\$.19. - Fig. 2.) 
(\$. 19. Fig. 2.)

\section{MESEMBRYANTHEMUM ROSSI Haw.}

MESEMBRYANTHEMUM Rossi; caule tortuoso angulato debili prostrato, foliis comatis glaucescenti-perviridibus saepe maculatis compresso-triquetris elongatis erecto-incurvulis ad angulos laevissimis roseis, petalis basi albis.

M. Rossi; caulibus decumbenti-prostratis, foliis acinaciformibus seu compresso-triquetris glaucescentibus margine cartilagineis roseis laeviusculis. DC. Prodr. 3 p. 129.

M. Rossi; foliis acinaciformibus seu compresso-triquetris glaucescentibus, nargine subcartilagineo roseo laeviusculo, caulibus decumbenti-prostratis. IIaw. Revis. p. 120.

RADIX lignosa, ramosa, fibrosa.

CAULES prostrati (nisi suffulti), subpedales, crassitie pemae columbinae, flexiles, tortuosi, nodosi, ramosi, juniores ramique herbacei compressi, dein lignosi angulati, cortice primo ferrugineo, dein cinereo-fusco.

FOLIA subconferta, basi comata, juniora erecta, seniora patentia, varie in-aut recurvatu, compresso-triquetra, poll. 2-3 longa, et lin. 3 basi lata, angulo carinali subacinaciformiter moducto, apice in mucronem exeuntia, perviridia, rore glauco obducta, maculisque murpureis saepissime notata, impunctata, basi interne pustulata, ad angulos laevissima, subcartilaginea, et sole ardente mubro colorata.

FLORES solitarii, terminales, magni, speciosi, meridie expansi, pedunculati. Pedunculus brevis, anceps, superne dilatatus.

$\boldsymbol{C A L Y X}$ turbinatus, compressus, carnosus, quinquefidus; laciniis tribus trifuetris, carinatis, duabus margine membranaceis, quarum una carinata et altera planiuscula.

PETALA fere uniserialia erecto-incurvata, lanceolato-acuta, basi alba, superne intense purpurea.

STAMINA mumerosa, erecta, pistillum circumdantia. Filamenta alba. Antherae Aavae.

PISTILLUM. Ovarium turbinatum, supra depressum. Styli 9-10 subulati, ramentacei, divaricati, Aavidi.

CAPSULA 9-10 locularis; maturam non vidi.

Habitat in Terra Van-Diemen. Floret aestate satis frequenter.

Observ. E seminibus in Terra Van-Diemen collectis orta est haec species in Horto Dom. Guillı. Ross anıo 1820. Debilis est planta semper fere aegrotans, caule gracili tortuoso, quae ad $\boldsymbol{M}$. aequilaterale proxime accedit. Differt foliis crassioribus compresso-triquetris, petalisque basi albis. 




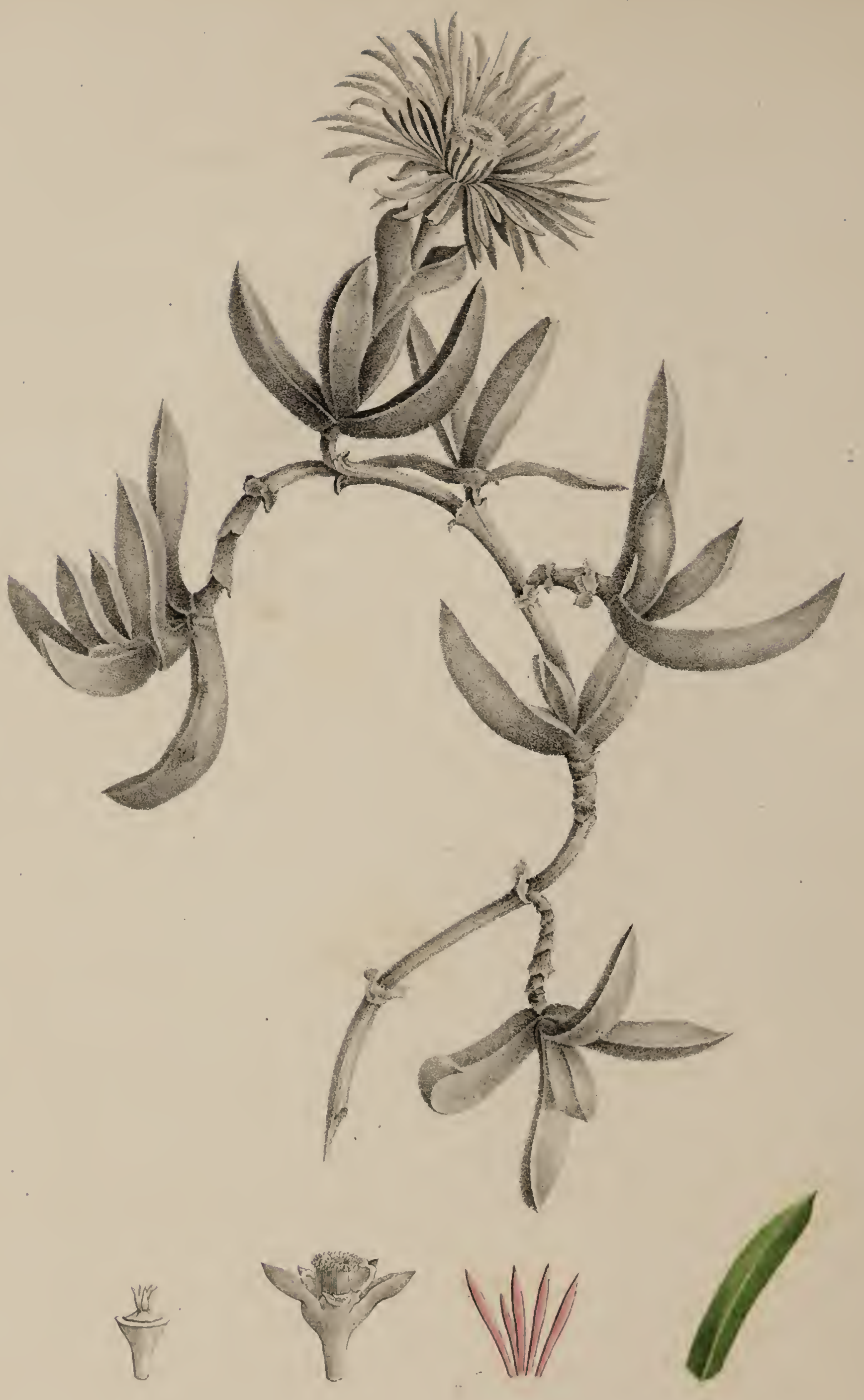

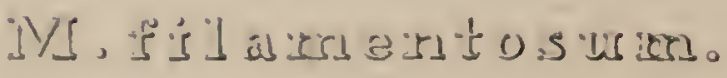

$$
\text { (\$.20. - Fig. 1.) }
$$


(\$. 20. Fig. 1.)

\section{MESEMBRY ANTHEMUM FILAMENTOSUM Lin.}

MESEMBRYANTHEMUM filamentosum; caule ramoso ramisque sulsarmentosodecumbentibus, foliis subacinaciformibus crassis laete viridibus laevissimis ad margines cartilagineis serrulato-asperis, floribus solitariis, petalis acutis.

M. Filamento sum; caulibus decumbentibus brevibus, foliis compresso-triquetris subacinaciformibus confertis crassis laete viridibus punctatis internodio longioribus ad margines serrulato-asperis, floribus solitariis. DC. Prodr. 3. p. 428.

M. filamentosum; foliis subacinaciformibus punctatis confertis margine cartilagineis serrulatis, caule prostrato reptante angulato. spreng. Syst. 2. p. 524 .

M. filamentosum; foliis laete viridibus confertis crassis compresso-triquetris subacinaciformibus punctatis, marginibus serrulato-asperis internodio longioribus; caulibus decumbentibus brevibus contiguis. Haw. Revis. $p .116$.

M. filamentosum; foliis confertis compresso-triquetris subacinaciformibus punctatis, marginibus serrulato-asperis internodio longioribus. IIaw. Synop. p. 23s. - Ait. Kew. ed. 2. vol. 3. 1.210 .

M. Filamentosum; foliis aequilateri-triquetris acutis subpunctatis connatis, angulis scabris, ramis lıexagonis. Lin. Spec. pr. p. 69.4. - Willd. Spec. 2. p. 1051. - Ait. Kew. ed. 1. vol. 2. p. 189.

M. falcatım majus, flore purpureo inediocri. Dill. Eult. p. 28.5. t. 212. fig. 273.

\section{RADIX lignosa, ramosa, fibrosa.}

CAULIS suberectus, angulosus, ramosus; rami breves vel sarmentos()-extensi, prostruli, juniores herbacei suepe rubicundi, seniores lignosi corlice cinereo.

FOLIA conferta, comata, erecto-putentia, incurvula, sesquipollicem longa, et lin. - busi lata, subaerpuilateri-triquetra, angulo carinali superne subacinaciformiter moducta, basi intus subpustulata, apice mucronata, late viridia, temaissime pellucido-punctatu, ad angulos cartilaginea, sermulata.

FLORES solitarii, terminales, mediocres, meridie expansi, pedunculati. Pedunculus pollicaris et ultra, medio bracteis duabus vaginato-connatis, latis, carinatis, obtusis cum mucromulo instruches.

CALYX suburbinatus, quinquefidus; laciniis ducabus triquetris acutis, tribus plromiusculis margine membranaceis quarum ducue apice mucronatue.

PETALA biserialia, recurvato-expansa, lineari-lanceolata, acula, purpurascentia.

STAMINA mumerosa, erecta, conferta. Filamenta alba. Antherce hatecte. 
PISTILLUM. Ovarium obconicum, suprı vix convexum. Slyli 5 erecti, rorassinsculi, aculi, Aavidi.

CAPSULA quinquelocularis; maturam non vidi.

Habitat in Prom. bon. Spei. Floret mensibus Februario et Martio.

Observ. Haec antiqua species, cujus denominatio valde impropria, in tab. 212. Fig. 273. Horti Elthamensis non bene agnoscenda est. Rarissime ramos tam extensos ac prostratos profert; rarius quoque in hortis nostratibus occurrit, et inde imperfecta cognita est. A sectione $\boldsymbol{M}$. Reptcmlium caule erectiore foliisque acinaciformibus recedit, et a sectione Acinaciformizum floribus pentagynis; locus ergo ei tribuendus est prope $\boldsymbol{M}$. serrulatum et rubricaule. 



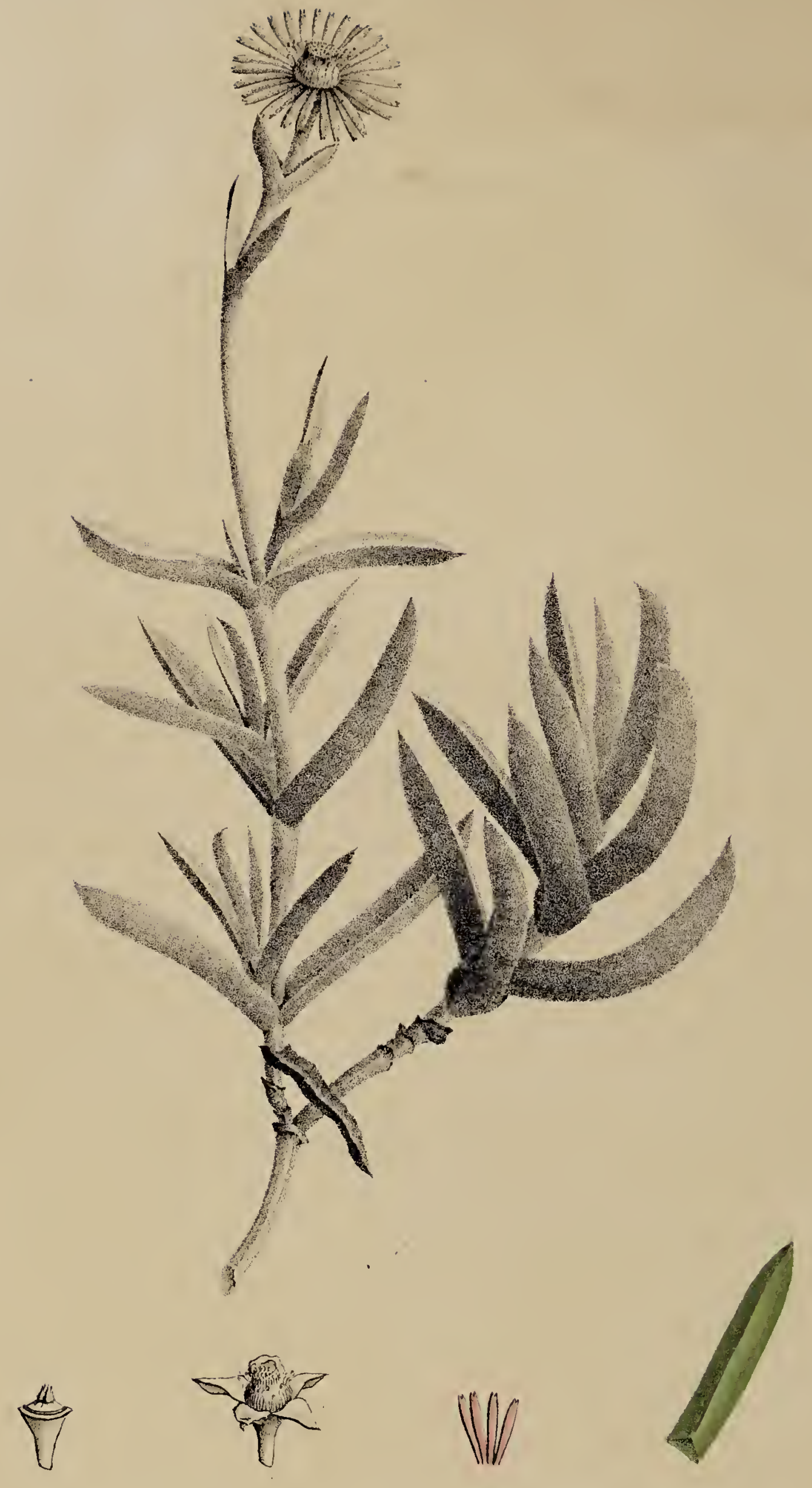

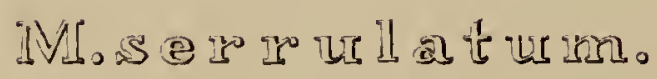

(\$.20. - Fig. 2.) 
(\$. 20. Fig. 2)

\section{MESEMBRYANTHEMUM SERRULATUM Haw.}

MESEMBRYANTHEMUM serrulatum; caule ramoso ramisque erecto-decumbentibus, foliis sulbacinaciformibus crassis glancescenti-viridibus asperiusculis ad margines cartilagineis tenuissime serrulatis, floribus solitariis petalis bidentatis.

M. serrulatum; caule fruticoso juniore erecto, ramis erecto-decumbentibus, foliis compresso-triquetris subacinaciformibus subglaucis internodio saepe longioribus margine minute serrulatis vix cartilagineis, floribus solitariis. DC. Prodr. 3. $p$. $42 s$.

M. servulatum; foliis compresso-triquetris subacinaciformibus subglaucis, margine minime serrnlatis vix cartilagineis, internodio saepius longioribus: ranulis erecto-decunbentibus contiguis. Haur. Reris. p. 11\%.

M. serrulatum; foliis compresso-triquetris marginibus minime sermlatis vix cartilagineis, internodiis saepe longioribus; ramulis purpurascentibus asperiusculis; styli subocto ramentacei. Haw. Synop. p. 23.9. - Ait. Kew. el. 2. Vor. 3. p. 23.9.

RADIX lignosa, ramosa, fibrosa.

CAULIS erectus, teres, lignosus; rami erecti breves vel extensi, erecto-decumbentes, juniores compressi, herbrcei, saepe rubicundi, seniores lignosi cortice cinereo.

FOLIA conferta, comnata, erecto-patentin, incurvula, sesquipollicem longa et lin: F lati, subaequilateri-triquetra, angulo carinuli superne subacinaciformiter produclo, basi intus subpustulata, apice mucronula, gluucescenti-viridia, pellucido-punclata punctis vix prominulis, ad angulos cartilaginea, temissime serrulata.

FLORES solitarii, terminales, merliocres, meridie exponsi, pedunculati. Pedunculus poll: 2 cum dimidio longus, superne bibractertus, bracteis vaginato-comalis, carinatis, acutiusculis cum mucromulo.

CALYX obconicus, quinquefidus; lnciniis tribus triquetris aculis, duabus planiusculis margine membranaceis, quarum una sub apice mucronata.

PETALA biserialia, expansa, subcumeiformia, apice emarginato-bidentala, late purpurea.

S'TAMINA collecta, filumentis sterilibus albis apice roseis circumduta. Filamentu alba. Antherae luteae.

PISTILLUM. Ovarium obconicum, supra comexiusculum. Styli s erecti, crassiusculi, acuti, Ravidi. 
CAPSULA quinqueluculuris; maturam non ridi.

IIabital in Prom. bon. Spei. Floret mensibus Februario et Martio.

Observ. Jom. Masson hane speciem in Angliam advexit versus annum 1795. Planta non florens a $\boldsymbol{M}$. filamentoso vix discernenda est. Folia tamen paulum confertiora et crassiora sunt caulisque erectior; sed flores omnino diversi. Varietas viridior a Cl. Haworth huic speciei tributa non constans se praebet. 



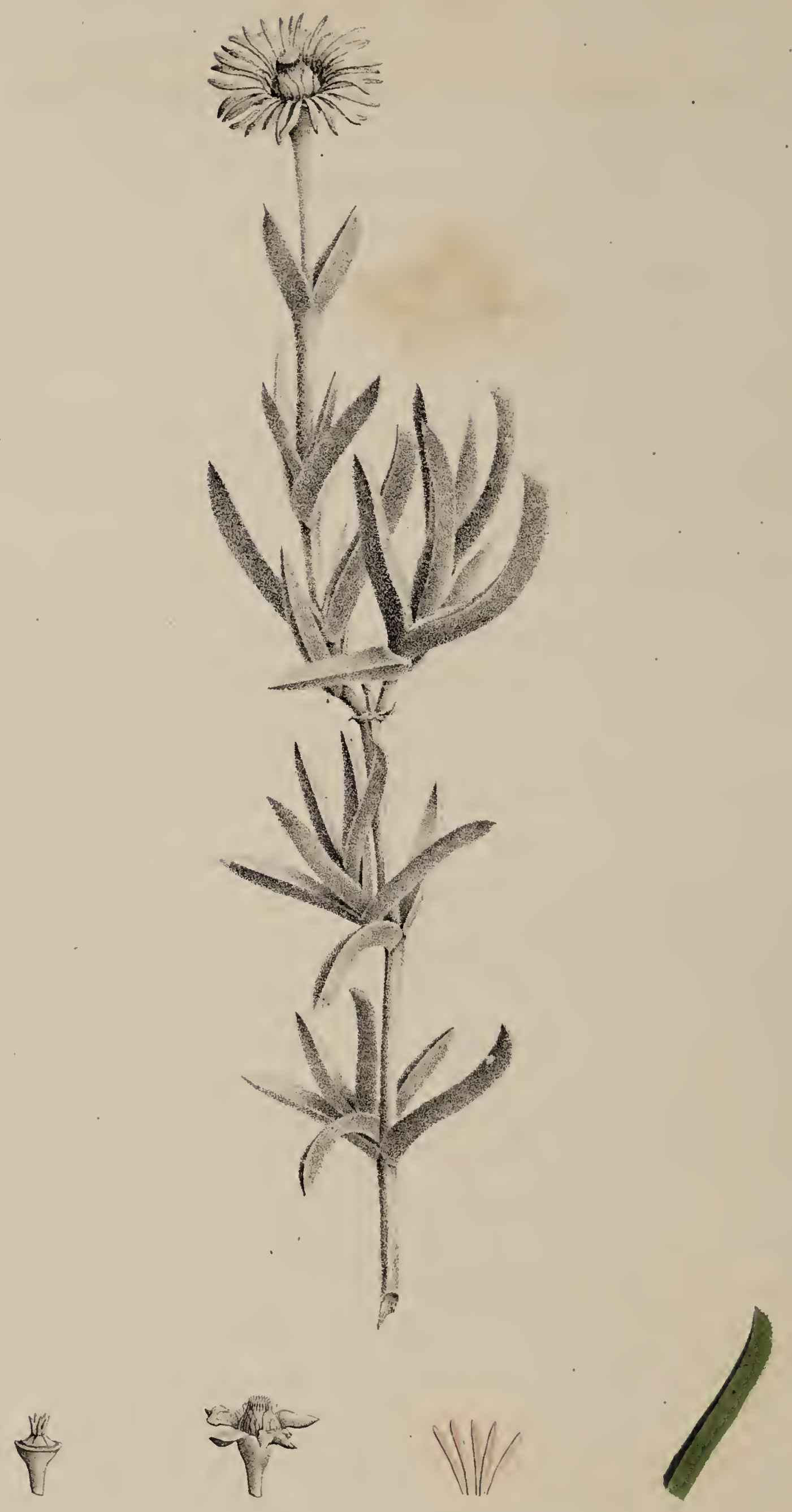

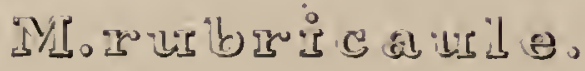

$$
\left(S .20 .-F_{i g} 3 .\right)
$$


(\$. 20. Fig. 3.)

\section{MESEMBRYANTHEMUM RUBRICAULE Haw.}

MESEMBRY ANTHEMUM rubricaule; caule ramoso ramisque erectis saepissime rubicundis, foliis subaequilateri-triquetris incurvulis virescentibus rugosiusculis ad margines cartilagineis serrulatis, floribus solitariis, petalis acutis pallide purpureis nervo centrali saturatiore.

M. rubricaule ; caule fruticoso juniore suberecto, ramulis oppositis subeffusis, foliis compressotriquetris internodio saepe brevioribus ad margines cartilagineis et serrulatis, floribus solitariis, stigmatibus 5 expansis. Dc. Prodr. 3. p. 428.

M. rubricaule; foliis subacinaciformibus marginibus serrulatis, ramis coloratis asperis. spreng. Syst. 2. p. 525.

M. rubricaule; gracilius, foliis subcompresso-triquetris virescentibus rugosiusculis marginibus cartilagineo-serrulatis internodio saepius brevioribus, ramulis oppositis ruberrimis. Haw. Revis. p. 117.

M. rubricaule; foliis compresso-triquetris marginibus cartilagineis serrulatis internodiis saepe brevioribus; ramulis rubris oppositis; stylis 5. Haw. Synop. 1. 239. - Ait. Kew. ed. 2. Vor. 3. p. 240.

\section{$\boldsymbol{R A D I X}$ lignosa, ramosa, fibrosa.}

CAULIS ramique stricti, angulosi, lignosi, juniores compressi rubicundi, seniores cortice albicante.

FOLIA subconferta, connata, erecto-patentia, incurvulu, pollicem ad sesquipollicem longa, et lin. 2-3 basi lata, subuerpuilateri-triquetra, angulo carinali subproducto, basi intus subpustulata, apice mucromulata, glaucescenti-laeteviridia, pellucido-punctata, punctis promimulis, ad angulos cartilaginea, scabrido-serrulata, praesertim angulo carinali.

FLORES solitarii, terminales, mediocres, meridie expansi, pedunculati. Pedunculus fere bipollicaris medio bracteis duabus vaginato-connatis subfolifformibus instructus.

$C A L Y X$ subturbinatus, quinquefidus; laciniis duabus triquetris, acutis, tribus planiusculis margine membranaceis, quarum duae sub apice mucronatae.

PETALA subbiserialia, recurvato-expansa, lanceolata, pallide puerpurea, linea media saturatiore.

STAMINA collecta, filamentis sterilibus albis apice murpureis circumdata. Filamenta allu. Antherae luteae.

PISTILUM. Ovarium obconicum, supra vix comicum. Styli s evecti, crassiusculi, acuti, favidi. 
CAPSULA quinquelocularis; maturam non vidi.

Habitat in Prom. bon. Spei. Floret mensibus Martio et Aprili.

Observ. Versus annum 1802 in Angliam advecta et in hortis frequentissima, facillime discernitur haec species a congeneribus ramis strictioribus laetissime rubicundis. Varietates ambae ei in Revisionibus Cl. Haworthii adscriptae vegetationis casus solum esse videntur. 


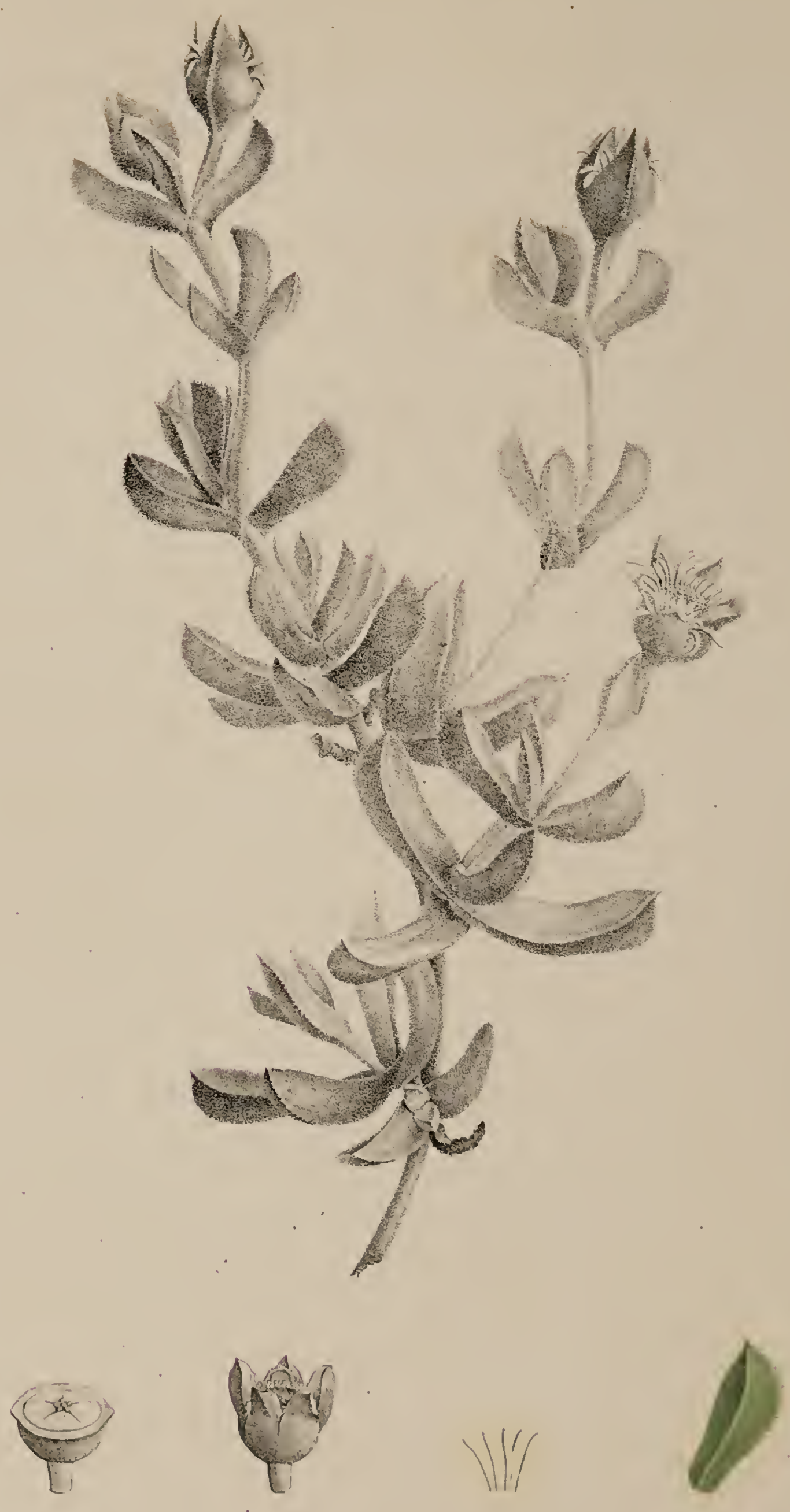

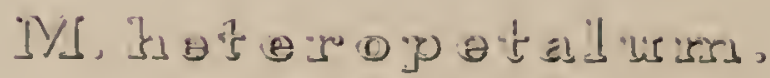

$$
\text { (\$.21. - F. 2.) }
$$


(ङ. 21. Fig. 2.)

\section{MESEMBRYANTHEMUM HETEROPETALUM IIav.}

MESEMBRY ANTHEMUM heter op et a lum; caule ramisque compressis erecto-patulis, foliis glaucis subfalcatis compresso-triquetris angulo carinali producto lacero, corollis inclaudentibus, petalis inaequalibus inconspicuis, laciniis calycinis crassis triquetris erectis.

M. heteropetalum; caule fruticoso brevi, ramis confertis adscendentibus, foliis confertis glaucis compresso-triquetris subacinaciformibus, angulis cartilagineis, carina lacera, petalis inaequalibus calyce magno 5 cornuto brevioribus, stigmatibus 5 brevissimis. DC. Prodr. 3. p. 429.

M. heteropetalon; foliis acinaciformibus subfalcatis glaucis confertis, angulis cartilagineis, carina lacera, petalis inaequalibus calyce magno brevioribus. spreng. Syst. 2. p. 525 .

M. Leteropetalum; foliis confertis impunctatis glaucis breviter falcato-gladiiformibus, angulis cartilagineis, carina lacera; petalis calyce vasto brevioribus. Haw. Revis. p. 132.

M. Leteropetalum; foliis acinaciformi-triquetris connatis, carina cartilagineis serratis glaucescentibus, calycibus quinque cornibus corolla longioribus. Will. Enum. Suppl.p. 36.

M. Leteropetalum; foliis confertis glaucis falcato-acinacifornibus, angulis cartilagineis carina lacera, petalis inaequalibus calyce magno brevioribus. IIaw. Synop. p. 29. Miscel. nat. p. 6\%. - Ait. Kew. ed 2. Vol. 3. 1. 234.

RADIX lignosa, ramosa, fibrosa.

CAULIS erectus, ramosus; rami erecto-patuli, compressi sulffexuosi, primo carnosi virides, dein lignosi corlice badio, senecti corlice fusco-cinereo.

FOLIA in ramis sterilibus conferta, in ramis florenlibus remotiuscula, connatu, erecto-patentia, lin. 12-15 longa, et lin. 4 basi lata, compresso-triguetro, incurvata, angulo carinali superne dilutato, basi interne subpustulata, apice mucromulata, glanca, grosse pancipunctala, ad angulos cartilaginea, angulis lateralibus integerrimis, carinali lacero.

FLORES terminales, inclaudentes, miseri, verisimiliter rite ternali, pedunculati; pedunculo medio semipollicari ebracteato, lateralibus saepe deficientibus bractealis.

CALYX globosus, magmes, compressus, quinquefulus; laciniis crussis, triquelris, erectis nec patentibus, duabus validioribus, tribus paulo brevioribus margine submembranaceis.

PETALA genitalia fere tegentia, inaequalia, diversiformia, interiora brevissima, subulala, exteriora lineari-lanceolata, laciniis calycinis breviora, alba vel pallide rosea. 
STAMINA numerosa, pistillo incumbentia. Filamentu brevissima alba. Antherae luteat.

PISTILLUM. Ovarium globosum, latum, supra valde depressum. Styli quinque subglobosi, parvuli, flavidi.

CAPSULA quinquelocularis; maturum non vidi.

Habitat in Prom. bon. Spei. Floret aestate.

Observ. Species haec a Dom: Masson anno 1794 in Angliam advecta petalis brevissimis laciniisque calycinis, inter anthesin semper erectis, a congeneribus valde differt. Foliis glaucis angulo carinali laceris proxime accedit ad $\boldsymbol{M}$. lacerum. Corolla inconspicua semper aperta remamet. 


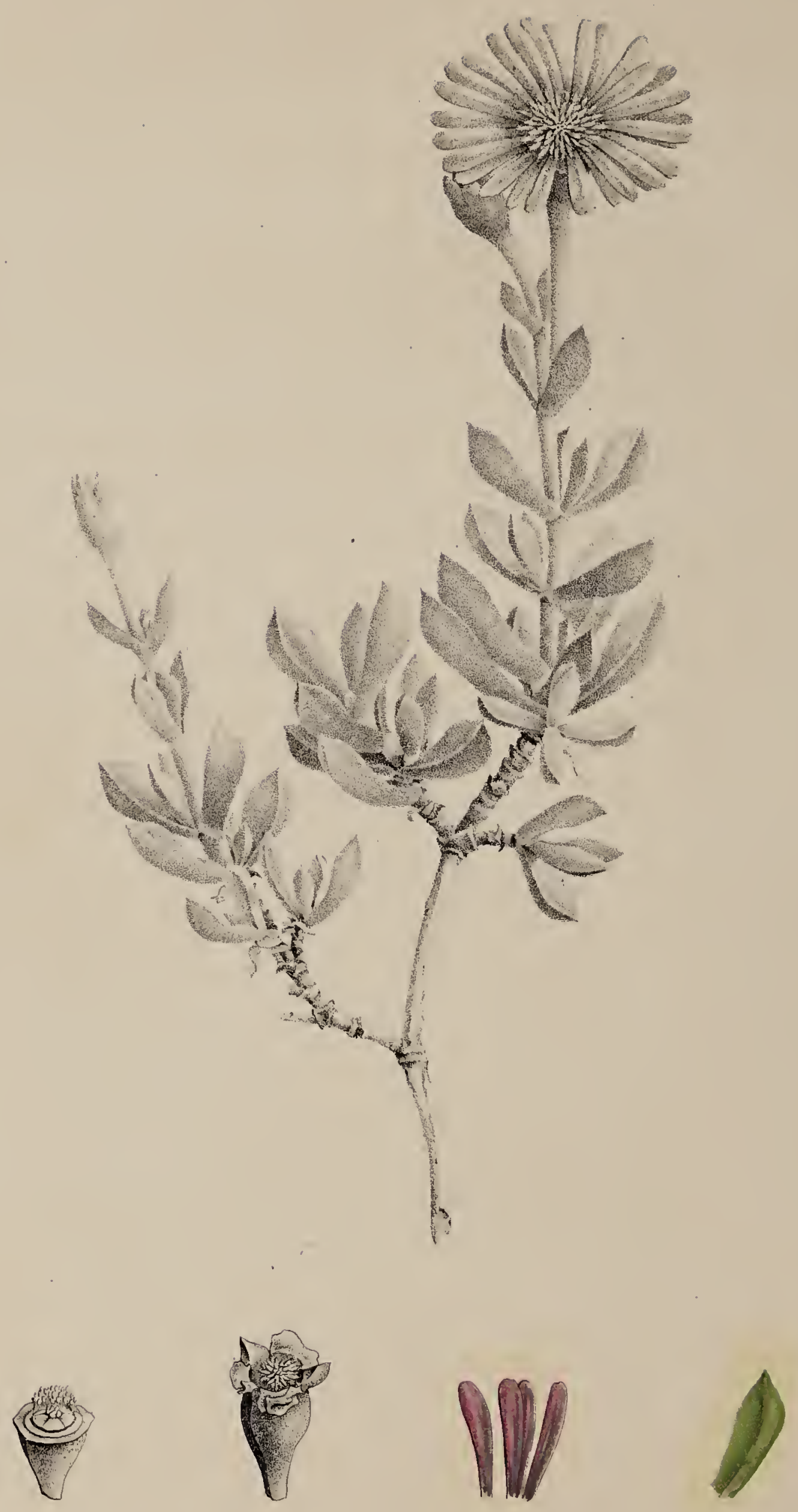

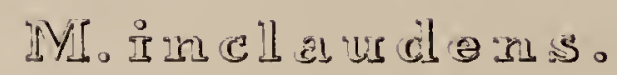

$$
\text { (s.21. - Fig.4.) }
$$


(\$. 21. Fig. 4.)

\section{MESEMBRYAN'THEMUM INCLAUDENS Haw。}

MESEMBRYANTHEMUM inclundens; caule ramoso ramisque tortuosis patulis, foliis perviridibus nitidis acinaciformibus angulo carinali superne gibboso, corollis inclandentibus, petalis inaequalibus, interioribus abbreviatis imbricatis exterioribus subspathulatis radiantibus.

M. inclandens; caule fruticoso, foliis triquetris subdeltoidibus laevibus perviridibus, carina gibbosa crenulata, petalis interioribus valde abbreviatis imbricatisque. Dc. Prodr. 3. p. 430.

M. inclaudens; foliis acinaciformibus triquetris, carina serrata, calycibus scabris punctatis. simeng. Syst. 2. p. 521 .

M. inclaudens; foliis subdeltoidibus laevibus perviridibus, carina gibbosa integra, petalis inclaudentibus, interioribus imbricatis abbreviatissimis. Haw. Revis. p. 133.

M. inclaudeus; foliis triquetris subdeltoidibus laevibus perviridibus, carina gibbosa, corollis inclaudentibus, petalis interioribus valde abbreviatis imbricatisque. Iaw. Bot. Reposit. Vol. 6. t. 388. synor. p. 295.

RADIX lignosa, ramosa, fibrosa.

CAULIS erectus, ramosus; rami juniores erecti, compressi, cortice mimo rubicundo dein badio, seniores tortuosi, deflexo-patentes, teretes, cortice fusco-cinereo.

FOLIA conferta, subcomnata, erecto-patentia, lin. 7-8 longa, et lin. 2-3 basi lata, compressa-triquetra, retuse acinaciformia, angulo carinali superne valde dilatato, integerrimo ant vix scabrido, apice acutinscula, laevissima, nitida, perviridia, grosse pancipunctata, ard angulos basi et apice saepissime rubicunda.

HLORES terminales, inclaudentes, speciosi, verisimiliter rite ternali, pedunculati; perhunculo medio subsesquipollicari, superne incrassato, ebracteato, lateralibus uno rilterore saepe deficiente, bracteatis.

CALYX turbinutus, compressus, quinquefidus; laciniis putentibus, dunbus triquetris, tribus planinsculis margine membranaceis.

PETALA genitalia omnino tegentin, inaequalia, diversiformia, interiora angustissima valde ablreviata, stellatim imbricantia, exteriora lata, semipollicem et ultra longa, linertrisprathalatu, apice oblusa, erosula, recurvato-expansa, parpurea.

S'IAMINA pistillo incumbentia. Filnmenta brevissima, alba, basi mupurea. Antherae luteae. 
PISTILLUM. Ovarium obconicum supra valde depressum. Styli 5 brevissimi, erecti, crassiusculi, acuti, favidi.

CAPSULA quinquelocularis; maturam non vidi.

Habitat in Prom. bon. Spei. Floret aestate, copiosissime.

Observ. Haec pulcherrima et species hodie vulgatissima, amno 1805 in Angliam advecta, a Cl. Haworth primo in Bot. Repos. descripta est. A congeneribus foliis subdeltoideoacinaciformibus perviridibus, petalisque radiantibus latissinis intense purpureis omnino recedit. 



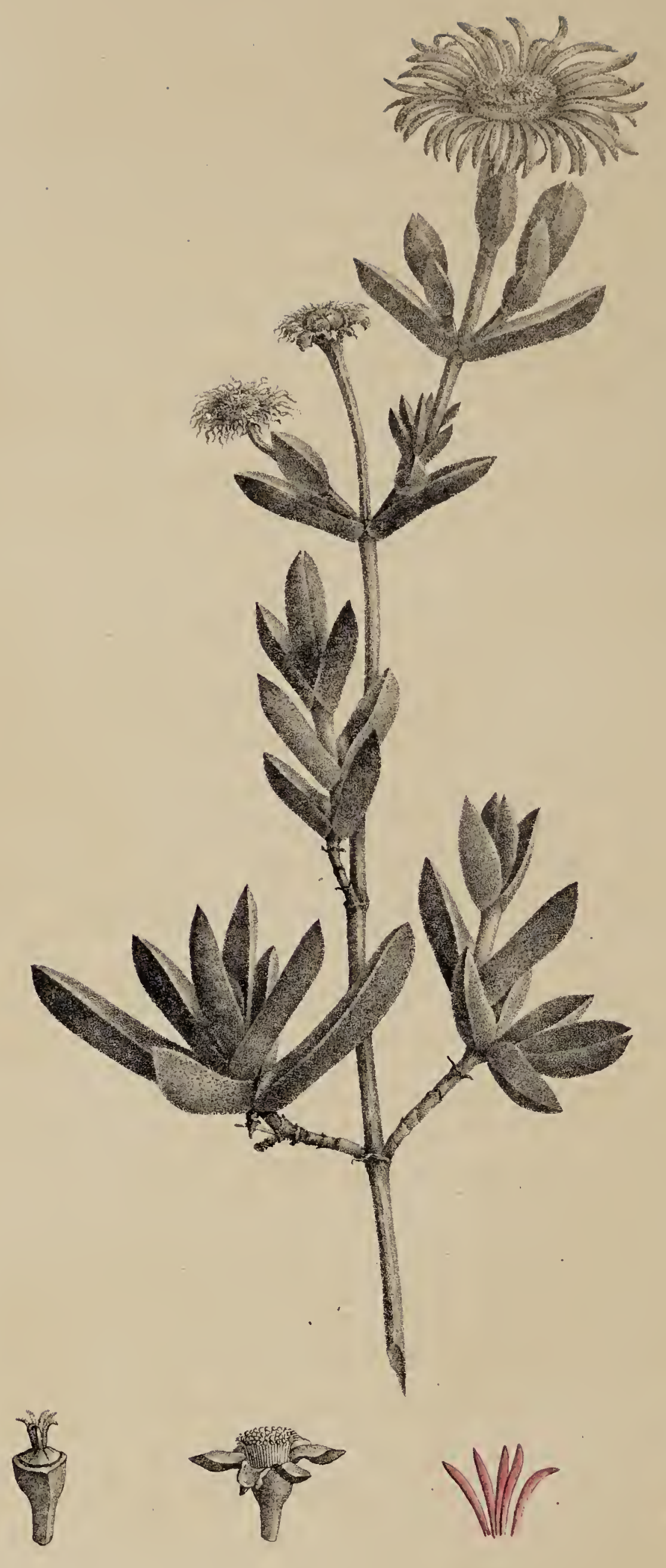

l

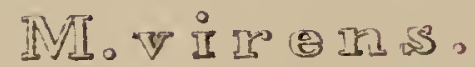

(S.24. Fig.1) 
(\$. 24. Fig. 1.)

\section{MESEMBRYANTHEMUM VIRENS Haw.}

MESEMBRYANTHEMUM virens; caule suffuticoso elato subramoso, ramis erectopatulis, foliis remotis compresso-triquetris basi interne pustulatis perviridibus laevibus, floribus teruatim dispositis hexagynis, calyce sexfido.

M. virens; canle suberecto, ramis demum patentibus, foliis compresso-triquetris subacinaciformibus laevibus viridibus, basi interne pustulatis, carina apice asperiuscula. $D C$. Prodr. 3. p. 429.

M. virens; foliis compresso-triquetris subacinaciformibus laevibus punctatis viridibus, basi interne subpustulatis, carina apice asperiuscula. Haw. Reris. $\mathbf{p} .121$.

\section{RADIX lignosa, ramosa, fibrosa.}

CAULIS elatus, debilis, superne ramosus, rami pauci, erecto-patuli, juniores compressi, primo herbacei, dein cortice ferrugineo, seniores teretes cortice cinereo.

FOLIA in ramis enascentibus conferta, in ramis adultis remota, subcomata, erectopatentia, lin. 12-15 longa, et lin. 3 lata, basi interne pustulata, compresso-triquetra, obtusiuscula cum mucronulo, multipunclala, perviridia, laevia, ad angulos integerrima.

FLORES terminales, rite ternatim disposili, pedunculati; pedunculo centrali pollicari saepe ebracteato, lateralibus uno alterove saepe deficiente, medio bracteatis, bracteis crassis valde corinatis.

CALYX subturbinatus, subcompressus, sexfidus, laciniis patentibus duabus carinatotriquetris, quatuor planiusculis margine membranaceis, quarum duae sub apice mucronatae.

PETALA laciniis calycinis duplo longiora, biserialia, irregulariter recurvato-expansa, lineari-lanceoluta, pallide purpurea, nervo centrali marginibusque saturatioribus.

STAMINA conferta, filanentis sterilibus albis apice purpurascentibus circumdala. Filamentu alba. Antherue favidae.

PISTILLUM. Ovarium subturbinatum, supra vix conicum. Styli 6 erecti, filiformes, apice recurvuli, subramenlacei, favidi.

CAPSULA sexlocularis; matur(un non vidi.

Habitat in Prom. bon. Spèi. Floret mense Majo et quandoque mense Octobri.

Observ. Haec species, anno 1821 in Horto Kewensi e seminibus Capensibus orta, nulli sectioni adscribenda est. A sectione Acinaciformium ounino recedit caule erecto nec prostrato, floribusque ternatim dispositis; hocce ultimo caractere etian a sectionibus Bracteatorum et Virgatorum differt, quibus caeterum multo magis affinis est, et Sectionem propriam ergo constituere debet. Varietas minor huic speciei primo tributa non constans se praebuit. 




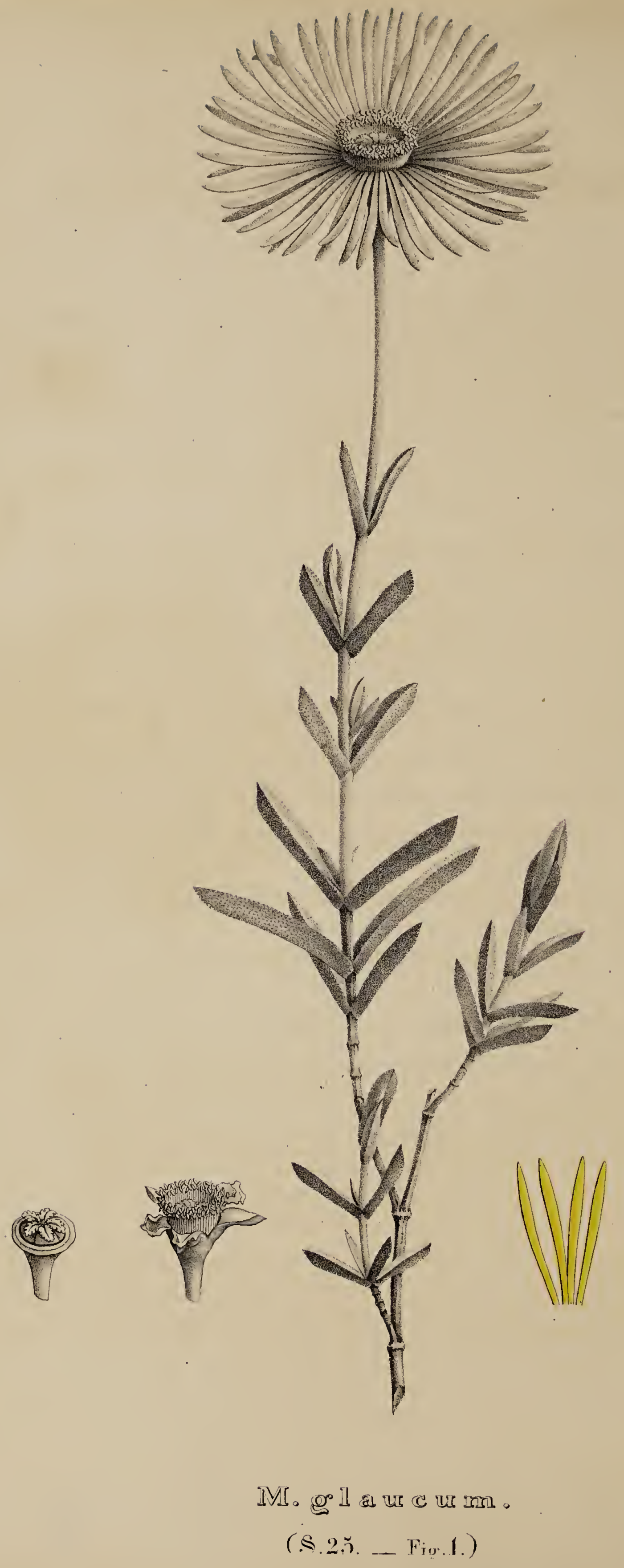


(\$. 25. Fig. 1 )

\section{MESEMBRYANTHEMUM GLAUCUM Lin.}

MESEMBRYANTHEMUM glaucum; caule suffruticoso ramisque subcompressis erectis strictis, foliis subconnatis compresso-triquetris obtusiusculis cum mucronulo glancis aspero-punctatis angulo carinali scabrido, flore amplo sulphureo.

M. glaucum; caule suffruticoso erecto foliis triquetris valde compressis glaucis scabriusculis, calycis lobis ovato-cordatis, stigmatibus luteis. DC. Prodr. 3. p. 437.

M. glaucum; foliis triquetris acutis compressis glaucis aspero-punctatis, laciniis calycis cordato-ovatis, floribus sulphureis. Spreng. Syst. 2. p. 522.

M. glaucum; foliis acute triquetris praecompressis glaucis scabriusculis; calycinis foliolis ovato-cordatis; petalis sulphureis, pistillis luteis. Haw. Revis. p. 148.

M. glaucum; foliis triquetris valde compressis glaucis subscabris, foliolis calycinis ovatocordatis, petalis subdistantibus sulphureis, pistillis luteis. Haw. Synop. p. 264. Miscel. nat. p. 83. - Ait. Kew. ed. 2. vol. 3. p. 243.

M. glaucum; foliis triquetris acutis punctatis distinctis, calycinis foliolis ovato-cordatis. Lin. Spec. pl. p. 696. Hort. Cliff. p. 220. - Roy. Lugd. p. 183. - Mill. Dict. Nr. 34. - Lam. Encycl. Nr. 39. — Willd. Sp. pl. 2. p. 1018. - Ait. Kew. ed. 1. vol. 2. p. 192. - DC. Pl. succ. t. 146.

M. scabrum, flore sulphureo Convexo. Dill. Elth. p. 2566. t. 196. Fig. 248.

Ficoides africana frutescens, folio triangulari breviori glauco. Moris. Hist. 3. p. 507. t. 6. Fig. 3.

Ficoides afra, caule lignoso erecto, folio triangulari ensiformi scabro, flore luteo magno. Bradl. Succ. 4. p. 15. t. 37.

B. tortuosum; foliis minoribus ramisque gracilioribus tortnosis.

\section{$\boldsymbol{R A D I X}$ lignosa, ramosa, fibrosa.}

CAULIS erectus, strictus, (in var. B. gracilior et tortuosus,) bispedalis et ultra, ranosus; rami sparsi, erecti, subcompressi, cortice primo ferrugineo, dein cinereo.

FOLIA subcomferta, basi.vix connata, erecto-patentia, compresso-triquetra, lin. 9-15 longa, et lin. 3 lata, (in var. B. lin. 6-9 longa, et lineam lata,) latere supero angustiore, luete viridia, rore glauco obducta, pellucide punctata, punctis prominulis, angulo carinali apicem versus subproducto, cartilagineo-serrulata, obtusa cum mucronulo.

FEORES terminales, solitarii, diametro bipollicari et ultra, meridie expansi, longe pedunculati. Pedunculus poll. 2 cum dimidio longus, teres, superne incrassatus, nudus.

CALYX turbinatus, quinquefidus; laciniis latis, tribus planiusculis margine membranaceis duabus carinatis acutis. 
PETALA subbiserialia, expansa, anguste lanceolata, acutiuscula, sulphurea.

STAMINA erecta, conferta. Filamenta lutea. Antherae flavae.

PISTILLUM. Ovarium turbinatum, supra convexum. Stigmata 5 patentissima, latiuscula, eroso-ramentacea, flavida.

CAPSULA quinquelocularis, obconica.

Habitat in Prom. bon. Spei. Floret aestate.

Observ. Haec vulgatissima species jam amo 1696 in Anglia culta erat. Cum M. eduli et bicoloro ad antiquissinas pertinet quae lodie in hortis nostris vigent. Varietas tortuosa propter ramulos gracillimos et valde tortuosos praesingularis est, sed hucusque non floruit. 


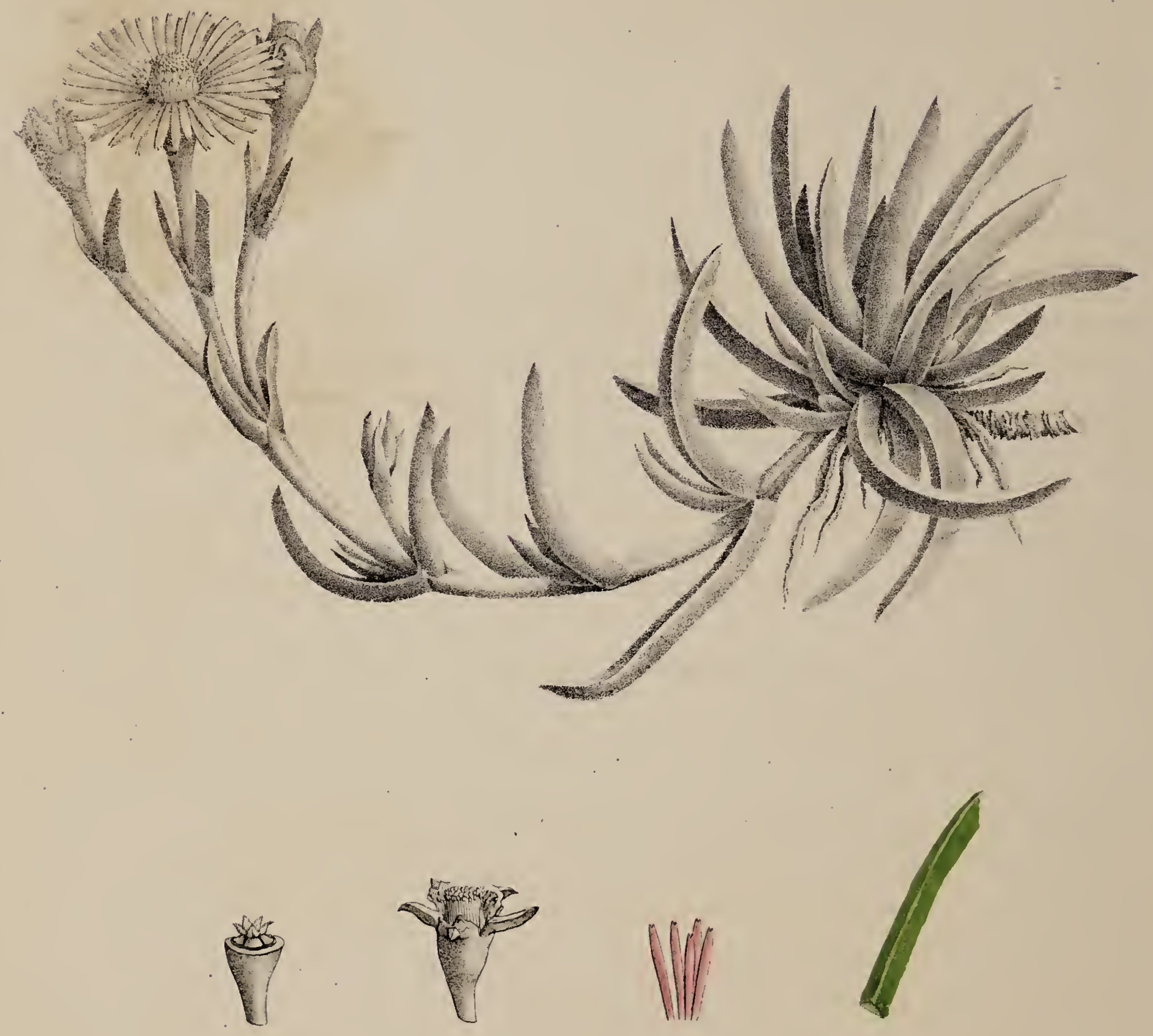

MJ.

$$
\text { (\$.27. - Fig. 4.) }
$$




\section{MESEMBRYANTHEMUM FORMOSUM Haw.}

MESEMBRYANTHEMUM formosum; caule suffruticoso ramuloso, ramulis sterilibus brevibus, floriferis elongatis adscendentibus, foliis confertis subdistinctis incurvopatentibus triquetris elongatis mucronatis, viridibus; floribus purpureis bigeminatim termatimve dispositis.

M. formosum; caulibus suffruticosis humilibus, ramis floriferis subdecumbentibus elongatis, foliis triquetris longis viridibus ad solem micantibus confertissimis, in ramis remotioribus floribus terminalibus ternatim dispositis, stigmatibus 5-6 filamentis brevioribus sublanceolatis. DC. Prodr. 3.p. 436.

M. formosum; lumile: foliis viridibus ad solem micantibus ramulisque confertissimis; caulibus floriferis decumbentibus. Haw. Revis. p. $\mathbf{1 4 5}$.

\section{RADIX lignosa, ramosa, fibrosa.}

CAULIS a basi ramosissimus, ramulique lignosi, conferti, foliorum rudimentis desiccatis onusti, apice foliosi, floriferi elongati, adscendentes, corlice laevi badio.

FOLIA capitatim conferta, in ramis floriferis remota, vix basi connata, incurvatoerectu, poll: 2 longa, et basi lin: 3 lala, sensim attenuata, triquetro-compressa, carinata, obtusiuscula cum mucronulo purpurascente, punctata, laevia, integerrima, viridia, ad solem micantia.

FLORES in rumis floriferis terminules, amöni, abortu saepe ternati, sed rite bigeminati cum intermedio tertio, et luxuriante planta quandoque quarto, pedunculati, meridie expansi. Pedunculi basi et medio bracteati, compressi, adscendentes, rigidi, pollicem vel sesquipollicem longi.

CALYX sublurbinatus quinquefidus, laciniis subaequalibus, duabus carnosis acutis, tribus planiusculis margine membranaceis.

PETALA subtriserialia, lineari-lanceoluta, apice bidentata, patentissima, lin: 6-7 longa, splendide purpuren.

STAMINA mumerosa, conferta, erectu. Filamenta alba. Antherae pallidae.

PISTILLUM. Ovarium subturbinatum, supra convexiusculum. Styli 5 erectoputuli, crassiusculi, acuti, ramentacei, lutescentes, filamentis dimidio breviorilnus.

CAPSULA quinquelocularis, obconica.

Habibat in Prom. bon. Spei. Floret mense Augusto.

observ. Haec species e seminibus Capensibus in horto Kewensi enata, ibi anno 1820 primo floruit. Accedit ad $\boldsymbol{M}$. amoenum colore foliorum perviridi; sed differt ramis florentibus prostratis. A. M. spectabile, cui statura et habitu proxima, differt floribus minoribus, aliter dispositis, brevius pedunculatis, coloreque foliorum nullo modo glaucescente. 



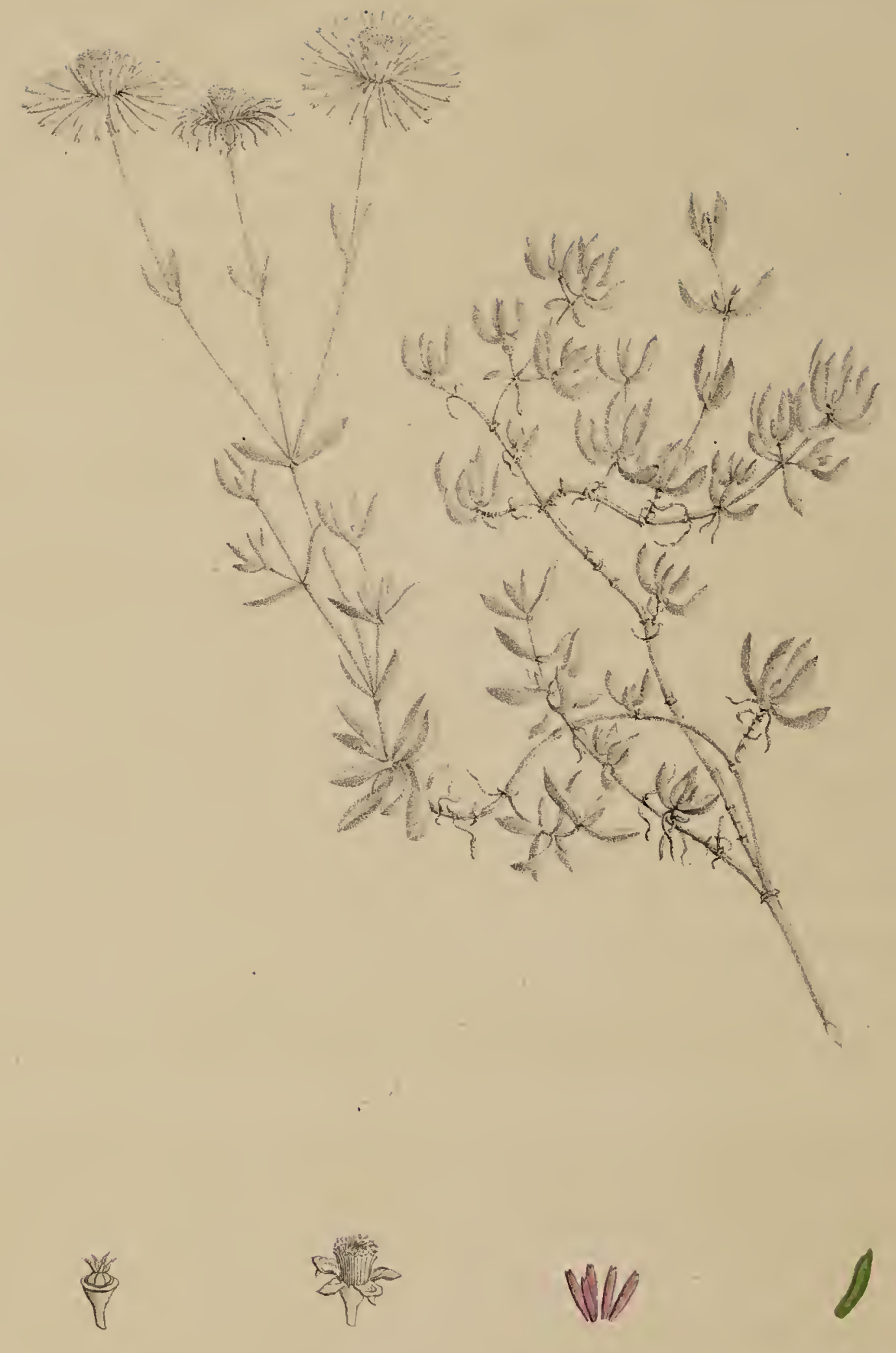

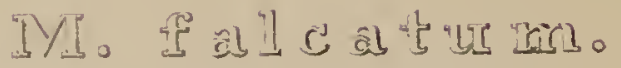

$$
(\$ .29 .-1 \mathrm{ig} .2)
$$


(ङ. 29. Fig. 2.)

\section{MESEMBRYANTHEMUM FALCATUM Lim.}

MESEMBRY ANTHEMUM falcatum; caule suffiticoso erecto ramosissimo, ramulis divaricatis filiformibus, foliis minutis confertis subtriquetro-compressis arcuatim illcurvatis utrinque atlenuatis glaucis grosse pellucido-punctatis.

M. falcatum; caule lignoso erecto, ramis numerosis paniculatis filiformibus, foliis minutis distinctis compresso-triquetris falcatis subglaucis. DC. Prodr. 3. p. 433.

M. falc atum; foliis subfalcatis minutis glaucis basi attenuatis punctatis, ramis teretibus, floribus paniculatis. spreng. Syst. 2. p. 525.

M. falcatum; foliis minutis distinctis compresso-triquetris falcatis; ramulis numerosis filiformibus. Haw. Revis. p. 136.

M. Falcalum; foliis minutis distinctis perglaucis falcatis compresso-triquetris, ranulis numerosis filiformibus. Haw. Synop. p. 298. - Ait. Kew. ed. 2. vol. 3. p. 236.

M. falc atum; foliis subacinaciformibus incurvis punctatis distinctis, ramis teretibus. Lin. Spec. pl. 694. Hort. Cliff. p. 219. Nr. 19. - Roy. Lugdb. 285. - Knorr. Del. 2. t. M. 4.

M. falcatum minimum, flore purpureo parvo. Dill. Eith. 288. t. 213. Fig. 275 et 276.

Ficoides afra, folio triangulari ensiformi brevissimo, flore dilute purpurascente filamentoso. Boerh. Lugdb. 1. p. 290. - Bradl. Succ. 5. p. 9. 1. 42.

RADIX lignosa, ramosa, fibrosa.

CAULIS suberectus, flexuosus, lignosus, rigidus, ramosissimus. Rımi divaricuti, tortuosi, compressi, apice carnosuli viridiusculi, dein ocluracei, cortice in senectis brunnercinereo.

FOLIA in rumulis confertissima, juniora vix connata, seniora distincta, parvula, falciformiter incurvatu, vix subtriquetro-compressa, angulis rotundatis, lin. 2-3 longa, et lineam lata, utrinque attenuata, in mucronulum saepe rubentem exeuntia, glauco-viridia, punclis quibusdam validis instrucla.

FLORES terminales, rite ternati, sed obortu quandoque gemini aut solitarii, meridie expansi, longe pedunculali, fragrantes. Pedicelli tenuissimi, superne subincrussali, sesquipollicares, laterales bracleati, medius saepe bibracteatus, bracteis parvulis foliiformilus.

CALYX turbinatus, quinquefidus, laciniis subaequalibus, tribus aculis foliiformilus, duubus margine membrancaceis sub apice mucronatis.

PETALA biserialia, patentissima, latiuscula, apice bidentata, laele rubicundu.

STAMINA collecta, erecta. Filamenta rosea. Antherue favae. 
PISTILUM. Ovarium turbinatum, supra conrexum. Styli 5 subulati, erectorecurvuli, lutescentes, longitudine filamentorum.

CAPSULA quinquelocularis obconica.

Habitat in Prom. bon. Spei. Floret aestate.

Observ. Tempore Dillenii jam culta haec species in hortis frequenter occurrit, at saepe non bene agnita est. Nomen revera sat inproprium, et folia minutissima, carnosula, incurvati, potius teretiuscula quam triquetra, non recte falcata vocari possunt. A praecedente omnino differt ramis foliisque gracilioribus, flores quoque sunt multo minores, sed Crataegi Oxyacanthae odorem similiter spirant. 



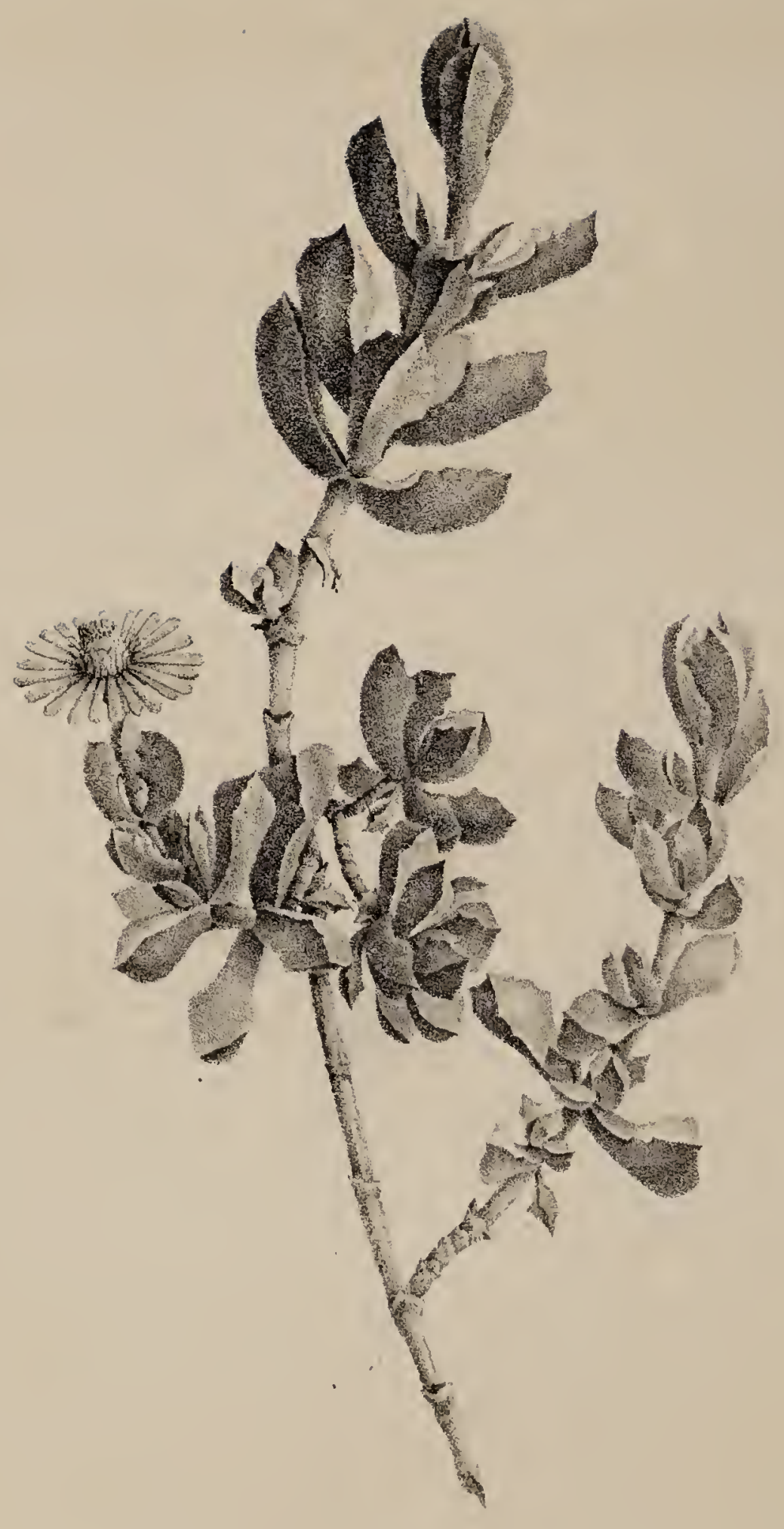

\&
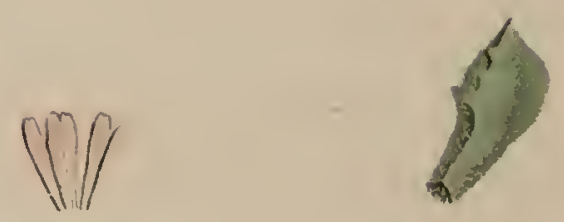

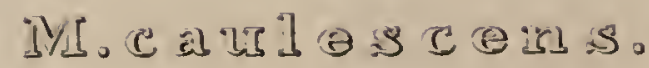

$$
\text { (\$.j0. - Fig. 1.) }
$$


(\$. 30. Fig. 1.)

\section{MESEMBRYANTHEMUM CAULESCENS Mill.}

MESEMBRYANTHEMUM caulescens; caule subramoso erecto, foliis incurvatoerectis confertis glaucis superne deltoideo-dilatatis acutiusculis, lateribus obtuse dentatis, carina integra, petalis obtusis emarginatis.

M. caulescens; caule erecto ramoso, foliis confertissimis glaucis longe triquetro-deltoidibus, lateribus minime dentatis, carina integra. Dc. proutr. 3 p. 432.

M. c a ulescens; foliis deltoideis confertis glaucis, lateribus denticulatis, carina integerrima. Spreng. Syst. 2 p. 525.

M. caulescens; foliis confertissimis glaucis longe triquetro-deltoidibus, lateribus minime dentatis, carina integra. IIw. Reris. p. 133.

M. caulescens; foliis perglaucis confertis triquetro-deltoidibus, lateribus minime dentatis, carina integra. Haw. Synop. p. 296.

M. deltoides; $\beta$. simplex, angulo carinali integro. nc. Pl. grass. No. 53.

M. caulescens; foliis perglaucis confertis deltoidibus triquetris, lateribus minute dentatis, angulo carinali integro. Haw. Miscel. nat. \%. \%1. - Ait. Kew. ed. 2. vol. 3 p. 237.

M. caulescens; foliis deltoidibus, lateribus minime dentatis. Mill. Dict. No. 12.

M. deltoides y. non dorso sed lateribus muricatis. Dill. Ellh. t. 195. Fig. 143 et 114. - Lin. Sp. m. ed mior p. 482. - Ait. Kew. ed. 1 e'ol. 2 p. 183. - Willd spec. pl. 2. p. 1052.

RADIX lignosa, ramosa, fibrosa.

CAULIS erectus, subramosus, pedalis et ullra ramique suberecti, lignosi, densi, cicatrisali, cortice brumeo-cinerascente.

FOLIA comata, conferta, lin. 6-9 longa, basi expansa usque ad medium fere subsemicylindracen et lin. 2 lala, superne incurvata briquetro-dilatata et lin. A lata, apice aculiuscula, glauca, impunclata, angulis lateralibus bi-vel tridentatis, dentibus grossis obtusis, angulo carinali producto integerrimo, omnibus saepissime mubro marginalis.

FLORES terminales rile ternatim disposili, meridie expansi, fragrantes, pedicellali. Pedicelli vix lin. 4 longi, superne incrassati, bibracleati, in pedunculum communem incidentes. Bracleae parrulae foliiformes.

CALYX subturbinatus, in pedicellum altemualus, quinquefidus; laciniis longihudine subaequalibus, duabus triquetro-aculis, tribus margine membranaceis sub apice mucromulatis.

PE'TALA uniserialia, subspathulata, oblusa, apice erosula, pallide rosea.

S'TAMINA collecta, filamentis sterilibus quibusdam circumdata. Filamenta albida. Antherae flavale. 
PISTILLUM. Ovarium turbinato-obconicum, supra convexum. Stigmata 5 erecto-recurvata, subulata, subramentacea.

CAPSULA quinquelocularis, obconica, convexiuscula.

Habitat in Prom. bon. Spei. Floret mense Junio.

Observ. Haec planta cun duabus sequentibus Dillenii temporibus jam culta, foliis carina integerrimis petalisque obtusis facile agnoscitur, et pro genuina specie propter haece discrimina habenda est. Folia quoque arcuato-incurvata minus sunt deltoideoretusa, et transitionem bonam praebent a $M$. falcatis ad deltoidea. 
4. 


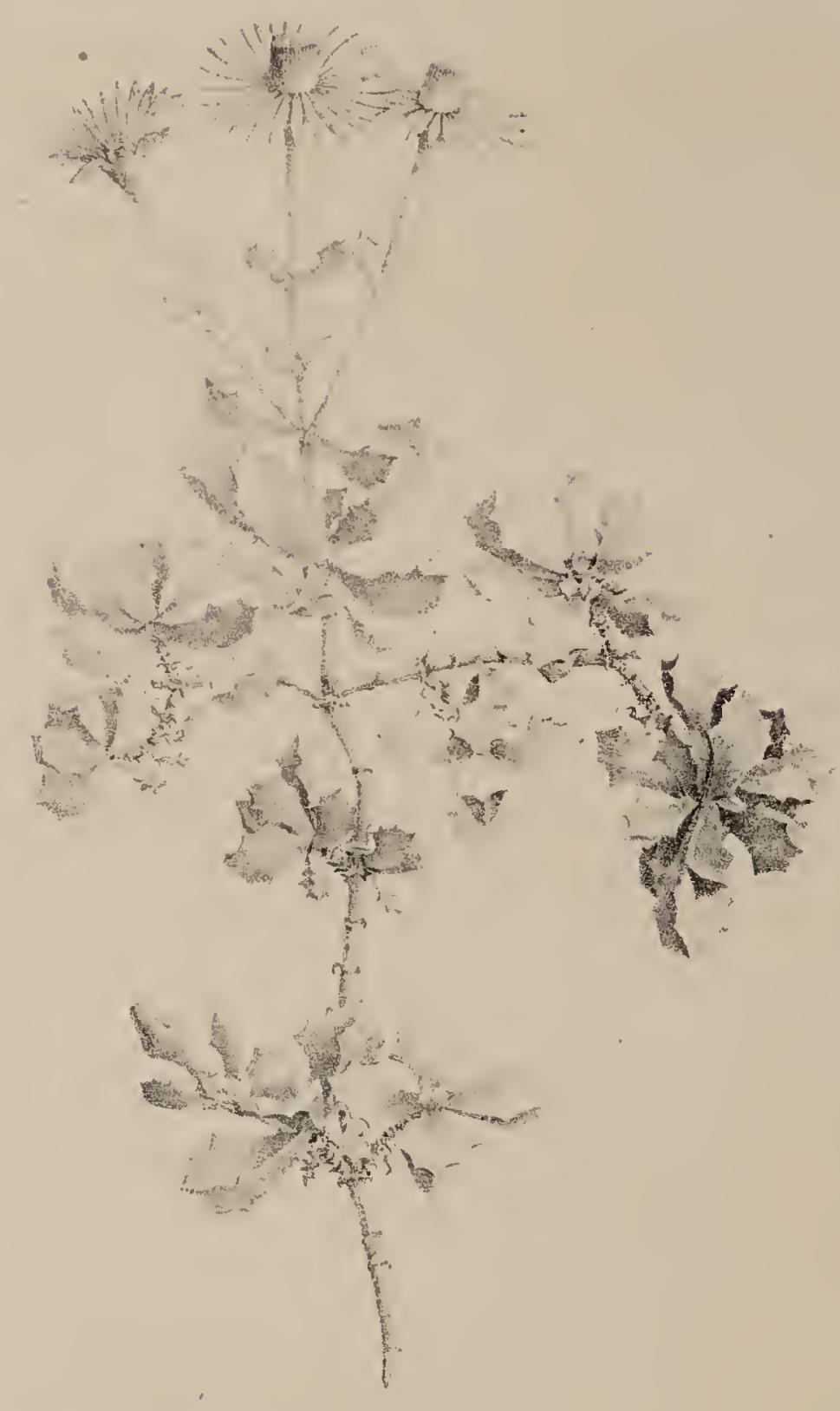

2

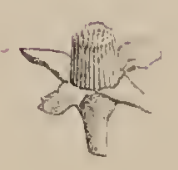

Wif

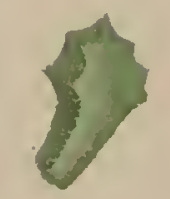

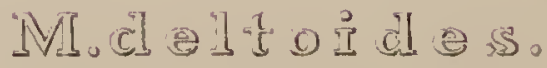

$$
\left(\$ .30 .-\mathrm{Fig}_{2}\right)
$$


(\$. 30. Fig. 2)

\section{MESEMBRYANTHEMUM DELTOIDES Mill.}

MESEMBRY ANTHEMUM delt oides; caule suberecto ramis divaricatis, foliis incurvatoerectis confertis glaucis deltoidibus trifariam grosse dentatis, pedunculis elongatis, petalis acutis.

M. deltoides; caule erecto ramoso, foliis confertis glaucissimis triquetris deltoidibus trifarian dentatis, carinis bractearum calycisque loborum integris. Dc. Prodr. 3. $p$. 433.

M. deltoides; foliis deltoideis confertis glaucis, lateribus carinaque dentatis, carina bractearum calycisque laciniis integerrimis. spreng. Syst. 2. p. 525.

M. deltoides; foliis confertis glaucissimis triquetro-deltoidibus trifarie dentatis; carina bractearum foliolisque calycinis integerrimis. Haw. Revis. p. 133.

M. deltoides; foliis glaucissimis confertis triquetro-delloidibus, lateribus carinaque dentatis, carina bractearum foliolisque calycinis integris. Haw. Synop. p. 296. Miscel. nat. p. 74. - Ait. Kew. ed. 2. vol. 3. p. 238.

M. deltoides triplex, angulis tribus dentatis. DC. Pl. grass. $\begin{gathered}53 . \\ \text {. }\end{gathered}$

M. detoides $\beta$. et dorso et lateribus muricatis majus. Dill. Eulh. t. 195. Fig. 245. - Linn. Spec. Pl. ed. prior 2. p. 482. - Mill. Dict. n. 11. - Ait. Kew. ed. 1. eol 2. p. 183. - Will. Spec. pl. 2. p. 1052.

RADIX lignosa, ramosa, fibrosa.

CAULIS suberectus, ramosus, pedalis el ultra ramique divaricato-patentes, lignosi, dhri, cicatrisati, corlice brunne»-cinerascente.

FOLIA connata, conferta, lin. 5-7 longa, basi expansa usque ad medium fere semicylindracea et sesquilineam lata, superne incurvata triquetro-dilatata et deltoideo-retusa lin. 4 lata, glauca, impunctata, angulis omnibus tridentatis, dentibus acutis suepe purpurascentibus.

FLORES terminales, rite ternatim aut biternatim dispositi, meridie expansi, frayrantes, pedicellati. Pedicelli in plantis junioribus pollicem longi, superne incrassati, bibracteati, in pedunculum communem incidentes. Bracleae parvulce foliiformes.

$\boldsymbol{C A L Y X}$ subturbinatus, in pedicellum attenuctus, quinquefidus; laciniis longitudine subbequalibus, dualus triquetro-acutis, tribus margine membranaceis sub apice mucronulatis.

PETALA uniserialia, lanceolata, acuta, patentia, rosea.

STAMINA collecta. Filamenta rosea. Antherae favae.

PISTILLUM. Ovarium obconicum, supra convexiusculum. Stigmata 5 erecta, subulata, flavescentia. 
CAPSULA quinquelocularis, obconica, convexiuscula.

Habitat in Prom. bon. Spei. Floret mense Julio.

Observ. Huic speciei nomen $\boldsymbol{M}$. deltoidis remansit. A praecedente omnino recedit floribus Ionge pedicellatis, petalis acutis, foliisque trifariam dentatis; sed valde accedit ad sequentem, a quo tamen, praesertim in plantis junioribus, floribus longius pedicellatis differt. Discrimen ergo parvum, et pro mera varietate haberi potuerit haec planta; sed quia in hortis frequens et generaliter pro specie recepta est, ei nomen $M$. delloidis servare volui. 



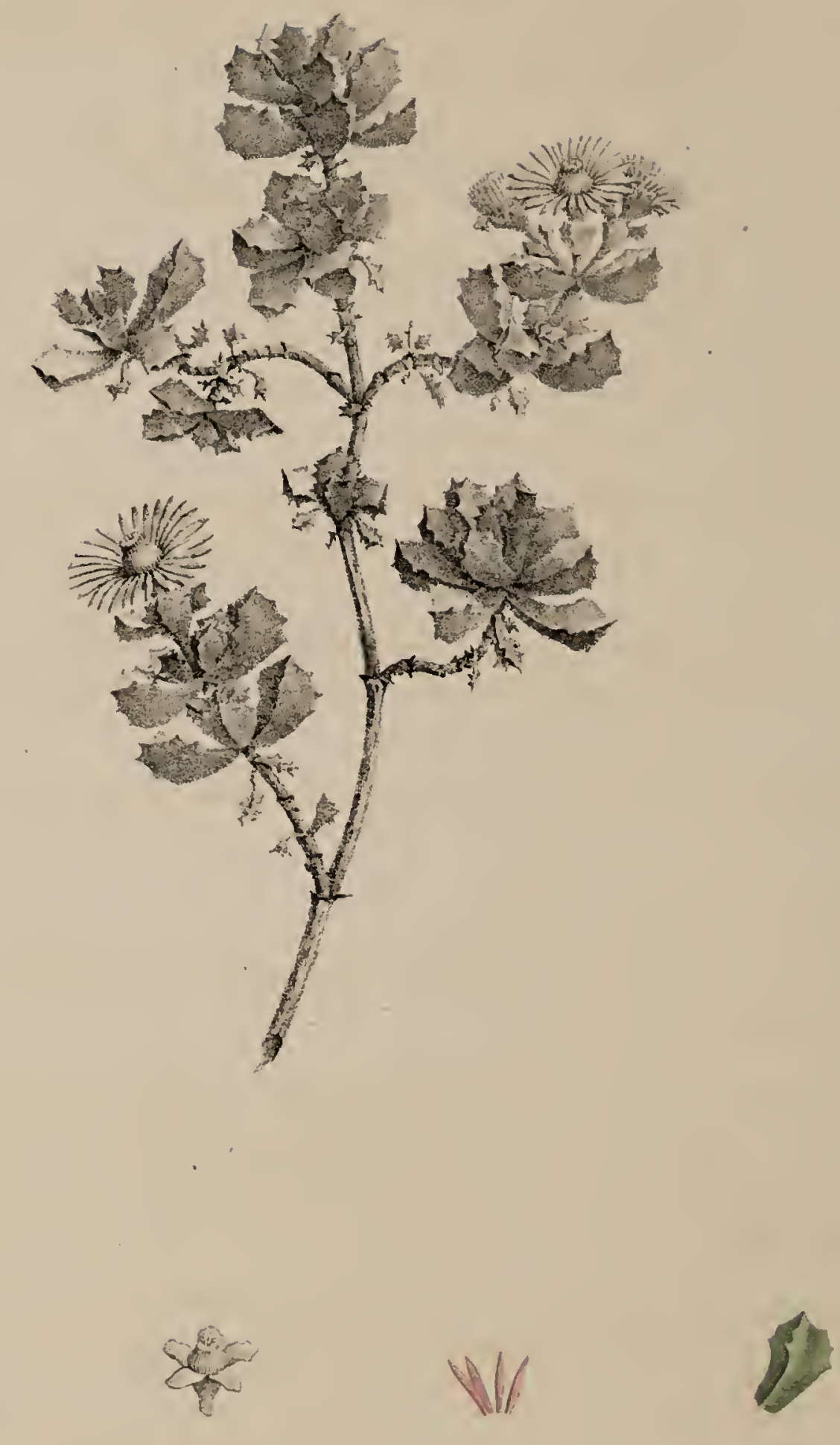

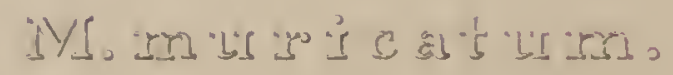

$(3.50 .-\operatorname{lig} .5)$ 


\section{MESEMBRYANTHEMUM IURICATUM Hä。}

MESEMBRYANTHE_HUM mur ic atum; caule ramulisque tortnosis, foliis patentibus confertissimis coerulescenti-glaucis deltoideo-retusis trifariam muricatodentatis, pedunculis brevibns, petalis acutis.

M. muricatum; canle erecto ramoso, foliis confertis deltoidibus subglancis cum bracteis et calycis lobis trifarie denticulatis. DC. Prod. 3. p. 133.

M. muric atum; foliis deltoideis coufertissimis, lateribus, carina foliorum calycibusque denticulatis. simeng. syst. 2. p. 525.

M. muric atum; foliis confertis deltoidibus bracteis foliolisqne calycinis triqnetris subglancis trifarie denticulatis Haw. Revis. p. 133.

M. muricatum; foliis confertissimis deltoidibus bracteis foliolisque majoribns calycinis triquetris glaucis, et trifarie denticulatis. Haw. Synop. p. 297. Miscell. nat. p. 75. - Ait. Kew. ed. 2. vol. 3. p. 238 .

M. deltoides; foliis deltoidibus triquetris dentatis impunctatis distinctis. Lin. sp. pl. ed. prior pag. 482. Hort. Cliff. p. 218. - Roy. Luyd. bat. p. 284. - Ait. Kev. ed. 1. vol. 2. p. 183. - Willd. Spec. pl. 2. p. 1052.

M. deltoides et dorso et lateribus muricatis minus. Dill. Elth. t. 195. Fig. 216, et forte t. 196. Fig. 247?

RADIX lignosa, romosa, fibrosa.

CAULIS ramosus, pedalis et ultra, rami tortuosi, divaricati, lignosi, duri, valde cicatrisati, cortice brumeo-cinerascente.

FOLIA connata, confertissima, lin. 3-5 longa, basi expansa ultra dimidium subcylindracea lineam lata, superne vix incurvata triquetro-dilatata lin. 3 lata, deltoideo-retusa, coerulescenti-glauca, impunctata, angulis omnibus tri vel quadridentatis, dentibus mucronutis scepissime murpurascentibus.

FLORES terminales, rite ternatim dispositi, meridie expansi, frayrantes, pedicellati. Pedicelli vix lin. 4 longi, superne incrassati, bibracteati, in pedunculum communem incidentes Bractea parvulae foliiformes.

$\boldsymbol{C A L Y X}$ subturbinatus in pedicellum attenuatus, quinquefidus; laciniis longitudine uequalibus, duubus triquetro-acutis anyulis subdenticulatis, tribus maryine membranuceis sub apice mucronatis.

PETALA uniserialia, lanceolato-racuta, patentia, rosea.

STAMINA collecta. Filamenta rosea. Antherce Ravae.

PISTILLUM. Ovarium obconicum, supra convexiusculum. Stigmata forecla, subulala, flavescentia. 
CAPSULA quinquelocularis, obconica, convexiuscula.

Habitat in Prom. bon. Spei. Floret mense Aprili.

Observ. Haec planta est species primigenia cui Ill. Limnaeus nomen M. deltoidis tribuit, ei ambae priores ut varietates adscribens. Ramosissima ac gracillima est lnijusce sectionis, foliisque maxime dentatis; quibus characteribus sicut et floribus brevissime pedunculatis a praecedente differt. Flores in lac sectione fragrantes sunt, et plantae ipsae sole ardente expositae odorem spargunt resinosum. 



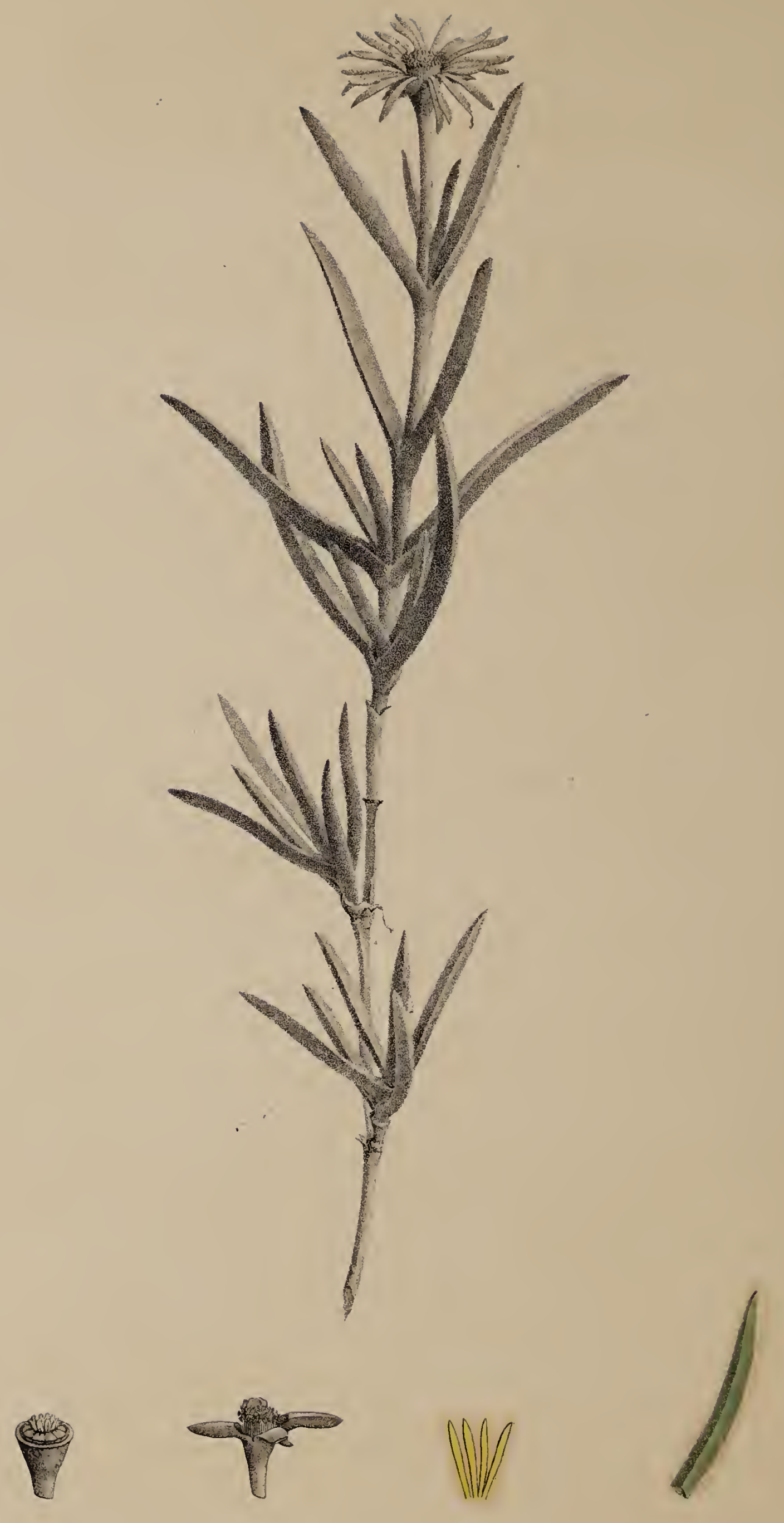

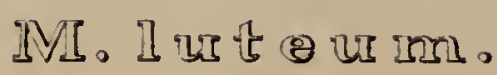

(\$.38. - Fig. 2.) 
(\$. 38. Fig. 2.)

\section{MESEMBRY A NTHEMUM LUTEUM Haw.}

MESEMBRYANTHEMUM luteum; caule erecto lignoso ramuloso, foliis vaginatocomnatis semicylindraceis attenuatis apice subtriquetris acutiusculis subsebaceis glaucis, petalis acutis concoloribus Inteis.

M. lu te um; Foliis obtusis, floribus ninoribus; caule ramuloso erecto rigido, nodis tumentibus radiculigeris. Haw. Plil. Mag. 1826. pag. 128.

M. purpureo-croceum; $\beta$. flavo-croceum; foliis subconfertis distantibusve iuternodio brevioribus tereti-senicylindraceis valde obtusis farinoso-glaucis glaucescentibusve: corollis utrinque flavis, nuptatis seu morientibus croceis: caulibus magis flexis. Haw. Revis. p. 155 ?

\section{RADIX lignosa, ramosa, fibrosa.}

CAULIS sesquipedalis, valde ramosus, ramique erecti, crassilie pennae columbinae, primo carnosi dein lignosi, nodulosi, cortice tenui, striatulo, fulvo-cinereo.

FOLIA subcomferta, erecto-patentia, valde connata, mollia, sebacea, basi semicylindracea intus subgibbosa, superne attenuta triquetro-compressa, apice aculiuscula, pollicem aut sesquipollicem longa et lin. 2 basi lata, lutescenti-viridia pruinoso-glauca.

FLORES terminales, solitarii, ante meridiem expansi, pedunculati. Pedunculus pollicaris et ultra, subcompressus; superne incrassatus.

CALYX subturbinatus in pedunculum attenuatus, quadrifidus; laciniis duabus elongatis turgido-triquetris, duabus brevioribus membranaceis sub apice mucronatis.

PETALA uniserialia, lineari-lanceolata, acuta, divaricata, utrinque flava, post anthesin crocea.

STAMINA mumerosa, collecta. Filamenta flava basi barbata. Antherae flavae.

PISTILLUM. Ovarium obconicum, supra planiusculum. Stigmata 8 erectr, compressa, fava, brevia, ramentacea.

CAPSULA octolocularis; maturam non vidi.

Habitat in Prom. bon. Spei. Floret aestate.

Observ. Ad hanc bonam egregianque specien, quae in Horto Kewensi anno 1825 primo floruit, retuli varietatem flavo-croceam M. purpureo-crocei $\mathrm{Haw}$; dubitanter attamen, quia folia apice obtusa dicuntur; at in juventute plantisque luxuriantibus folia saepe turgidiora sunt et usque ad apices incrassata. Calycis laciniae majores longioresque sunt quam in $\boldsymbol{M}$. croceo, et petala acuta, lutea, post anthesin marcescentia, et tunc crocea. 


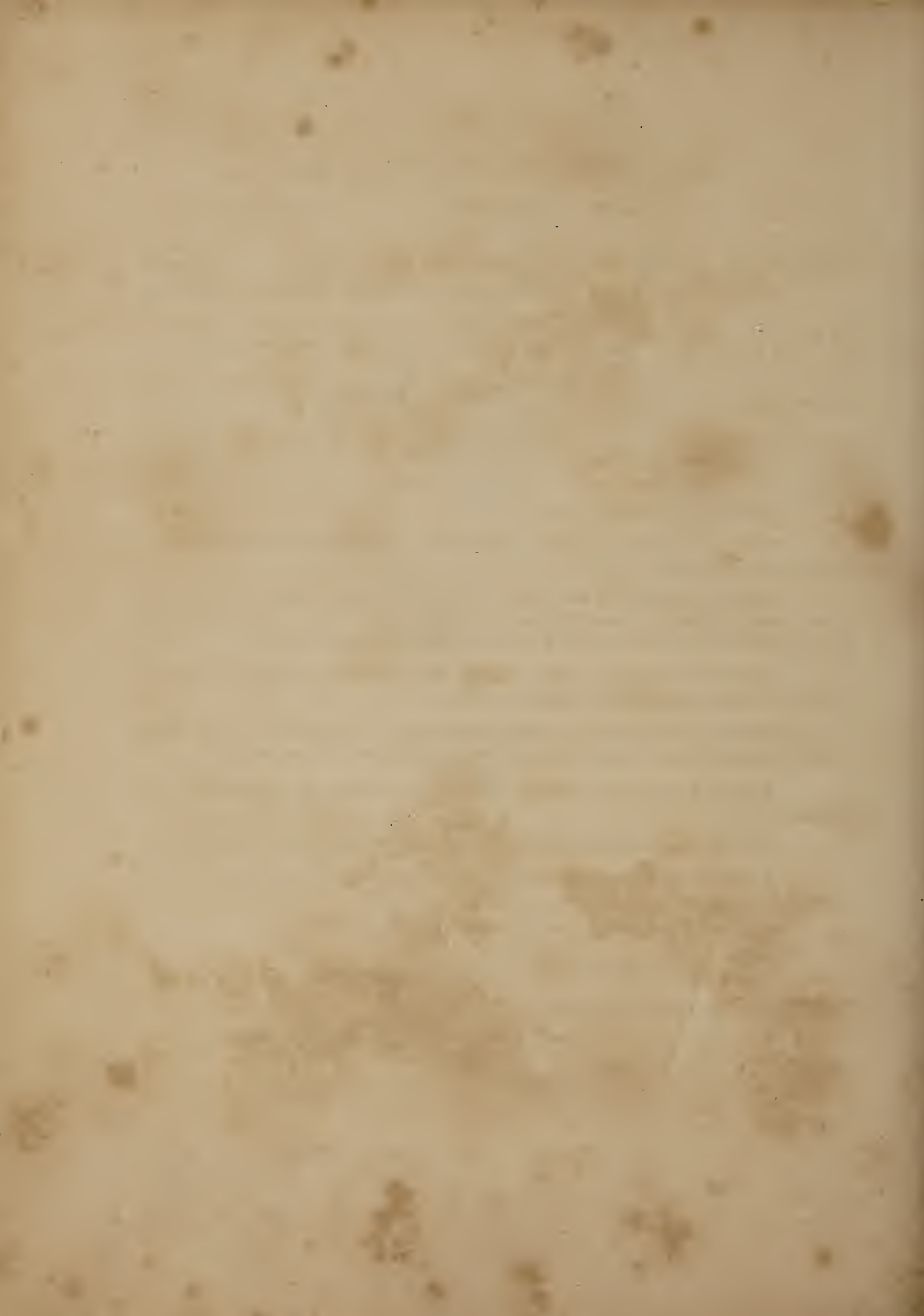




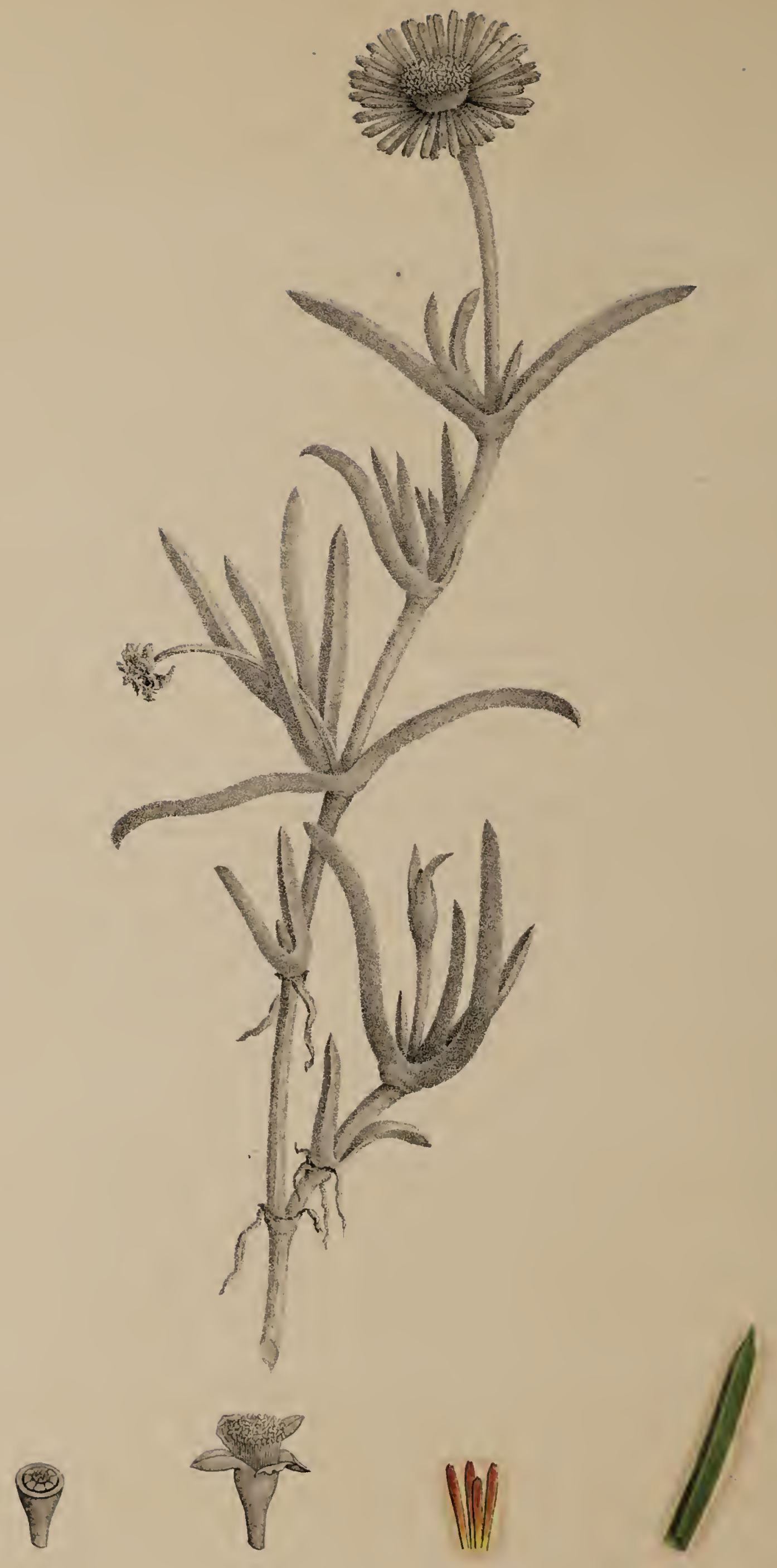

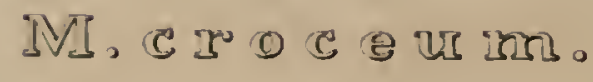

$(.9 .58 . \mathrm{Fig} .5)$ 
(5. 38. Fig. 3.)

\section{MESEMBRYANTHEMUM CROCEUM Jacq.}

MESEMBRY ANTHEMUM croceim; caule erecto sublignoso crasso, foliis vaginatoconnatis semicylindraceis turgidis apice vix triquetro-compressis obtusis subsebaceis farinoso-pruinosis, petalis erosis intus croceis extus plus minusve purpurascentibus.

M. croceum; caule erecto, foliis confertis semicylindricis farinoso-glaucis obtusiusculis intentodio brevioribus subsebaceis calycis lobis inaequalibus. Dc. Prodr. 3. $\%$. 438.

M. purpureo-croceum; foliis confertis teretiusculis obtusis glaucis, laciniis calycis inaequalibus. Syreny. Syst. 2. p. 520 .

M. purpureo-croceum; foliis confertis tereti-triquetro-semicylindraceis farinoso-glaucis obtusis internodio brevioribus sebaceis, foliolis calycinis productim praeinaequalibus; corollis inuptis croceis extus purpureis. Haw. Revis $p .155$. (excl. var. $\beta$ et $\gamma$.)

M. croceum; foliis confert is triquetris semiteretibus farinoso-glaucis subsebaceis obtusiusculis internodiis brevioribus, foliolis calycinis subinaequalibus, petalis obtusis croceis. Huw. Revis. p. 156.

M. purpureo-croce $u m$; foliis confertis tereti-triquetris obtusis perglaucis, foliolis calycinis valde inaequalibus, petalis extus laete rubicundis intus croceis. Haw. Miscel. nat. p. 81 . Synop. p. 259. - Ail. Kew. ed. 2. vol. 3. p. 242.

M. insititiun ; foliis triquetris obtusis, connatis glaucis impunctatis, pedunculis unifloris axillaribus compressis, calycibus bicornibus. Willd. Emum. p. 536. - Spreng. Syst. 2. p. 522.

M. croceum; foliis confertis tereti-triquetris glaucis, foliolis calycinis subaequalibus, petalis oblongis obtusis utrinque croceis. Jacq. Fragm. p. 17. Tab. 59. Fig. 2. - Haw. Suppl. p. 97.

$\boldsymbol{R A D I X}$ lignosa, ramosa, fibrosa.

CAULIS sesquipedalis, subramosus ramique erecti, crassitie pennae anserinae, mimo curnosi dein lignosi, nodulosi, cicatrisati, cortice crasso, suberoso, fulvo-cinereo.

FOLIA in ramis sterilibus conferta, valde connata, jumiora erecta, seniora palentiu, mollia, sebucea, turgido-semicylindracea, basi intus subgibbosu, apice vix triquetro-compressa, obtusa, pollicem ad sesquipollicem longa et diametro trilineari, pallide viridia, pruina densa firinosa obtecta.

FLORES terminales, solitarii, pedunculati, ante meridiem expansi. Pedunculus pollicaris et ultra, subcompressus, superne incrassatus.

CALYX turbinatus, in pedunculum attemualus, rite quadrifidus; lacinies duabus elongyatis turgidn-Iriquetris, duabus membranaceis sub upice mucronatis, una quandoque bifida.

PE'TALA biserialiu, Intiuscula, patentia, apice obtusa, denticulatu, intus crocea, exhus purpurascentia vel utrinque crocea aut aurantio-purpurea.

STAMINA mumerosa, collecta. Filamenta flava. Antherue flavae. 
PISTILLUM. Ovarium turbinato-obconicum, supra planinsculum. Stigmatı 8-.) subglobosa, fleva, parvula.

CAPSULA octo vel novemlocularis; maturam non vidi.

Habitat in Prom. bon. Spei. Floret aestate.

Observ. Haec pulcherrima species versus amnum 1780 in hortis nostratibus e seminibus Capensibus enata, et fere eodem tempore a Cl. Jacquinio, Haworthio et Willdenowio descripta est. Nomen a Jacquinio, anno 1801 ei impositum, prioritatis ratione sẹrvandum est. Petala intus crocea et extus purpurascentia, quandoque-crocea aut aurantio-purpurea utrinque evadunt, sed coloris haec variatio non constans se praebet, et delendae sunt varietates a CI. Haworthio institutae. A praecedente differt caule crassiore suberoso, foliis albidioribus obtusioribus, petalisque apice erosis purpureo-croceis. 



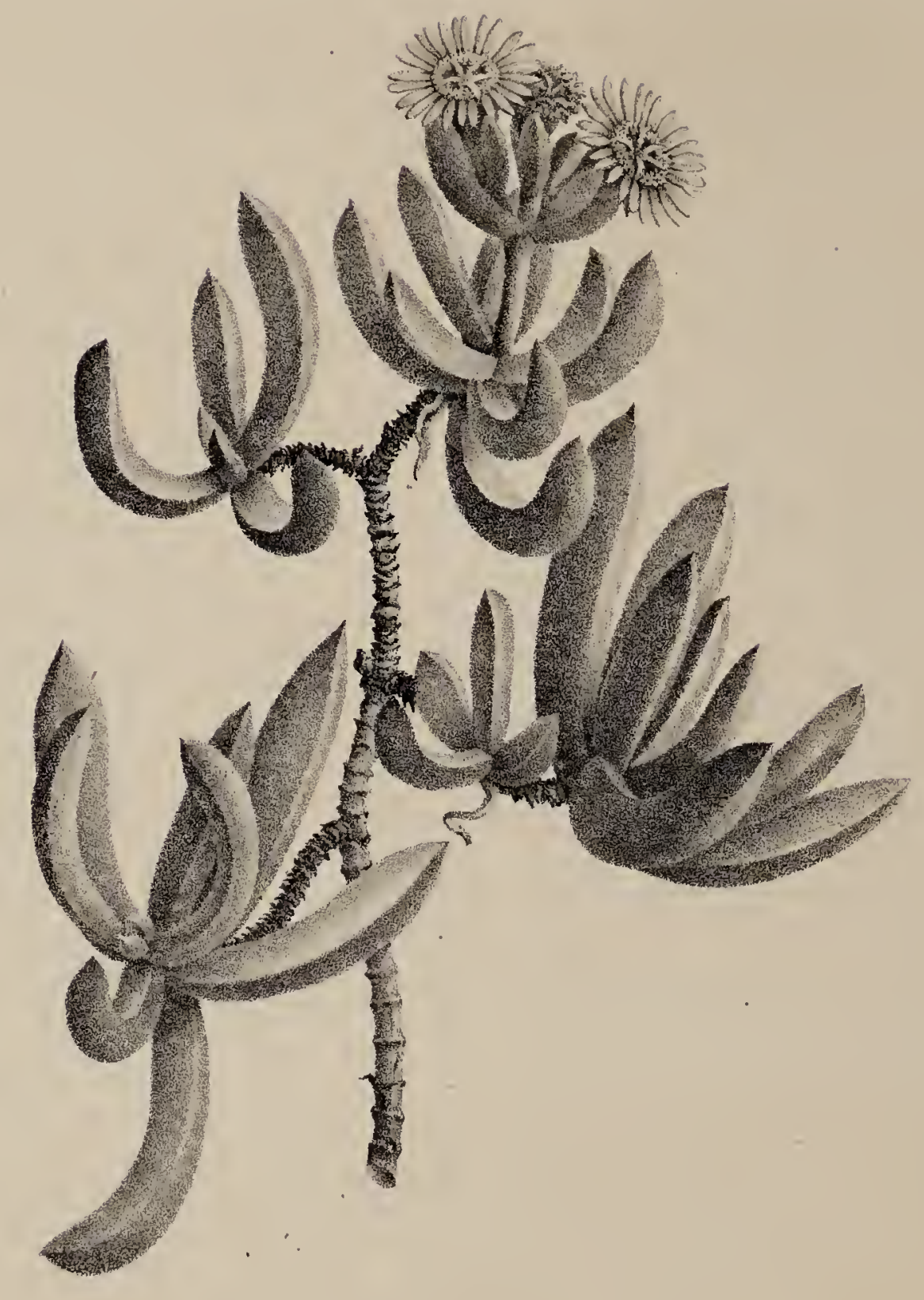

d8

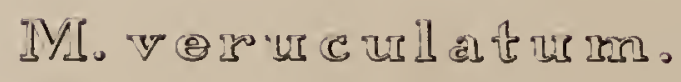

$$
(\$ .39 .- \text { Fig } 1 \text {.) }
$$


(\$. 39. Fig. 1.)

\section{MESEMBRYANTHEMUM VERRUCULATUM $L$ im.}

MESEMBRYANTHEMUM verruculatum; caule erecto ramoso, foliis fasciculatis incurvatis subtrigono-cylindraceis apice obtusis cum mucronulo purpurascente, subsebaceis farinoso-prninosis, floribus ternatis.

M. veruculatuon; caule erecto, foliis confertissimis glancissimis cylindraceis vix subtriquetris obtusis submucronatis sebaceis internodio longioribus nc. Prodr. 3 p. 438.

M. verruculutum; foliis fasciculatis teretiusculis acutis glaucis incurvis, floribus corymbosis flavis. smreng. Syst. 2. p. 520 .

M. veruculatum; foliis basi connatis confertissimis praeglaucis triquetro-cylindraceis arcuatis obtusis submucronatis sebaceis: floribus pomeridianis. Haw. Reris. $\%$ 15\%. (exclus. var. ß.)

M. veruculalum; foliis confertis perglaucis triquetro-cylindricis acutis arcuatis distinctis, floribus pomeridianis. Haw. Synop. p. 258. Miscel. nat. p. 7\%. - Ait. Kew. el. 2. vol. 3 \%. 211.

M. veruculatum; foliis triquetro-cylindraceis acutis connatis arcuatisimpunctatis distinclis. Lin. Spec. pl. p. 696. - Roy. Lugll-hal. p. 285. - Mill. Dict. n. 33. - Ail. Kiew. ed. 1. vol. 2 \%. 192. Willd. Spec. pl. 2. p. 1011.

M. verrulatum; foliis subcylindraceis acutis connatis arcuatis laevibus. Iin. Horf. Cliff. 1 . 220. IIort. Upsal. p. 128. - DC. Pl. grass. t. 36 .

M. foliis veruculiformibus, floribus mellinis umbellatis. Dill. Ellh. t. 203. Fig. 2.5.

\section{RADIX lignosa, ramosa, fibrosa.}

CAULIS erectus, pedculis et ultra, ramosus, rumi lignosi patentes, tortuosi, valde cicatrisali, cortice rugoso fulvo-cinerascente.

FOLIA in apice ramorum fasciculatim conferta, connata, pollicem ad sesquipollicem longa et dianetro 3-4 lineari; juniora erecta, seniora patentia, arcuctim incurvata, laevia, impunctata, pallide viridia, pruina furinosa densa obducta, mollia, sebacea, subcylindracea repice obtusa vix trigona, suepissime marpurascentia cum macromelo parvo.

FLORES terminales, ternatim dispositi, meridie expansi fragrantes, pedicellati. Pedicelli crassi, breves quculrilineares, busi et medio bracteati, in pedhonculum communem sexlinearem incidentes. Bructeale foliiformes.

CALYX hemisphuericus, quinquefudus; laciniis subuequulibus latiusculis margine membranaceis, sub apice mucronatis.

PETALA amiserialia, latiuscula, brevia, patentia, splendide lutea.

S'TAMINA trevia. Filamentu et Antherce luterte. 
PISTILLUM. Ovarium hemisphaticum, supva comvexiusculum. Stigmata 5 erecto-patentia, subulata, ramentacea, staminibus longiora.

CAPSULA quinqueloculuris, subglobosa.

Habitat in Prom. bon. spei. Floret mense Junio.

Observ. Haec antiqua et in hortis species vulgatissima sectionem propriam constituere debet, et nullae aliae exacte est adscribenda. Foliorum forma ad $\boldsymbol{M}$. calamiformia et crocea accedit, sed floribus ternatim dispositis ab ambabis sectionibus differt. Nulla est quoque huic speciei adscribenda varietas, et discrimen e foliorum numero sumptum omnino fortuitum est. 



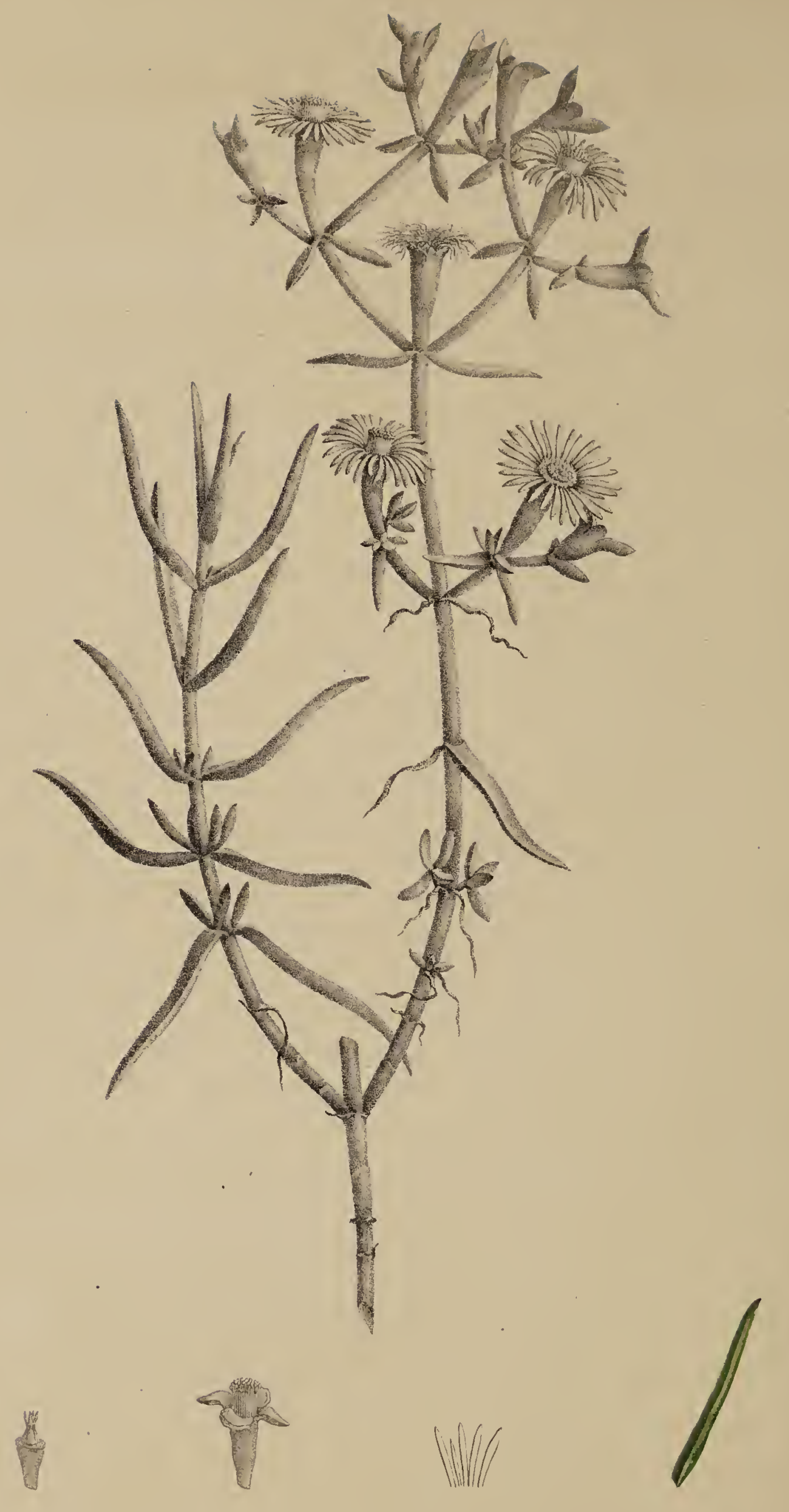

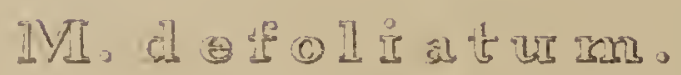

(‥5. . . Tig. 
(5. 43. Figg. 1.)

\section{MESEMBRYANTHEVUM DEFOLIATUM Haw.}

MESEMBRYANTHEMUM de foliatum; caule erecto subramoso inferne defoliato, foliis patentibus subcylindraceis obtusis mox deciduis, floribus dichotome ternatim ant biternatim dispositis, pedunculis clavatis.

M. clavatum; caule erecto parce ramoso, foliis teretiusculis remotis lorizontalibus, pedunculis clavatis aggregatis cymosis. DC. Prodr. 3. p. 4.t.s.

M. defoliatum; foliis semiteretibus, pedunculis terminalibus aggregatis clavatis, cymosis. IIau. Revis. p. 181. Miscel. nat. p. s1.

M. horizontale; foliis remotis subcylindricis glaucis exacte horizontalibus, floribus termatis stramineis intus albis. Haw. Revis. p. 181. Synop. p. 261.

M. clavatum; foliis subteretibus impunctatis distinctis, pedunculis terminalibus aggregatis clavatis, Willd. spec. pl. 2 p. $103 \mathrm{~s}$.

M. clavatum; foliis subteretibus impunctatis distinctis, pedunculis clavatis, calycibus quadrifidis. Jacq. Hurt. Schoenbr. 1. p. 56. t. 108.

$\boldsymbol{R A D I X}$ lignosa, ramosa, fibrosa.

CAULIS pedalis et ullra, ramique paucissimi, erecti, primo carnosi cortice laevi livido, dein lignusi, rigidi, valde defuliati, cicatrisati, cortice fulvo-cinereo.

FOLIA distincta, in ramis junioribus subconferta, erecto-incurvata, mox patentissina, marcescentia et decidua, pollicem ad sesquipolticem longa, diamelro 3 lineari, farclim semicylindracea, apice obtusa, livide viridia, impunctata, glaucescentia.

FLORES in ramis adullis terminales, inclaudentes, dichotome subcymosi, centrali praecociore subsessili ebracteato, lateralibus in peduncutum communem (9 linearem) ternalim et quandoque bilernalim incillentibus, brevissime pedicellatis. Pedicelti clavali, bracleati. Bracleae sub calyce insertue, parvulue, crassae, gramiformes.

CALYX clavatus, quadrifulus; laciniis duabus longioribus semicylindraceis acutis, sluabus latioribus margine membranaceis.

PETALA uniserialia, lanceolata, recurvato-patentia, alba cum linctura straminea.

S'TAMINA collecta, erecta. Filamenta alba. Antherae luteae.

PISTILLUM. Ovarium clavatum sipra pyramidato-convexum. Stigmata 4 erecla, subulata, flavescentia.

CAPSULA clavata, quadrilocularis; maturam non vidi.

Iabitat in Prom. bon. Spei. Floret a mense Junio ad Septembrem.

Olserv. Mesembr. clavati nomen huic speciei forte servandum foret, sed quia valde improprium, et nomini M. clavellati valde consonans, prioritatis quoque in dobio, Haworthianam denominationem meliorem esse censui. Flores nocte diuque expansi inodori sunt.

In icone folia nimis acuta depicta sunt. 




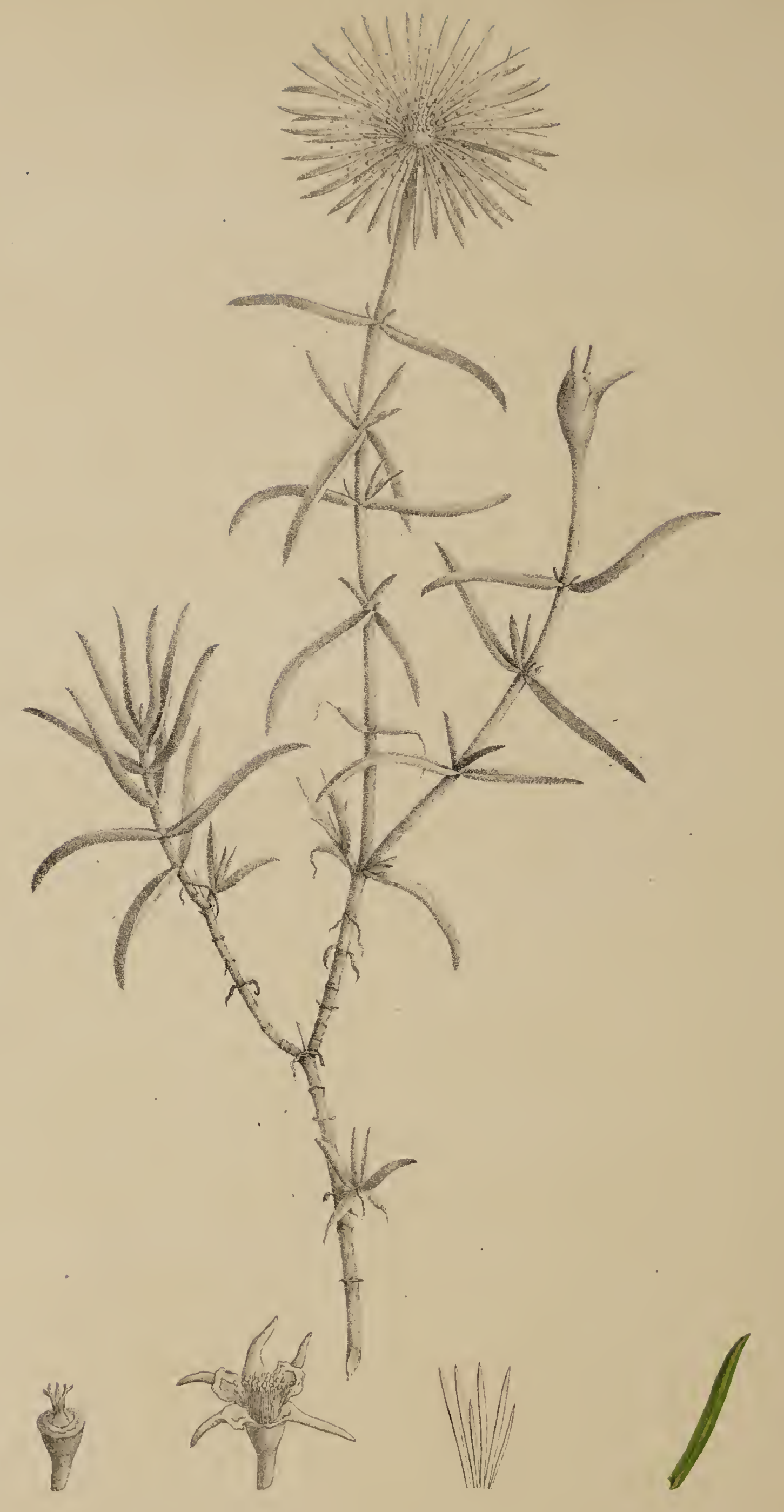

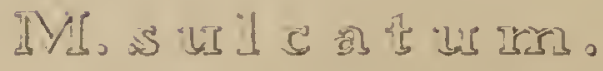

$$
(3.44-F+1)
$$


(\$. 41. Fig. 1.)

MESEVIBYANTHEMUM SULCATUM Haw.

MESEMBRYANTHEMUM sulcatum; caule ramisque erectis rigidis strictis, foliis coufertis lineari-subulatis obtusiusculis laete viridibus, junioribus erecto-incurvatis canaliculatis, senioribus expansis teretiusculis; floribus pallidissime roseo-albis.

M. sulc alum; caule fruticuloso erecto, foliis confertis lineari-subulatis semiteretibus subcanaliculatis pallide viridibus, adultis expansis semiteretibus, calycis lobis foliiformibus acutis. DC. Prodr. 3. p. 445.

M. sulc atum; foliis confertis lineari-subulatis semiteretibus pallide viridibus alte canalicu- latis, adultis expansis semiteretibus, calycis foliolis acutis. Haw, Revis. $\%$. 173.

\section{RADIX lignosa, ramosa, fibrosa.}

CAULIS bipedalis et ultra ramiyne erecti, stricti, primo carnosi, laete viridles, laevissime papulosi, dein lignosi, rigidi, cortice laevi, ferrugineo, griseo.

FOLIA in ramorum apicibus conferta, distincta, primo erecto-patentia, semiteretia, sulcata, dein patentissima, teretiuscult, axillis saepe proliferis, lin. 6 ad 13 longa, et lineam basi lata, sensim attemuata, apice obtusiuscula cum mucromulo parvo, laetissime viridia, impinctata.

FLORES terminales solitarii, inclaudentes, pedunculati. Pedunculi subpollicares saepe brevissimi remanent, superne incrassati, nudi, laevissime papulosi.

CALYX turbinato-clavatus, papillosus, quinquefidus; laciniis subulatis foliiformibus, tribus paulo brevioribus basi membranaceis.

PETALA plariserialia, anguste lanceolala, acuta, patentissima, alba ad apices linctura rosea.

STAMINA centralia erecla, collecta; exteriora radiatim patentissima. Filamenta longitudine inaequalia, interiora.brevia, exteriora duplo triplove longiora, interdum sterilia, alba. Antherae flavidae.

PISTILLUM. Ovarium subturbinatum supra pyramidato-convexum. Stigmata 5 subulata, ramentacea, flexuoso-erecta, flava.

CAPSULA obconica, quinquelocularis; maturam non vidi.

Habitat in Prom. bon. spei. Floret aestate.

Observ. Haec species statura maxima est hujusce sectionis valde difficilis, et a Dom. Burchell versus anıum 1819 in Angliam advecta. Folia juniora solum sulcata sunt. 



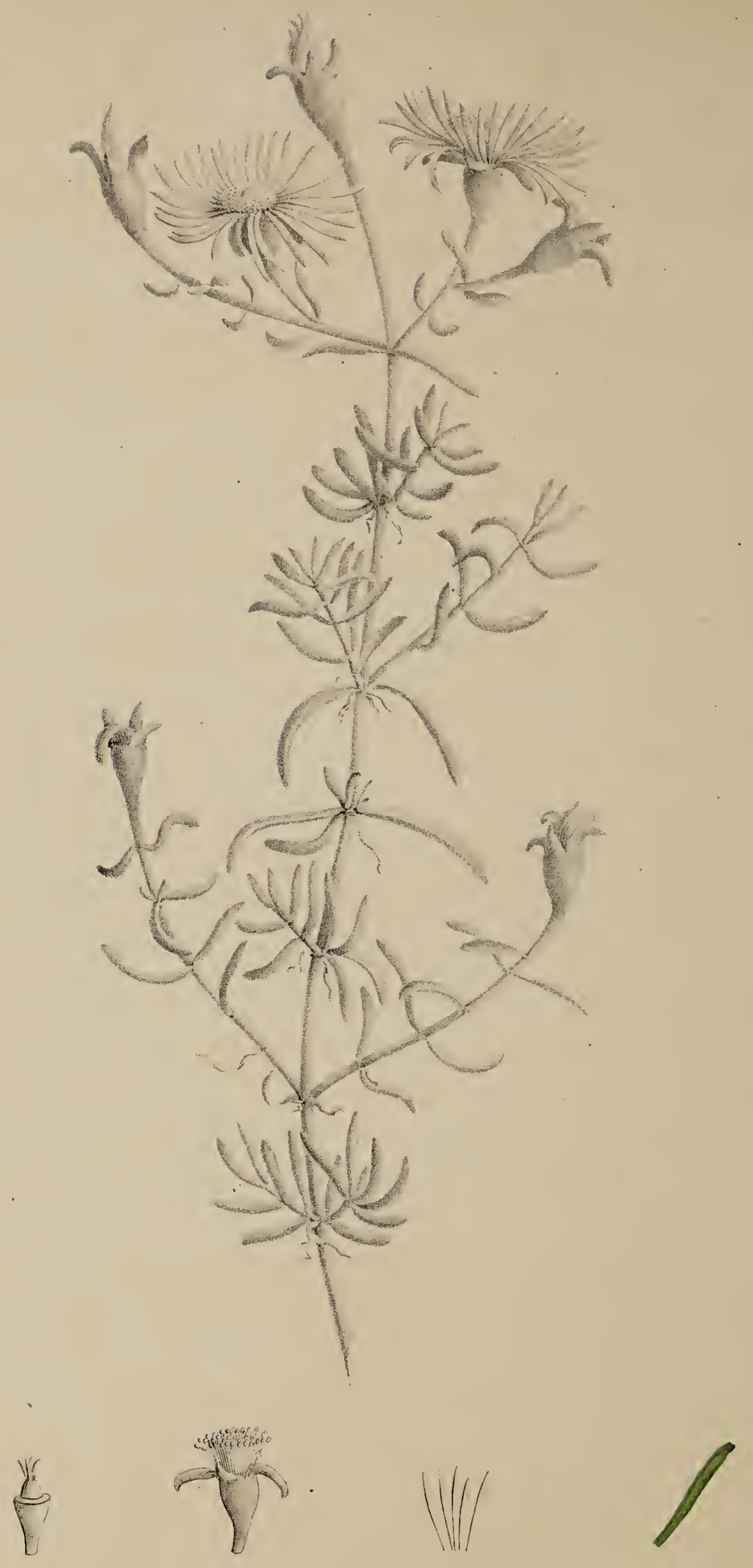

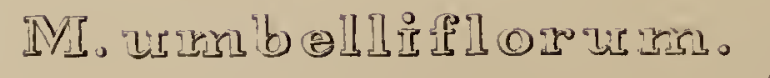

$$
\text { (\$.44. - Fig.6.) }
$$


(\$. 44. Fig. 6.)

\section{MESEMBRY ANTHEMUM UMBELLIFLORUM Jacq.}

MESEMBRY ANTHEMUM umbelliflor $\bullet m$; caule ramisque erectis flexilibus, foliis coufertis curvato-patentibus depresso-teretiusculis obtusis subglaucescentibus, in ramis florentibus lineari-elongatis, in ramis sterilibus brevioribus subclavatis, floribus subpaniculatim dispositis violaceo-albis.

M. थomb elliflor um; caule erecto, foliis distinctis teretiusculis papulosis, ranulis unifloris. DC. Prodr. 3. p. 446.

M. umbelliflor um; foliis teretiusculis papulosis, distinctis, ramulis unifloris, floribns incarnatis. spreng. Sysl. 2. p. 520.

M. umbelliflorum; foliis distinctis teretinsculis papulosis, caule erecto, ramulis uniforis. Willd. Enum. 1. 534. - Haw. Rev. p. 1 rt.

M. umbelliflorum; Jacq.

RADIX lignosa, ramosa, fibrosa.

CAULIS bipedalis el ullia, rami graciles, erecti, flexiles, primo carnosi, virides, laevissime papulosi, dein lignosi, cortice laevi favescenti-cinereo.

FOLIA distincta, recurvala, patentissinu, teretiuscula, in ramis slerilibus conferla, subclavatim obtusa, in ramis florentibus linearia, semipollicem ad pollicem longa, diamelro lineari, axillis saepe moliferis, viridla, impnunctata.

FLORES solilarii, in ramis ramulisve (saepe sulpaniculatim erectis) terminales, inclandentes, pedunculali. Pedunculi lin. 3 an 13 longi, laevissime papulosi, superne incrassati.

$\boldsymbol{C A L Y X}$ turbinalo-clavatus, papillosus, quinquefidus; laciniis subulatis foliiformibus recurvalo-patentissimis, trilus paulo brevioribus margine membranaceis.

PETALA phariserialia, angusle lanceolala, acuta, palentissima, recurvatu, alba ad apices tinctura primo fulva dein violacea.

STAMINA subcollecta, erecla. Filamenla alba. Antherae flavidae.

PISTILLUM. Ovarium horbinatum supra pyranidato-convexum. Stigmala 5 subulata, erecto-recurvula, fluva.

CAPSULA obconica, quinquelocularis; maturam non vidi.

Habitat in Prom. bon. spei. Floret aestate.

Observ. In Horto Schoenbrunnensi e seminibus Capensibus enata, et a Cl. Jacquinio suls nomine M. umbelliflori horto Berolinensi comurunicata, haec species ab III. Willdenowio anno 1809 primo descripta est. Flores in plantis luxuriantibus subumbellatim dispositi, saepissime attamen solitarii apparent. A $\boldsymbol{M}$. fastigialo, cui caeterum proximum, differt caule laxiore foliisque minus confertis. 


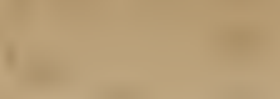

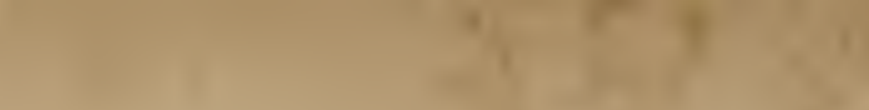

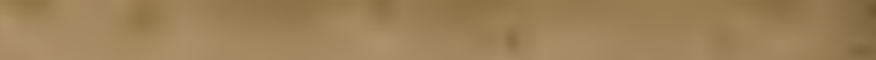

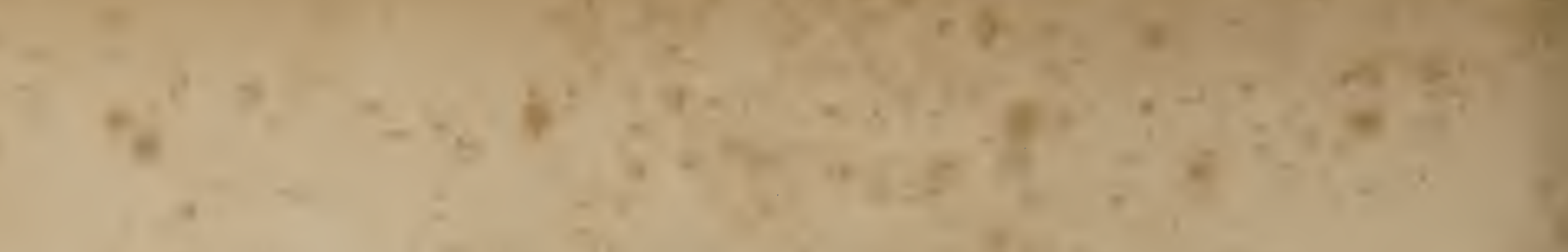

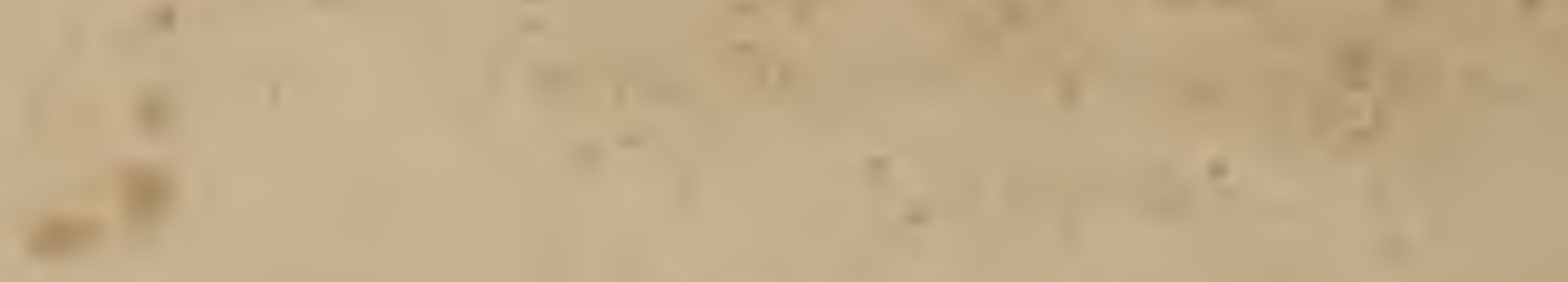

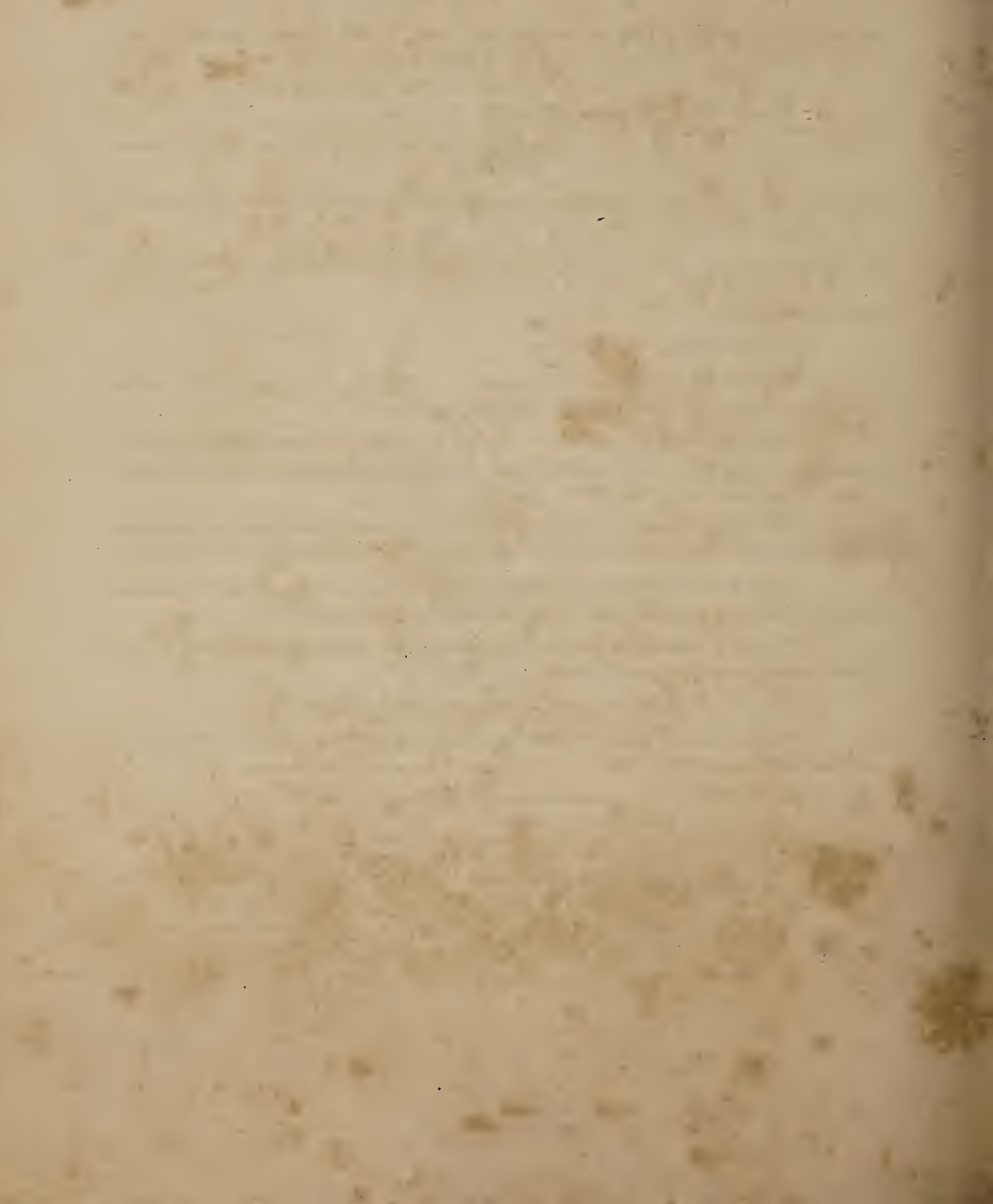





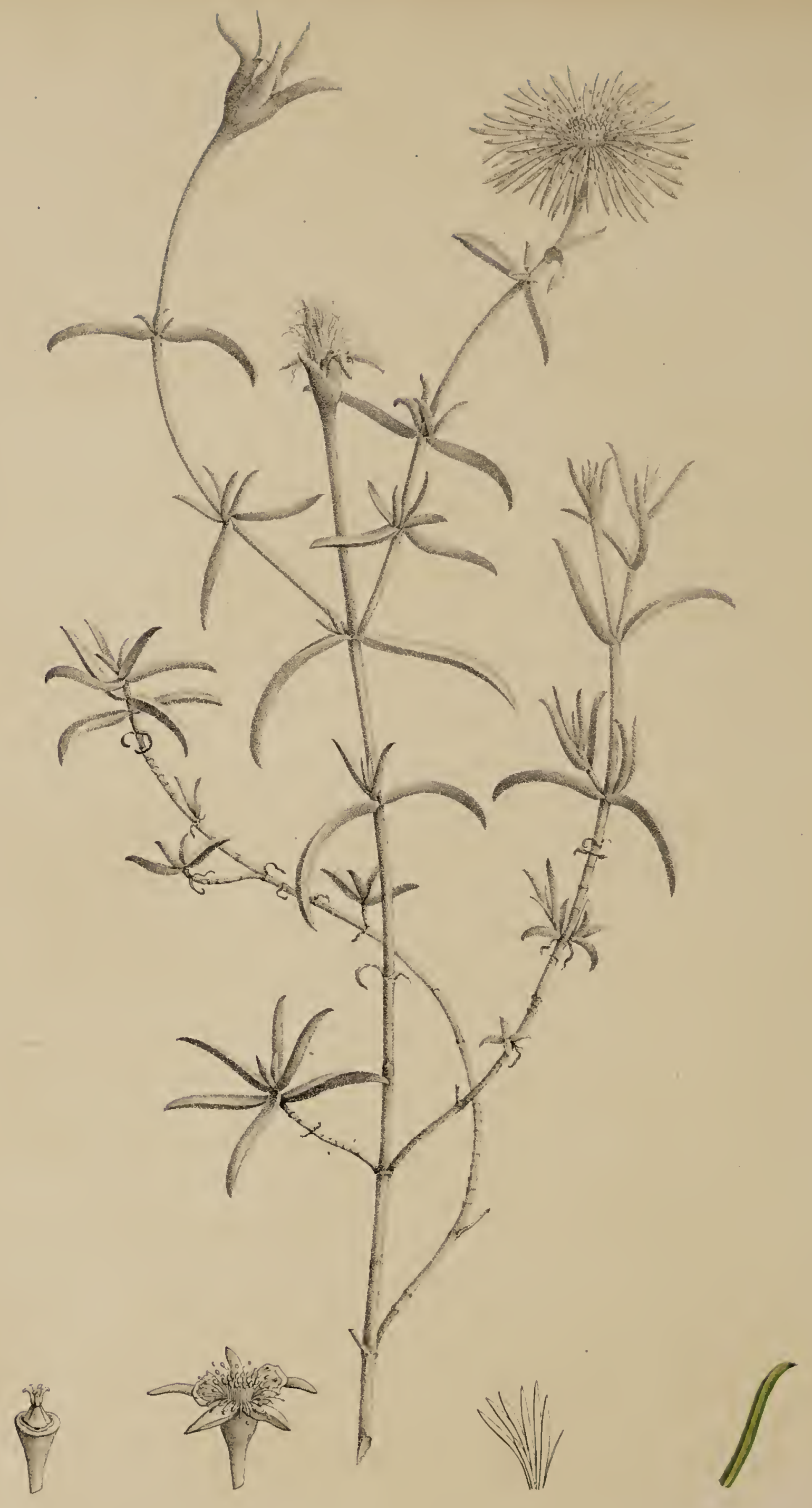

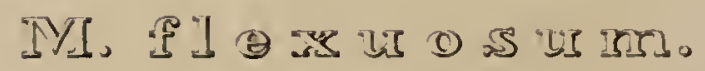

(\$.44. - Fig.7.) 
(\$. 44. Fig. 7.)

\section{MESEMBRYANTHEMUM FLEXUOSUM Haw.}

MESEMBRYANTHEMUM fl exuosum; caule ramisque erecto-divaricatis flexuosis, foliis confertis curvato-patentibus depresso-teretibus mucronulatis perviridibus nitidis, in ramis florentibus elongatis, in ramis sterilibus brevibus sublanceolatis, floribus stramineo - albis.

11. flexuosum; caule suffruticoso ramisque flexuosis gracilibus lucidis, foliis confertis flexuoso-recurvis perviridibus semiteretibus, calycis lobis digitiformibus. DC. Prodr. 3. $p .115$.

M. flexuosum; foliis semiteretibus yiridibus flexuoso-recurvis, ramis gracilibus lucidis, laciniis calycis digitiformibus. spreny. Syst. 2 p. 518.

M. flexuosum; foliis confertis flexuoso-recurvis perviridibus semiteretibus, laciniis calycinis digitiformibus, caulibus subflexuosis gracilibus lucidis. Haw. Revis. p. 172. Synop. p. 257. Miscel. nat. p. 61. - Ail Kew. ed. 2. vol. 3. pag. 231.

\section{RADIX lignosa, ramosa, fibrosa.}

CAULIS pedalis et ultra ramique graciles, flexuoso-vel tortuoso-erecti, primo carnosi virides laevissime papillosi, dein lignosi cortice laevi flavescenti-cinereo.

FOLIA distincta, recurvato-patentissima saepe arcuala, depresso-teretia, in ramis sterilibus confertissima, utrinque attenuata, apice nucronata, in ramis florentibus remola, linearia, lin. 4 ad pollicem longa, diametro lineari, axillis saepe proliferis, perviridia, nitida, impunctata.

FLORES in ramis florentibus solitarii, terminales, inclaudentes, pedunculati. Pedunculi lin. 6 ad 13 longi, superne incrassati, laevissimi, nitidi.

CALYX clavatus in pedunculum attemuatus, laevis, quinquefidus; laciniis subulatis, foliiformibus, patentissimis, tribus margine membranaceis.

PETALA pluriserialia, anguste lanceolata, acuta, patentissima, alba basin versus linctura straminea.

STAMINA centralia erecta collecla, exteriora radiatim expansa. Filamenta longitudine inaequalia, interiora breviora, exteriora duplo longiora, alba. Antherae flavidae.

PISTILLUM. Ovarium obconicum, supra pyramidato-convexum. Stigmata E subulata, erecta, apice uncinata, ramentacea, flava.

CAPSULA obconica, quinquelocularis; maturam non vidi.

Habitat in Prom. bon. Spei. Floret aestate.

Observ. Cl. Masson hanc speciem anno 1795 in Auglianı advexit. Caule ranisque gracilibus, flexuosis, foliisque nitidis, perviridibus, a congeneribus differt. 


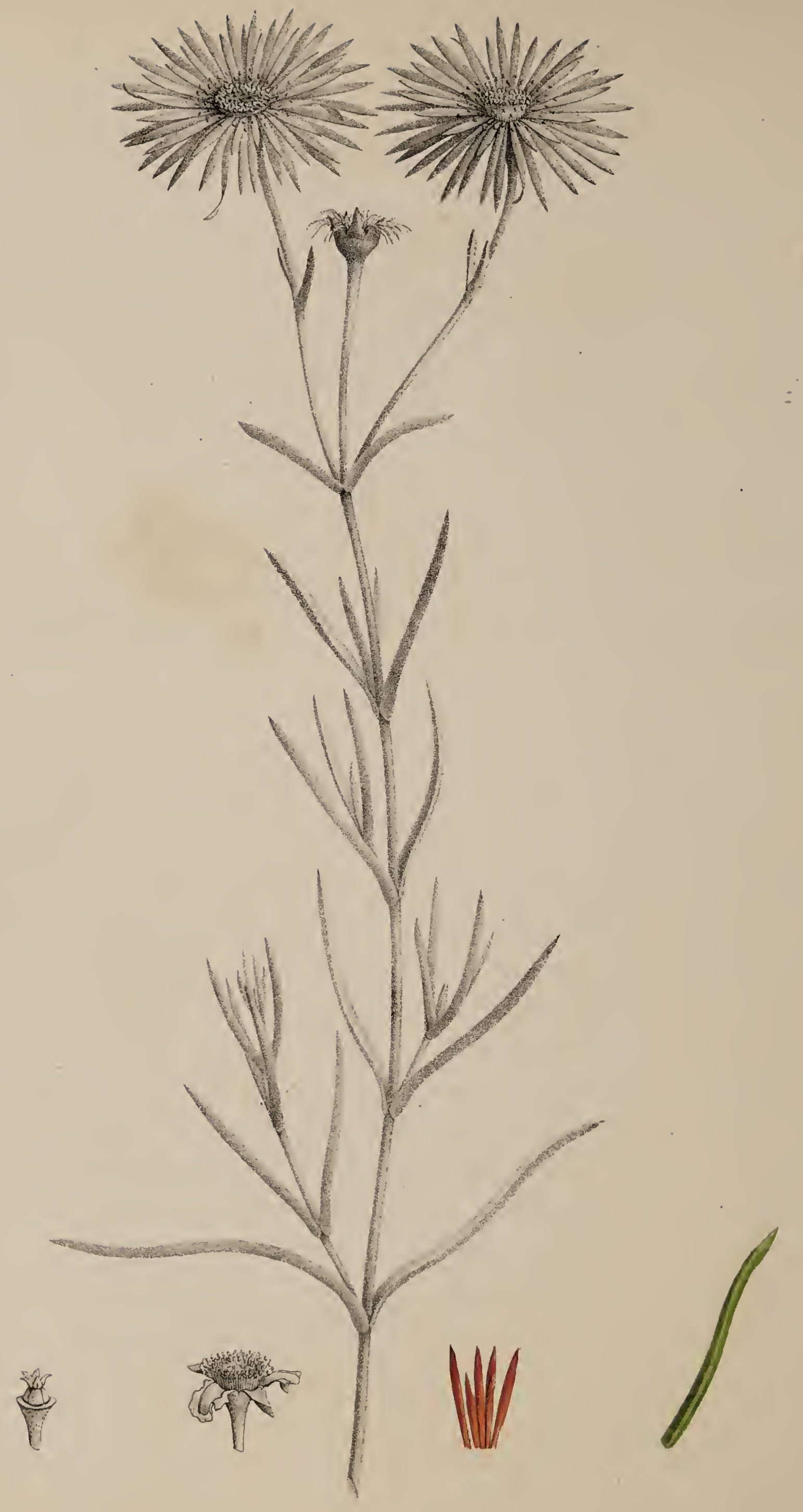

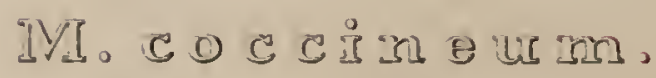

(\$.40. - Fig. 1.) 
(\$. 46. Fig. 1.)

\section{MESEMBRY INTHEMUM COCCINEUN Haw.}

MESEMBRYANTHEMUM coccineum; caule fruticoso ramisque strictis, foliis subtriqaetro-semicylindraceis erectis prominule punctatis glaucescentibus obtusis, pedunculis basi laevibus, floribus coccineis.

M. coccineum; caule fruticoso erecto, foliis tereti-triquetris subcompressis obtusis glaucescentibus, pedunculis basi laevibus, calycis lobis obtusiusculis subaequalibus. DC. Prodr. 3 p. 438.

M. co c cin eum; foliis trigonis obtusis glaucescentibus, pedunculis basi laevibus, floribus coccineis. spreng. Syst. 2. p. 521 .

M. coccineum; foliis tereti-triquetris subcompressis obtusis glaucescentibus, pedunculis basi laevibus, calycinis foliolis obtusis subaequalibus: petalis coccineis. Hav. Revis p. 150. (exclus. varietatibus.) Synop. p. 26.5. Aliscel. nat. p. 85. - Ait. Kew. ed. 2. vol. 3. p. 215.

M. coccineum; ramis strictis, compressis, foliis trigonis obtusiusculis carinatis, stigmatibus approximatis erectis. DC. Pt. grass. t. 83.

M. coccineum; Lodd. Bot. Cab. t. 1033.

M. bicolorum; Curt. Bot. Mag. t. 59 .

M. bicolorum (coccineum) willd. spec. pl. 2.p. 1039.

$\boldsymbol{R A D I X}$ lignosa, ramosa, fibrosa.

CAULIS bi vel tripedalis, erectus, ramique stricli, rigidi, cortice brumeo-cinereo.

FOLIA in ramis conferta, distincta, erecta, lin.6-18 longa, et basi vix lineam lata, inferne semicylindracea, superne subtriquetro-compressa, paululum dilatala, apice obtusa cum mucromulo parvo, glaucescentia, pellucide punctata, punctis prominulis.

FLORES in vamorum apicibus solitarii, lerminales, meridie expansi, pedunculati. Pedunculi pollicares et ultra, basi laeves, superne incrassali, scabrido-punctati.

CALYX subturbinatus, scaber, quinquefidus; laciniis duabus aututis, subaequalibus, tribus margine membranaceis sub apice mucronalis.

PETALA pluriserialia, lanceolato-acuta, patentia, intus coccinea, extus pallidiora.

STAMINA centralia erecta collecta, exteriora patentia. Filamenta basi burbata, lutea. Antherae flavae.

PISTILLUM. Ovarium obconicum, supra convexum. Stigmala 5 lanceolatoacuta, erecto-recurvula, ramentacea, fara.

CAPSULA obconica, quinquelocularis.

Habitat in Prom. bon. Spei. Floret aestate.

Observ. Haec vulgatissima species bene cognita est. Pro varietate $\boldsymbol{M}$. bicoloris (a quo revera vix differt) primo habita, antiqua est hortorum nostrum incola. Varietates a Cl. Haworth ei adscriptae nec constantes nec notabiles sunt. 




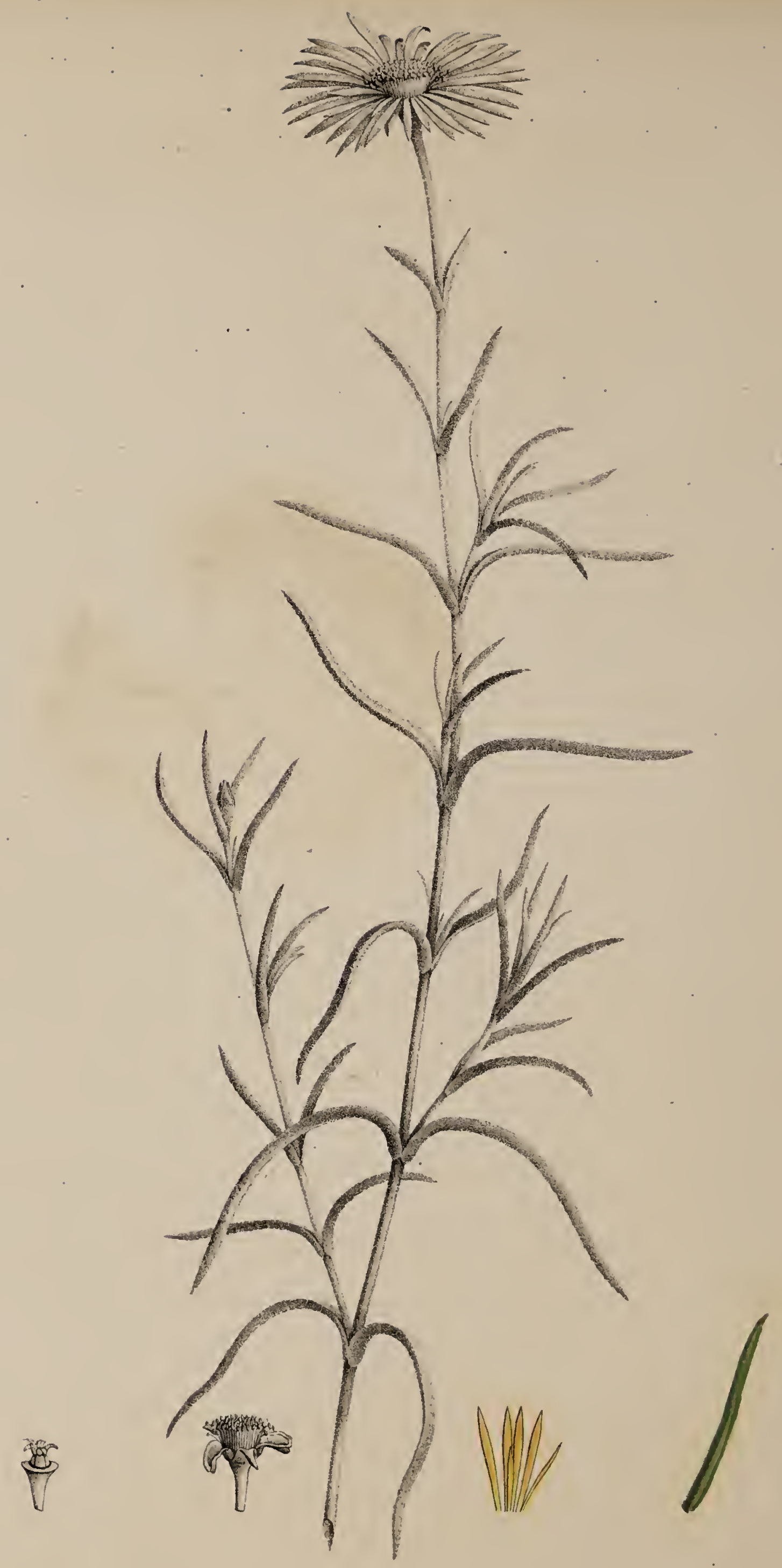

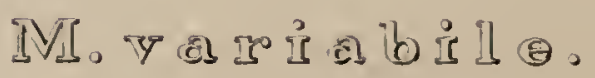

$(\$ .46 .-\mathrm{rig} .2$. 
(\$. 46. Fig. 2.)

\section{MESEMBRYANTHEMUM VARIABILE Haw.}

MESEMBRYANTHEMUM variabile; caule fruticoso ramisque effusis gracilibus, foliis subtriquetro-cylindraceis patento-erectis scabrido-punctatis glaucescentibus acutiusculis, pedunculis basi laevibus, floribus versicoloribus armeniaceis aut roseis.

M. variabile; caule fruticoso effuso subdecumbente, foliis subtriquetris compressis glaucis scabris, calycis lobis subaequalibus. DC. Prodr. 3 p. 43.

M. variabile; foliis trigonis compressis glaucis, caule decumbente, floribus versicoloribus flavis demum rubris. spreng. Syst. 2. p. 521.

M. variabile; foliis subtriquetris compressis glaucis scabris, calycinis laciniis subaequalibus, petalis luteis mox subroseis, caulibus effusis subdecumbentibus. Haw. Revis. p. 152. (exclusis varietatibus.) Synop. p. 266. Miscel. nat. p. 85. - Ait. Kew. ed. 2. vol. 3. p. 244.

$\boldsymbol{R A D I X}$ lignosa, ramosa, fibrosa.

CAULIS bipedalis et ultra, effusus, ramique graciles subdecumbentes, cortice cinereo-brumeo.

FOLIA in apice ramorum conferta, distincta, primo erecta, dein in-aut recurvatopatentia, lin. 6-18 longa, et vix lineam basi lata, inferne semicylindracea, superne vix tripuetro-compressa, apice in mucromulum parvum subattemuata, glaucescentia, pellucide punctata, punctis promimulis scabridis.

FLORES in ramorum apicibus solitarii, terminales, meridie expansi, pedunculati. Pedunculi pollicares, basi laeves, superne incrassati, scabrido-punctati.

$\boldsymbol{C A L Y X}$ in pedunculum altemuatus, scabridus, quinquefidus; luciniis duabus acutis, tribus latioribus margine membranaceis sub apice mucronatis.

PETALA pluriserialia, lanceolato-acuta, patentia, colore variabili lutescente, armeniaceo aut tandem spurco-roseo.

STAMINA collecta, erecta. Filamenta basi barbata, flava. Antherae flavae.

PISTILLUM. Ovarium obconicum, supra convexum. Stigmata 5 lanceolatoacuta, erecto-recurvata, ramentacea, flava.

CAPSULA obconica, quinquelocularis.

Habitat in Prom. bon. Spei. Floret aestate.

Observ. Cl. Haworth hanc speciem jam anno 1796 coluit. Foliis glaucescentibus scabridis ad $M$. coccineum accedit; sed colore variabili petalorum et ramis gracilibus, effusis, subdecumbentibus ab illo omnino differt. 




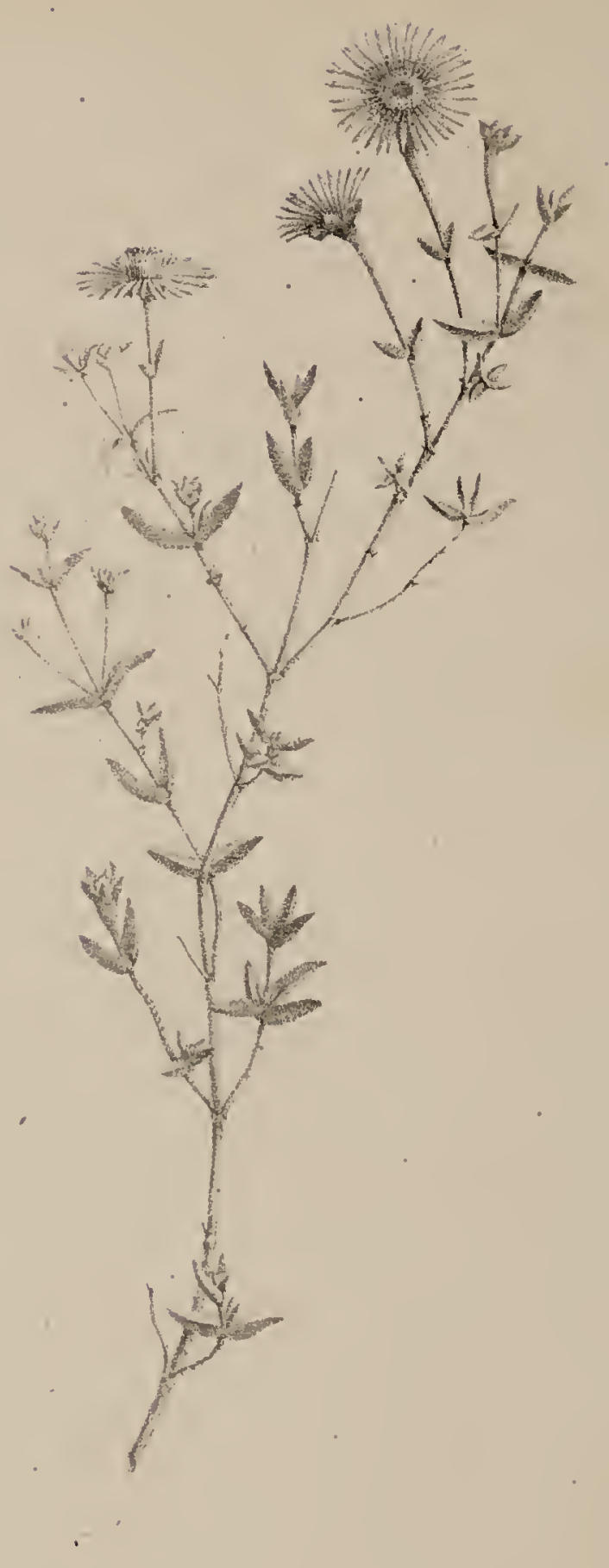

P. $P$

Wr

1

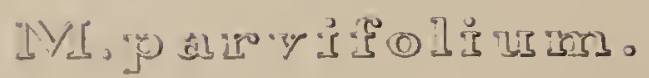

$$
\left(8.50 .-k_{i g} .5 .\right)
$$


(5. 50. Fig. 3.)

\section{MESEMBRYANTHEMUM PARVIFOLIUM Haw.}

MESEMBRYANTHEMUM parvifolium; caule suberecto ramisque diffusis filiformibus asperis, foliis minutissimis confertis expansis triquetris subcymbaeformibus papulosis, petalis minutis saturate purpureis.

M. parvifolium; caule suberecto, ramis subconfertis filiformibus asperis duris, foliis graniformibus expansis obtuse triquetris papulosis submicantibus. DC. Prodr. 3. p. A12.

M. parvifolium; foliis graniformibus expausis obtuse triquetris papulosis submicantibus: ramis subconfertis filiformibus asperis duris suberectis. Haw. Revis. p. 18t.

\section{RADIX lignosa, ramosa, fibrosa.}

CAULIS suberectus, semipedalis, crassitie pennae anserinae, ramosissimus. Rami filiformes diffusi, primo carnosi papilloso-micantes, dein lignosi, duri, asperi, cortice rufescente aut brumeo-cinereo.

FOLIA in apice ramulorum conferta, expansa, lin. 2 longa et lineam lata, triquetra, ad corinam subdilatata, acutiuscula, lueteviridia, et papillis mimutissimis ad angulos micantibus adspersa.

FLORES terminales, soliturii, minuti, meridie expansi, pedınculati. Pedunculi breves, semipollicares, superne incrassati, micantes.

$\boldsymbol{C A L Y X}$ in peduncudum uttenuatus, micans, quinquefidus; laciniis aequalibus, angustis, acutis, subfoliiformibus.

PETALA uniserialia, lanceolato-acuta, patentia, vix lineas tres longa, intense purpurea. Anthercue lutescentes.

STAMINA centralia erecta, collecta; exteriora patentia. Filamenta pallide rosea.

PISTILLUM. Ovarium clavatum, supra convexiusculum. Stigmata 5 recurvatopatentia, acuta, lutea.

CAPSULA quinquelocularis, obconica; maturam non vidi.

Habitat in Prom. bon. Spei. Floret mense Junio.

Observ. Folia in hac specie minntissima omuium in genere, potius cymbaeformia sunt quam graniformia propter carinam satis acutam. E seminibus Capensibus in Horto Kewensi anno circiter 1819 enata, accedit ad $M$. Urevifolium; sed caule humiliore diffuso, ramis gracilioribus, foliis floribusque minoribus omnino differt. 




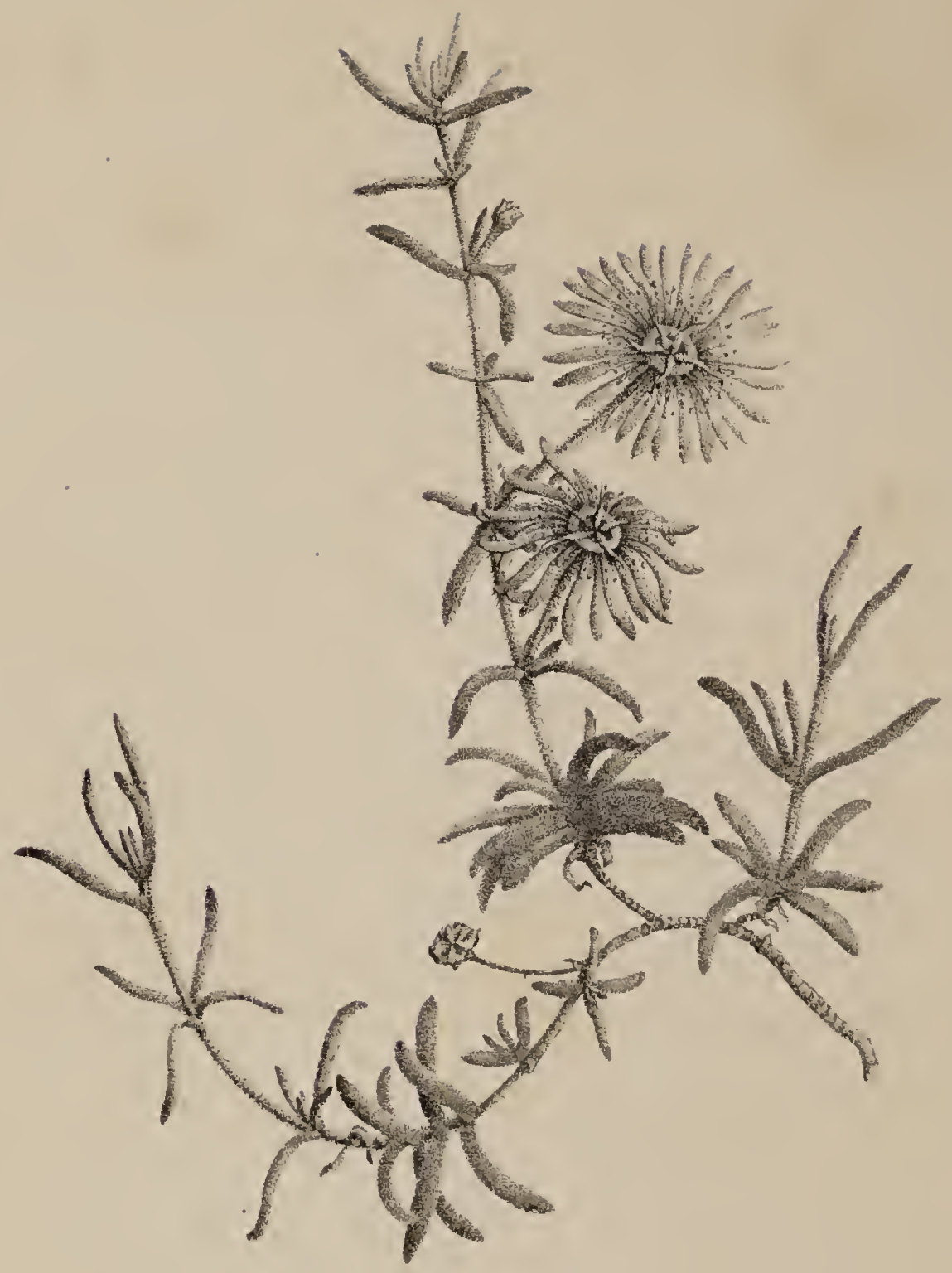

F

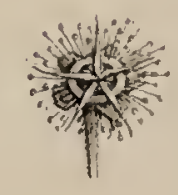

W

l

IVL。㩆

$$
(\$ .51 \text { - Fig. } 7 .)
$$


(\$. 51. Fig. 7.)

\section{MESEMBRYANTHEMUM FLORIBUNDUM Haw.}

MESEMBRY ANTHEMUM floribund um; caule ramisque tortuosis subdecumbentibus setosis, foliis cylindraceis papillis uninutis micantibus, petalis roseis, staminibus effusis, stylis exsertis.

M. floribundum; ramis patulis numerosissimis, foliis subcylindraceis subincurvis papulosis obtusis, calycibus hemisphaericis papulose pilosis, staminibus stigmata non aequantibus. DC. Prodr. 3. p. 111.

M. Floribundum; B. torqueatum DC. ᄂ.c.

M. Floribundum; foliis teretibus obtusis papulosis, calycibus hemisphaericis papuloso-pilosis, pistillis stamina superantibus, ramis hispidis. spreny. Syst. 2 p. 520.

M. furfureum; ramis confertis rectiusculis rigidis furfuraceis, foliis cylindricis obtusissimis calycibusque obsoletius papuloso-crystallinis, floribus parvulis numerosis. Haw. phit. Mag. 1831. Dec. 13.

M. floribundum; foliis cylindraceis subincurvis papulosis obtusis, calycibus hemisphaericis papulose pilosis confertis; staminibus pistillis brevioribus : ramis numerosissimis patulis. Inuw. Revis. p. 187.

H. torquulum; foliis subcylindraceis incurvis canescente viridibus papulosis obtusis: calycibus hemisphaericis papuloso-pilosulis numerosis: staminibus pistillis longioribus: ratlis tortuosis subdecumbentibus. Haw. Revis. p. 187.

M. floribundum; foliis cylindricis obtusis papulosis, calyce hemisphaerico papuloso-piloso, floribus inbricatis, staminibus pistillis brevioribus. Haw. Synop. p. 271. Miscet. nat. p. 100. Ait. Kew. ed. 2. vol. 3. p. 251.

1. Lispidum B. pallidum; Willd. spec. pl. 2. p. 1011. - Ait. Kew. ed. 1. vol. 2. p. 18.

M. pilosum micans, flore purpureo pallidiore. Dill. Eul. p. 290. t. 214. Fig. 279. 2s0.

B. erectius; ramis erectioribus et floribus minoribus.

RADIX lignosa, ramosa, fibrosa.

CAULIS suberectus, lignosus, rigidus, ramosus. Rumi graciles, lortuoso-divergentes, decumbentes, (in var. B. suberecti,) primo carnosuli virides setis albis palentibus instructi, (ralidionibus in var.) dein lignosi, cortice brumeo-cinereo laevi, piloso vel lepidoto.

FOLIA in ramis encascentibus confertissima, in ramis enatis remotiuscula, subconmata, patentia, saepe arcuato-curvata, lin. 4-10 longa, diametro vix lineari, cylindracea, apicem versus paulum incrassata, obtusa, axillis moliferis, labteviridia el papillis mimutissimis micantibus undique adspersa.

FLORES in ramulis jumioribus uxillaribus solitarii, ante meridiem expansi, diametro pollicari, (in var. B. minores,) pedunculati. Pedunculus in planlis junioribus sesquipollicaris, in crmusioribus brevior, setosus. 
CALYX suburbinailus, papillis crystallinis micans, quinquefidus; laciniis aequalibus, oblusis, micantibus, duabus margine membranaceis.

PETALA uniserialia, subspathulata, acuta, distantia, deflexo-patentia, laciniis calycis duplo triplove longiora.

STAMINA effusa. Filamenta rosea. Antherae favidue.

PISTILLUM. Ovarium subturbinatum, supra convexum. Styli quinque patentes, subulati, aristato-acuti, staminibus longiores.

CAPSULA quinquelocularis, obconica, pentagona.

Habitat in Prom. bon. Spei. Floret aestate.

Observ. Haec antiqua species, temporibus Dillenii jan cognita, aetate et cultura formas valde diversas assumit. Cl. Haworthii $\boldsymbol{M}$. torquatum et furfureum nihil nisi formae variationes, adeo inconstantes sunt, ut ea cum $\boldsymbol{M}$. floribundo conjunxerim. Planta alia attamen, caule suberecto minus ramuloso, in Horto Dyckensi e semine Capensi orta adest, quae primo intuitu ad $\boldsymbol{M}$. Kispidum spectare videtur, sed propter flores minores ac pallidiores, stylosque patentes staminibus longiores melius ad $\boldsymbol{M}$. foribundum referenda est. 

